2009

\title{
A Historical Analysis of Public School Sex Education in America Since 1900
}

Valerie Huber

Cedarville University

Follow this and additional works at: http://digitalcommons.cedarville.edu/education_theses

Part of the Education Commons

\section{Recommended Citation}

Huber, Valerie, "A Historical Analysis of Public School Sex Education in America Since 1900" (2009). Master of Education Research Theses. 21.

http://digitalcommons.cedarville.edu/education_theses/21 


\section{A HISTORICAL ANALYSIS OF PUBLIC SCHOOL SEX EDUCATION}

IN AMERICA SINCE 1900

A thesis submitted in partial fulfillment of the requirements for the degree of

Masters of Education

By

VALERIE J. HUBER

B.A. History, Cedarville College, 1980

2009

Cedarville University 


\section{CEDARVILLE UNIVERSITY \\ SCHOOL OF GRADUATE STUDIES}

September 15, 2009

\section{HEREBY RECOMMEND THAT THE THESIS PREPARED} UNDER MY SUPERVISION BY Valerie J. Huber ENTITLED A Historical Analysis of Public School Sex Education In America Since 1900 BE ACCEPTED IN PARTIAL FULFILLMENT OF THE REQUIREMENTS FOR THE DEGREE OF Master of Education.
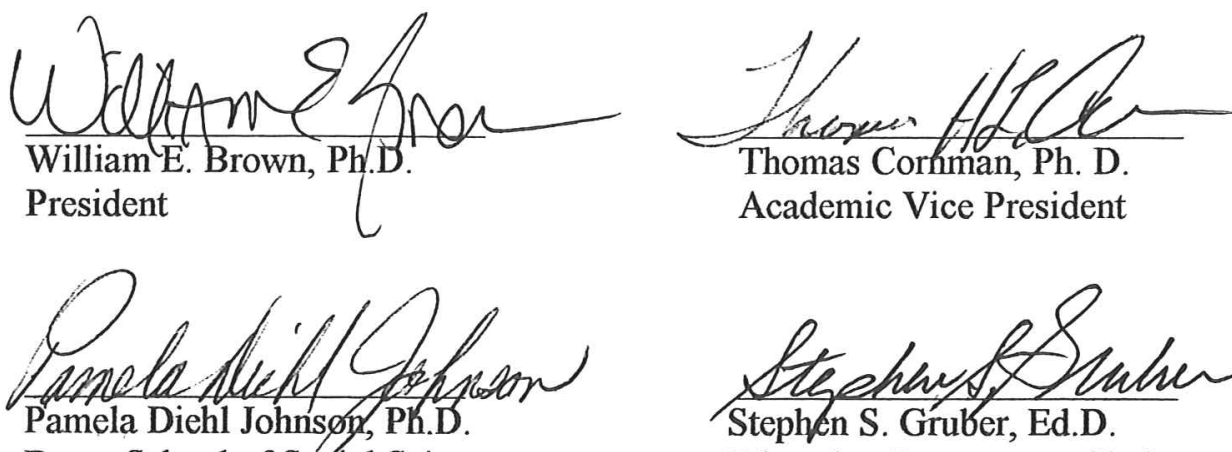

Dean, School of Social Sciences and Human Performance
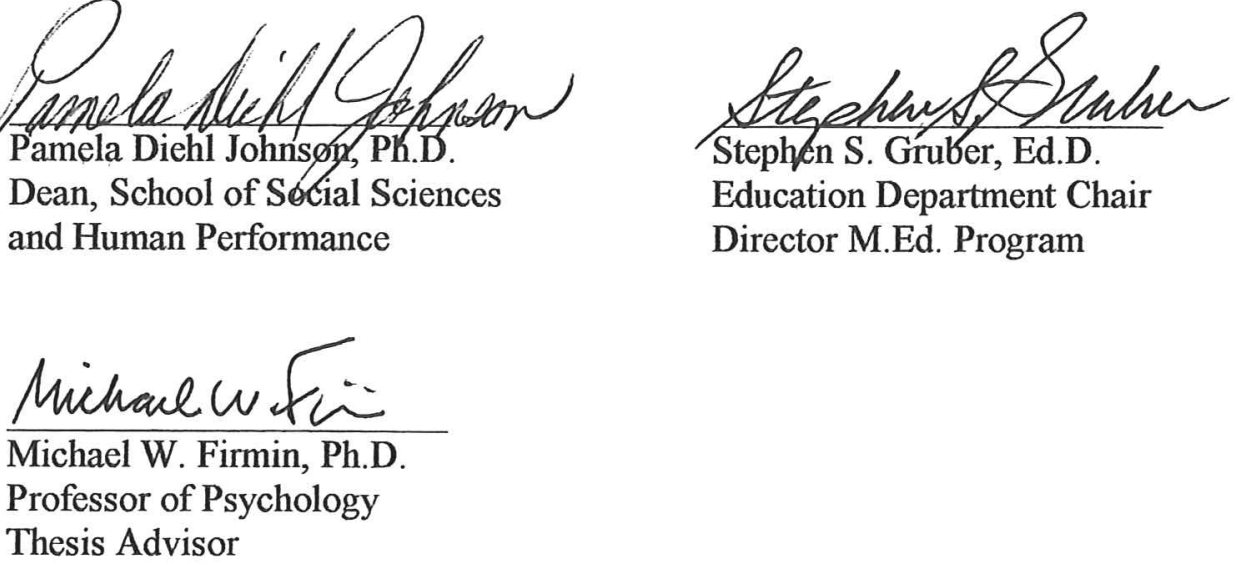


\begin{abstract}
Huber, Valerie J. M.Ed., Education Department, Cedarville University, 2009. A Historical Analysis of Public School Sex Education in America Since 1900.
\end{abstract}

This thesis explored the history of American public school sex education since 1900. It identified key points in sex education development. Six historical events were highlighted: (1) The social hygiene and the birth control movements, (2) research by Alfred Kinsey, (3) the sexual revolution, (4) creation of SIECUS, (5) the discovery of AIDS and, 6) the reform of the welfare system. An interpretation of these factors suggested: (1) countercultural voices of previous eras have become the dominant voices in current sex education, (2) the philosophical development of "comprehensive" sex education was linked to a personal justification of unconventional sexual behaviors, (3) inserting "science" within the sex education debate usually meant "change" of the status quo, (4) the progressive era of the early 1900s may be reinventing itself. Parents, policymakers, and educators can use this study to design a message that helps teens avoid all risks related to sexual activity. 


\section{Table of Contents}

I. Introduction of the Study..................................................................................................1

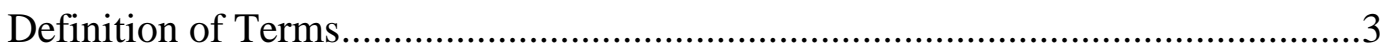

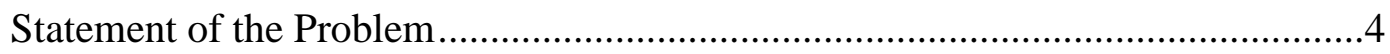

Scope of the Study and Delimitations.....................................................................

Significance of the Study ..................................................................................

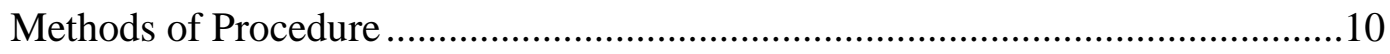

II. Plenary Literature Review .............................................................................................12

Sex Education in America Prior to 1900 ..............................................................12

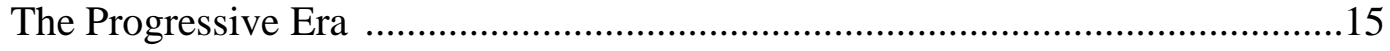

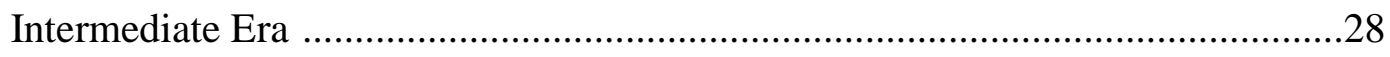

The Sexual Revolution Era (1960s and 1970s) ....................................................35

The Modern Sex Education Era (1980 to the Present) ..........................................44

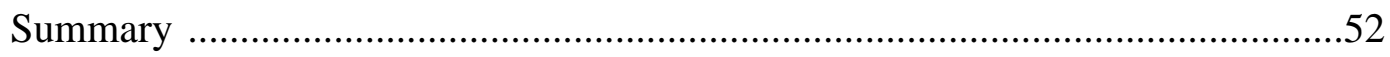

III. Methodology ....................................................................................................................54

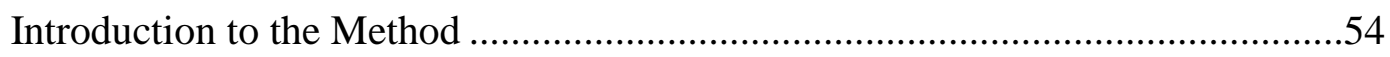

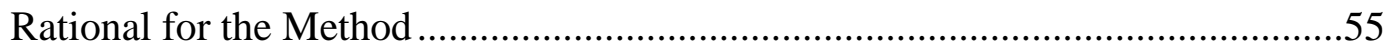

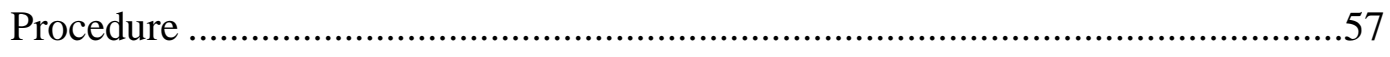

IV. Results and Analysis.............................................................................................60

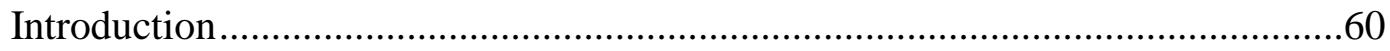

Description and Analysis of the Key Turning Points ............................................61 


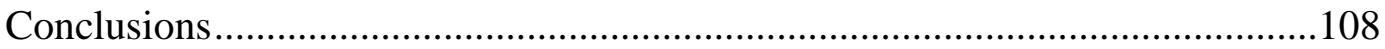

V. Discussion and Implications.......................................................................................109

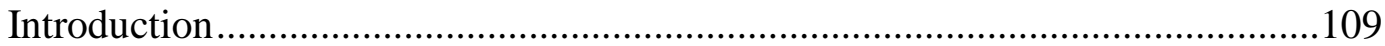

Ways Relevant Paradigms Affect the Study .........................................................110

Interpretations of the Results ..........................................................................112

Potential Applications of the Findings...........................................................119

Biblical Integrative Component \& Implications ....................................................122

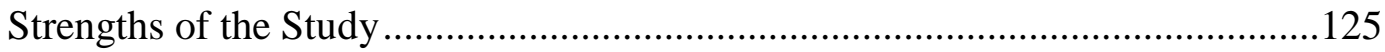

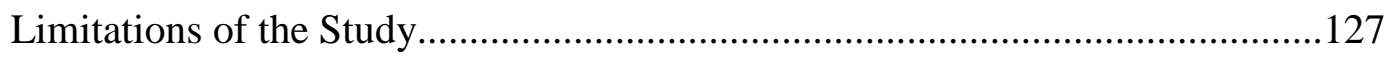

Suggestions for Future Research .....................................................................129

References ...........................................................................................................................131 


\section{List of Figures}

Figure Page

1. Poster 22 from the Public Health Service "Keeping Fit” Campaign .....................22

2. Poster 29 from the Public Health Service "Keeping Fit” Campaign .....................23 


\section{List of Tables}

Table

1. Hygienist Sex Education Model \& Modern Sex Education ...................................69

2. Kinsey’s Assertions \& Modern Sex Education ........................................................78

3. Cultural/Countercultural Influences of the Sexual Revolution on Sex Education 86

4. Family Planning \& Abstinence Education Funding: Clinton \& Bush..................106 


\section{Introduction To The Study}

The public conversation of sex has significantly changed over the last century. What was once discussed in hushed tones is now proclaimed on newspaper front pages. The average American receives about 38 sexual media messages per day (Committee on Public Education, 2001), but sex education classes provide the traditional and foundational information vehicle in the schools. The present sex-saturated culture belies an ongoing dispute over what constitutes appropriate sex education for youth. This topic has long been the subject of fierce debate, but is now at fever pitch (Masland, 2009). Sex education in America has been influenced by a number of factors, including the spread of STDs, cultural changes within the nation, the onset of HIV, as well as an attempt to mitigate upwardly spiraling welfare rolls. Formal government-sponsored classes in community settings began around the turn of the $20^{\text {th }}$ century with the advent of the social hygiene movement (Luker, 1998). Then, various vices brought a new wave of problems during the Depression era together with movements created to control excess and moral depravity (Setran, 2003). Almost every decade leading up to the present showed an ebb and flow of public expectations regarding sexual behavior, but the overriding public belief heavily reinforced the honorability of bearing children within marriage (Balanko, 2002). If an "accident" occurred, then often immediate efforts were made to cover the embarrassment by sending the young unwed mother to visit, say, a relative in another town, until the baby was born and adopted or, in other milieu, by covering the embarrassment with a shotgun wedding of the "errant couple." 
The 1960’s publicly gave voice to a highly sexualized counter culture, but social mores in favor of sex inside of marriage generally continued. The late 1960's and early 1970's ushered in widespread availability of birth control and liberalization of abortion laws (Akerlof, 1996). Both of these events provided a turning point in sexual traditions. The shotgun wedding was not necessary with easier availability of abortion and the fear of pregnancy was substantially reduced with the use of birth control pills. While both contraception and abortion logically would seem to have negative effects on the number of out of wedlock births, the opposite was actually true. The 1970's ushered a sharp increase in the number of nonmarital births that continues to spiral out of control. In 1959, for example, $8 \%$ of births were nonmarital, but today the figure is nearly $40 \%$ (Ventura, 2009).

The discovery of AIDS in the 1980's brought a stark reality to America's consciousness - that sex had risks far beyond the STDs of past generations or the embarrassment of an unplanned pregnancy. Sex could and did kill. This concern, coupled with the ever-increasing welfare costs of nonmarital births helped launch the modern abstinence education movement (Haskins \& Bevan, 1997). The emphasis was on primary prevention, particularly among teens, with the thought that, if skills and attitudes toward avoiding sex until marriage could be increased in young people, then the potential consequences of such activities could be mitigated. The results were encouraging. Teen birth rates plummeted in the ensuing decade and sexual activity among teens also decreased, despite an ever-increasing sexualization of the cultural conversation. (Centers for Disease Control [CDC], 2009d). Out of wedlock birthrates continued to increase, but 
most dramatically among young adults who were out of high school and who no longer received any reinforcement to abstain from sex (Ventura, 2009).

Individuals and organizations that were heavily influenced by the permissive values of theorists such as Kinsey mobilized their efforts and built a convincing web of counter arguments against the value of abstinence. The recent election of President Obama gave these organizations the cogent voice they previously lacked. An agenda to deconstruct a cultural more and public health model that stresses sexual abstinence is aggressively underway at the highest levels of public policy; at long last, it is beginning to mirror the sexual permissiveness that has pervaded cultural segments for more than 100 years.

\section{Definition of Terms}

Abstinence-centered. This is abstinence education, as funded by Congress. It involves a holistic approach that may discuss many topics, including how to identify a healthy and unhealthy relationship, refusal skills, STDs, contraception and goal setting, but always within the context of why abstinence is the healthiest choice (NAEA, 2009A).

“Comprehensive” sex education. Risk reduction approach to sex education in which condom negotiation and skill-building activities are typically central to the educational strategy. It often is used as a synonym for contraceptive education, HIV/STD prevention, pregnancy prevention, and abstinence-plus programs (HHS, 2007).

Hedonism. A Greek philosophy that taught the chief goal of existence is pleasure (Hall, 1920).

Sexual abstinence. Choosing not to engage in sexual activity until marriage (HHS, 2008b). 
Sexual activity. Genital contact or sexual stimulation including, but not limited to, sexual intercourse (HHS, 2008b).

SIECUS. The Sexuality Information and Education Council of the United States. It is a non-profit organization founded in 1964 by Mary Calderone to promote sexual rights and "comprehensive” sex education (SIECUS, n.d. [a]).

SIECUS Guidelines. The prominent framework for the implementation of "comprehensive" sex education, beginning in kindergarten and continuing through 12th grade (SIECUS, 2004).

Social hygiene. A movement devoted to the improvement of all social ills, particularly those pertaining to sexual problems such as venereal disease and prostitution (Bigelow, 1916).

\section{Statement of the Problem}

The debate over the appropriate role of the school in providing sex education as well as the content of this education is not new. Since Chicago tried the first public school sex education experiment in 1913, public sentiment has vacillated from outrage to gratitude (Jensen, 2007). Today, most Americans acknowledge that schools must provide some sort of sex education to its teens, but the debate over the content of this education still rages (Irvine, 2002).

Since the turn of the $20^{\text {th }}$ century, there has been a tense disagreement over the place and content of sex education. Who should teach the information to youth? What is age appropriate? When should discussions begin? How should the material be presented? Should information be shared from a moral, amoral, religious or medical standpoint? Should the education be directive or non-directive? What is the goal of the education? 
Educators, psychologists, physicians, clergy, parents, and policy-makers have wrestled with these questions for decades. A tension between two views separates the debate along a fairly distinct continuum. On one side are those who argue that youthful sex is natural and essential to healthy development. Whether or not to engage in sex is a deeply personal decision and society should have little concern other than to assure that the relationship is consensual and that precautions are taken to minimize disease transmission (Hogben \& Byrne, 1998). On the other side are those who argue that the family structure, society in general, and the involved individuals, are best served when sex is reserved for marriage. An emphasis is given to teaching skills that encourage teens to delay all sexual experimentation as the healthiest decision for their sexual health (Nicoletti, 2005).

The diverse views over the content of sex education have produced more than a platform for lively debate; the impact on societal norms and subsequent behavioral expressions of the incumbent values produce both short and long-term consequences. Current social science and medical research paints a chilling picture of the risks teens face when they become sexually active. Physical consequences are disconcerting (Weinstock, Berman, \& Cates, 2000). The Centers for Disease Control (2008) reported that one in four teen girls has at least one Sexually Transmitted Disease (STD). African American girls shoulder even more of the burden with one in two girls infected. Of all reportable STDs, teens carry about half of all new cases, although they represent only $25 \%$ of the sexually active population (CDC, 2008). In 2007, about 9.5 million young people between the age or 15 and 24 became infected, with many unaware of their infectivity, and therefore, likely to pass the STD on to others (CDC, 2009c). Teen birth 
rates have steadily declined over the past decade, but are beginning to inch upward again, with a 5\% increase documented between 2005 and 2007 (National Center for Health Statistics [NCHS], 2009).

If a teen bears or fathers a baby, that child is likely to bear hardships as a result. Nearly $86 \%$ of births to 15-19 years olds are non-marital (NCHS, 2009). Children born to single parents are prone to live in poverty during their formative years. They also are at risk for a host of short and long term physical, educational and sociological difficulties, including health problems, poor grades, incarceration and teen pregnancy (Waite \& Gallagher, 2000). In short, when children are raised by a single, teen parent, they often find that some impediments are difficult to overcome.

Traditionally, most attention has focused on the physical costs of teen sexual activity, but youth also are vulnerable for other consequences. Hallfors (2004) reported a causal relationship between teen sex and depression/suicide risk. Meier (2007) found young girls more likely to struggle with self-image, if sexually active. Rector and Johnson (2005) identified a correlation with decreased academic achievement. Armour and Haynie (2007) reported a relationship between sexual initiation and delinquency. Staton (1999) established a connection with drug and alcohol use. Rector, Johnson and Noyes (2003) found that adults who were sexually active as teens tended to have greater difficulty forming and sustaining stable marriages.

Differing views of sex education influence the manner in which taxpayer dollars address teen sex. The prevailing approach at any point in history has a lingering effect. Policy decisions, sometimes made as political thank you gifts to special interest groups, sometimes coupled with deep seated beliefs in the rightness of the decision, and other 
times made as a result of onerous misinformation, continue to have an effect down to the individual level. This study identifies the responsibility that significant historic events played in influencing cultural values and sexual decision-making over the last century as well as today.

\section{Scope of the Study and Delimitations}

I am studying sex education and the development of a formal system of instruction within the American public school system and community setting since 1900 . The influence of key historical events regarding the current sex education debate is explored in detail. The scope of the study involves the identification and explanation of specific event clusters that have played a marked role in the creation of two distinct views for sex education over the past century. While there are nuances in the two views and supporters fall along a rather broad continuum, the two perspectives are distinct in their goals and measures for success.

Although sex education often overlaps other related educational strategies, this study only concentrates on classes defined as sex education. These classes have changed their look over the decades but, for the purposes of this study, the common thread is that they addressed male-female relationships, reproduction, and/or sexually transmitted diseases. School-aged youth are the focus for this study, although, obviously, contemporary cultural traditions heavily impact the messages that are given to youth. Therefore, the state of the culture is discussed in terms of its impact on sex education and youth behavior.

A discussion of sex education in countries outside of the United States is not part of this research. Sex education developed on both parallel and divergent tracks in other 
countries, but a comparison of foreign sex education with the American sex education system would require a comprehensive treatment beyond the scope of the present study. Cultural changes throughout history are not discussed in terms of how they affected other topics of school instruction because this study is limited to the interrelationship between culture and sex education. Further, private and religious schools are not included in this research, although it would be an interesting topic for future study. This is because so many differences exist between private-public, private-religious, and religious-public schools that it would not be feasible to survey those differences vis-à-vis sex education. An entire thesis could be devoted solely to this topic. Moreover, the differences among the sub-domains of religious and parochial schools also makes covering this subject even more complex.

The present study only focuses on events after 1900. Although it can be argued that sex education existed prior to 1900 in America, this study does not explore any efforts prior to the turn of the $20^{\text {th }}$ century other than in general terms. The rationale for not giving coverage to pre-1900 sex education is because generally, school-based sex education did not begin until the turn of the $20^{\text {th }}$ century. Moreover, federal funding for the efforts only began after 1900. Finally, the public school system was less organized prior to 1900, so coordinated efforts at any systematic education were difficult to monitor or implement.

\section{Significance of the Study}

Some would argue that current policy decisions and adolescent sex education approaches are completely dependent upon contemporary problems and needs. They might insist that historical circumstances and deceased individuals have little impact on 
present-day strategies. I suggest that this view is narrow and inconsistent with a full understanding of the nature of cultural change. No single event stands alone. Antecedent and subsequent events are interrelated and create a ripple effect that typically grows in impact over time. Seemingly unrelated events in the history of America worked to change the priorities toward sex education. Dramatic historical events, like a world war, affected every aspect of American culture. Each individual was impacted, even those who neither went to war nor sent a family member to fight. The entire nation was changed as a result and sex education was no exception. Other seminal historical events provided similar changes.

The present study pulls a silver thread through the pages of history so that the casual surveyor of the past can understand why few issues elicit such visceral response as the sex education debate. The dispute over the content of sex education in public schools has resulted in the unseating of entire school boards and firing of administrators. The topic of sex education has been the catalyst for numerous individuals running for political office. It has been the source of lawsuits and the reason that some parents opt their children out of sex education classes. The primary lines of this debate have been drawn for over 100 years and significant historical events have solidified the resolve of both sides to "win" the debate. This debate, however, has consequences far beyond those who engage in the dispute. STD prevalence, teen pregnancy rates, and emotional turmoil are the individual consequences that must be weighed when making sex education policy decisions and history is a good teacher. 


\section{Methods of Procedure}

I have examined a full literature review of sex education in public schools since 1900. I searched for available research from online databases such as Academic Search Complete, Ebsco, OhioLink, Education Full Text and Education Research Complete, PsychInfo, ERIC, Google Books, and Google Scholar. I have consulted books on sex education as well as curricula that are or were implemented in schools across America. Additionally, I spent many hours consulting primary source materials at the Library of Congress and have spoken with modern leaders of both sides of the sex education debate. Unpublished personal letters and speeches from significant contributors to the development of sex education were also accessed from experts who had such documents in their possession. My own personal experience in the recent sex education debate also assisted my ability to draw connections from historical events.

After consulting the breadth of research named above, I analyzed the literature in order to identify key turning points in American sex education. I identified common themes throughout history and studied the primary source of each change, which drew me to six specific historical turning points that were critical to the development of sex education. Each of these key events was appraised by studying key figures, Zeitgeist influences, salient decisions made during this period, political implications, and impact on contemporary and future sex education policies. In each case, following the federal or local investment of money and time devoted to a given approach helped to identify priority messaging. In most cases, changes were not instantaneous, but significant historic events set a specific strategy in motion. 
Key persons preeminent in the development of sex education were identified based on selection criteria that included influences reaching beyond their own lives. Significant figures served as the source of cultural movements or the creation of influential organizations, or both. Zeitgeist influences were identified as prevailing ideas during a given historic time. These influences were deemed as significant influencers in the development of sex education if the ideas were expressed in literature and philosophy beyond the historic period in which they emanated. Salient decisions and political implications were "turning point” events vis-à-vis the implementation of new policies that significantly changed the direction of sex education in the future. All six of the identified turning point events produced a considerable change in existing sex education, but also offer foundational underpinnings for the eventual development of one of the two major views of sex education. 


\section{II: Plenary Literature Review}

The historical record of sex education in American public schools is relatively short. Developments after 1900 were the emphasis in this study, but a brief examination of events prior to 1900 provided an important foundation. Cultural and moral gatekeepers made sexual experimentation a frowned-upon activity during early American history, but those gates were forced open by a series of events after the turn of the $20^{\text {th }}$ century.

\section{Sex Education in America Prior to 1900}

Little has been written about sex education before 1900 (Pearsall, 2001). Searches within typical academic research vehicles do not provide much information.

Traditionally, in early American history, the home was the place where discussions of sex took place and, even then, the conversations tended to be minimal, usually a mix of practical physiology and moral instruction, grounded in religious standards (Peterson, 1983). Some children would learn about reproduction from watching animals in the barnyard, since much of early American society was agrarian. For human behavior, abstinence until marriage was expected and, although young people sometimes engaged in premarital sex, the social norm and family expectation discouraged such practice. One of the earliest examples of governmental expectations for premarital purity was included in the 1778 Journals of the Continental Congress stating that any soldier who was treated for venereal disease was required to pay for his own treatment (Blaine, 1778).

Sex education in pre-1900 public schools typically was not a general consideration because most believed this topic was not an appropriate responsibility for 
the school and that doing so, would supplant the role of the parent (Kaslow, 2006). In addition, population distribution significantly affected schooling opportunities afforded children in early America. The general populace was dispersed, with pockets of society congregating in growing towns and cities, but many more living far from community neighbors. Prior to the $19^{\text {th }}$ century, Christian theology often was integrated into subject matter, so morality and the development of character were prominent in textbooks (Brown, 2002). Many children learned at home. The extent or quality of education varied widely, depending on family wealth and geographic location (Delano, 1976). In the latter part of the Colonial period, school districts were established to afford educational opportunities to more children, but these schoolhouses had students of varying ages learning in the same room, making age-specific conversations difficult. Cultural mores precluded open discussions of sex and the unsystematic organization of schools made any coordinated sex education course impossible, had the mores been different (Parkerson \& Parkerson, 2001).

The $19^{\text {th }}$ century signaled the beginning of the Common School when education became available to the masses (Chang, 1985). Even then, schools varied widely. Some were one-room schoolhouses; others were larger schools separated by grades. The distribution of the population in a given area tended to predict the quality of education in that region (Cremin,1980). Homeschooling was still common, especially in the more remote areas of the country (Caither, 2008). McGuffey Readers were used widely, which heavily emphasized morality and Bible-based ethics (Ellenwood, 2006). Developing and maintaining healthy relationships with others was a theme throughout the readers, with a key emphasis on making character-based decisions in all interactions (Kammen, 2009). 
During this same time period, Whewell (1856) discussed how parents could teach morality and sex education by modeling behaviors before their children. He described marriage as the balance of "desires and affections" (p.126) and a place where men could “maintain” their morality. Mayhew (1850) contended that moral education was the most important purpose of education. Johnson (1883) wrote that the ability to teach morality in the schools was significantly hampered by the "sectarian spirit” (p. 749) that existed around how to best teach the subject. Moral citizenship predicted good citizenship, said Johnson, but the means of achieving it, apart from religious education, was just beginning to be discussed. Morality education served as a precursor to sex education, which was on the verge of becoming a new role of government (Moran, 1996).

Some events of the $19^{\text {th }}$ century paved the way for a differing consciousness regarding sex education, however. Luker (1998) noted that during the mid-1800s, some “experts" called for the tacit legitimacy of prostitution by police registration and inspection of prostitutes. Others wanted laws to strengthen the institution of marriage by requiring couples to obtain licenses but, instead, the courts began a precedent of recognizing "common law" marriages if a couple lived together for a certain number of years (Luker). The Purity Crusades opposed this institutionalization of immorality. King (1870), an activist at the time, feared that a "flood of sensuality" (p. 5) was sweeping the land and that the nation was on the verge of moral ruin unless something was done to reverse the tide. The Comstock Laws were passed in the 1870's and outlawed the distribution of birth control information or devices, characterizing them as "lewd" and “obscene” (Wardell, 1980). The previous laissez faire attitude regarding the topic of sex 
was quickly growing out of fashion near the end of the $19^{\text {th }}$ century as progressives whet their appetite for social reform and sex education for youth.

\section{The Progressive Era}

The progressive era ranged from around 1880 to 1920 and, during the span of those years, America experienced significant changes in the way it viewed sex, morality, and the sex education of children (Moran, 1996). A convergence of numerous, seemingly unrelated events during this time prepared the soil for the genesis of formalized sex education. The period represented a "hodgepodge of coalitions working for changes that often contradicted each other" (Muncy, 1991, p. 27). Within the mix were socialists, anarchists, purists, muckrakers, hygienists, eugenists, and social workers who wanted to improve American life according to their respective criteria (Mook, 2007). Many of these contradictions, however, worked together in seeming synchrony at times to quicken the arrival of school and community-based sex education. The process was aided through the nexus of the following: (1) an agreement that immorality had negative consequences on the individual as well as on "innocents," (2) a changing view regarding the purpose of sex, (3) a rise in the belief that society was better served if birth rates were monitored, (4) an agreement that government and other "experts" should take the lead in addressing social issues, and (5) a view that the school potentially could provide a virtual panacea for a host of societal problems (Tiles, 1999).

Immorality and its consequences. By the turn of the $20^{\text {th }}$ century, many Americans had reached a state of outrage over the moral decline in the nation. Prostitution, drunkenness, and a general moral laxity were resulting in serious problems of crime and disease. Illicit sex and alcohol were linked as vices harmful to society and 
degenerative to the individual (Edwards, 1909). Various groups coupled arms in order to stop the free flow of liquor, with the Woman's Christian Temperance Union (WCTU) at the lead. The $18^{\text {th }}$ amendment to the U.S. Constitution began the era of prohibition in 1919, continuing until it was repealed by the $21^{\text {st }}$ amendment in 1933 . But addressing the issue of drunkenness only represented the tip of the iceberg vis-à-vis the problem of vice permeating the contemporary culture.

At the front of the charge for moral reform was the social hygiene movement. Founded in the United States in 1905 by Prince A. Morrow, the social hygiene movement argued that the problems of sex arose, not from an evil human nature, but from ignorance. Education was key and teaching the young was essential (Bigelow, 1916). Sex education was described more holistically than merely "sex hygiene” which, at the time, concerned itself solely with avoiding sexually transmitted disease. Sex education included physical, social, "aesthetic," and ethical aspects of sex in order to improve overall sexual attitudes and to gain important knowledge. Scientific information bolstered moral rectitude. Moran (1996) noted that, although the "social evil" of prostitution had been attacked in the past by the purity movement, social hygienists added a heavy medical emphasis to the moral and religious arguments of their predecessors. Physicians largely populated the hygienist movement, contributing a professional and expert component previously missing. They insisted that sexual relations within the context of marriage were the best prevention of disease and immorality (Morrow, 1904).

Concerned that the low age for sexual consent led to forced prostitution, Engs (2003) noted that the White Cross Societies, WCTU, and Social Hygienists succeeded in raising the age of consent for sexual activity from 7-10 years old to 15-18 years of age in 
most states. They advocated that law could not make men and women moral, but they also believed that government regulation was a necessary first step toward producing a sexually moral society. (Morrow, 1904).

Jane Addams (1912), founder of the Settlement House movement, complained that prostitution was "semi-legal” in many cities. The rampant spread of Syphilis and Gonorrhea demanded a strong antidote. Once believed to be a "divine chastisement of the sin of unchastity" (Morrow, 1904, p. 348), sexual diseases were then known to afflict innocent women and children. Morrow was disgusted that a "conspiracy of silence" ignored the discussion of venereal disease in public, believing that knowledge and information were crucial to taming the effects of the diseases. Various sources cited the prevalence of venereal disease as infecting $50 \%$ to $90 \%$ of all men over the age of 18 , but these statistics were largely the product of guesswork or deliberate exaggeration in order to incite action (Bigelow, 1916). Even conservative estimates, however, stated that more than $50 \%$ of men had one of the diseases during their lifetime, which showed that moral laxity was profound. Hygienists refuted the myth repeated by men that they had a "sexual necessity" to engage in sexual relations from adolescence onward (Lowry \& Lambert, 1912). Blair (1980) indicated that the suffrage movement joined with the hygienists in order to banish the double standard of morality between men and women; they also supported the need for sex education for children ("New standard," 1908).

Changing view on the purpose of sex. During the progressive era, the public discussion of sex always stressed sexual abstinence until marriage. Sex generally was seen as a function primarily for procreation, particularly among eugenists; nonetheless Margaret Sanger and others also explored the recreation of sex (Reed, 2003). Sociologist, 
nudist, prolific author, and eventual member of the F. D. Roosevelt Administration, Maurice Parmelee, sought to dispel the notion that enjoying sex should be forbidden (Woodall, 2002). In fact, he advocated that ignoring the play function would be harmful to society. Parmelee (1920) called for youth to be taught all aspects of sex. He stressed the importance of fully developing the play function by a couple prior to children being brought into the world. In order for this information to be a part of marital decisions, Parmelee asserted that youth should be taught these aspects of sexual decision-making. Sex education, then, would better equip them to be responsible citizens in the future. Sanger expanded on Parmelee's view, arguing that women should have the freedom to enjoy sex without the fear of pregnancy, giving women both sexual and reproductive freedom (Chesler, 2003). Her newspaper, The Woman Rebel, used the motto: "No Gods. No Masters," which promised information that would potentially free women from pregnancy and the sexual restraint that it engendered (Galvin, 1998). Antonucci (1995) quoted Sanger's aversion to abstinence, insisting it caused mental disorders and "nervousness" and her similar aversion to the marriage bed as being a “degenerating influence” in society. Sanger’s views were radical at the time, but her voice gained strength in the coming decades, and became an early influence in what would become sex education in American public schools.

Monitoring of birth rate. The eugenics movement worked to change Americans views regarding human reproduction. It was also an important tenet in early public school sex education programs (Bigelow, Balliet, \& Morrow, 1913). Eugenics began in England near the end of the $19^{\text {th }}$ century by Sir Francis Galton, a cousin of Charles Darwin (Gerrard, 1914). The theory quickly moved to the U.S., reaching its highest point of 
acceptability between 1905 and 1930 when many in the church, the university, and wellknown leaders embraced the theory. Eugenics, or "good breeding,” was a theory having an intellectual birth closely tied to Darwinian survival of the fittest (West, 2005). It suggested that cultural progress for future generations was possible through selective breeding or discriminatory reproduction, encouraging strong hereditary lines that seemingly held the key to improving the culture (Parmelee, 1920).

Left to itself, American culture was on the verge of degeneration as the so-called "unfit" sectors of society were reproducing at a faster pace than the supposed "fit" genetic strains; charity and modern medicine were hindering nature's natural selection of those with weak heredity (Searcy, 1914). A chief American eugenist, Harry Laughlin (1920), believed eugenics provided a potential scientific solution. Sterilization, encouraging contraception, and restricting marriage for the "unfit" were important aspects of the national campaign. In addition to advocating the restriction of reproduction by those who displayed mental or physical disorders or weakness, the theory also stressed that social ills such as poverty, alcoholism, sexually transmitted disease, and prostitution could be eradicated by restricting reproduction of "unfit" classes and encouraging "fit" genetic lines to extend their superior gene pool (Baer, 2002).

The birth control movement was founded during this period by Margaret Sanger, a nurse who wanted birth control to be easily accessible (Jensen, 2007). She coined the term "birth control" (Galvin, 1998) and most historians agree that her work did more to advance access to contraception than any other person in American history (Vespa, 1980) Sanger (1922) purported that the primary purpose of birth control was to encourage fewer children from the "unfit" portions of American society, a common theme among 
eugenicists at the time. Some argue that her fight for birth control was selfishly motivated to cover her own continuous, illicit affairs but Sanger insisted her campaign began as a result of a plea for birth control from a poor woman dying from a self-induced abortion (Wardell, 1980). Gardiner (2006) suggested that eugenics and sexual freedom were actually the dual purposes of her campaign. Early on, her primary goal was to challenge the Comstock Laws, which essentially outlawed the distribution of contraception. She created many opportunities for her own arrest (Wardell , 1980), including illegally opening the first birth control clinic in 1916 (Tolson, 1999) and distributing a how-to manual for home remedies of contraception. Sanger's contribution to sex education did not outright present itself during the progressive era, but it would become a major element of the modern sex education movement.

Government involvement in social issues. The increase in government intervention in social problems laid the first cornerstone for sex education in American public schools. Progressives believed that experts could more aptly respond to the problems of the day and that a more "scientific" approach was needed. It followed that, for the solutions to be implemented broadly, the government needed to take a more involved role in planning and management. Government was, in fact, to be the primary agent for social change (Pestritto \& Atto, 2008).

The campaign to educate World War I soldiers about the dangers of sex provided one example of government participation. The crusade cautioned them that STDs could make them ill and unable to defeat the enemy in the lines of battle and could also injure their wives or children. Soldiers were tested for STDs and were praised for being free of venereal disease and potentially court-martialed if found newly infected ("Only 33," 
1919). As a result of the intensive effort, the venereal disease rate dropped to the lowest rate ever reported (Wisconsin State Board of Health, 1919). The War Department (1918) sought to continue the progress made with servicemen by giving them a book upon leaving the military. It encouraged returning soldiers to instruct their younger brothers on the dangers of venereal disease and advocate for stronger prevention measures in their communities. Eradicating this plague was viewed as a matter of national security and returning servicemen were called to help win the war on the home front.

The Chamberlain-Kahn Act began the flow of government monies to address the venereal disease problem during 1919-1920 (Fairchild, Colgrove, \& Bayer, 2003). The Public Health Service (1918) cooperated with state boards of health in order to prevent and control STDs. A number of states established free clinics for treatment and educational campaigns for prevention efforts. The New Jersey State Department of Health posted billboards advertising the clinics with the patriotic call to "fight the enemy at home” (Maxwell, 1919). Additionally, the Public Health Service created the single sexual standard campaign, "Keeping Fit," particularly targeting boys between the age of 15 and 21.Figures 1 and 2 illustrates two visual components of the campaign against nonmarital sexual activity (“Social hygiene posters," 2004). By 1921, 47 of the 48 state boards of health cooperated with the Public Health Service to control STDs (ASHA, 1921). These campaigns against STDs represented the first community sex education initiatives undertaken by the government.

The role of public schools in societal problems. Schools were increasingly seen as arenas for social activism and reform by progressive advocates like John Dewey (1916). Heavily grounded in pragmatism, educational experts were divided between 


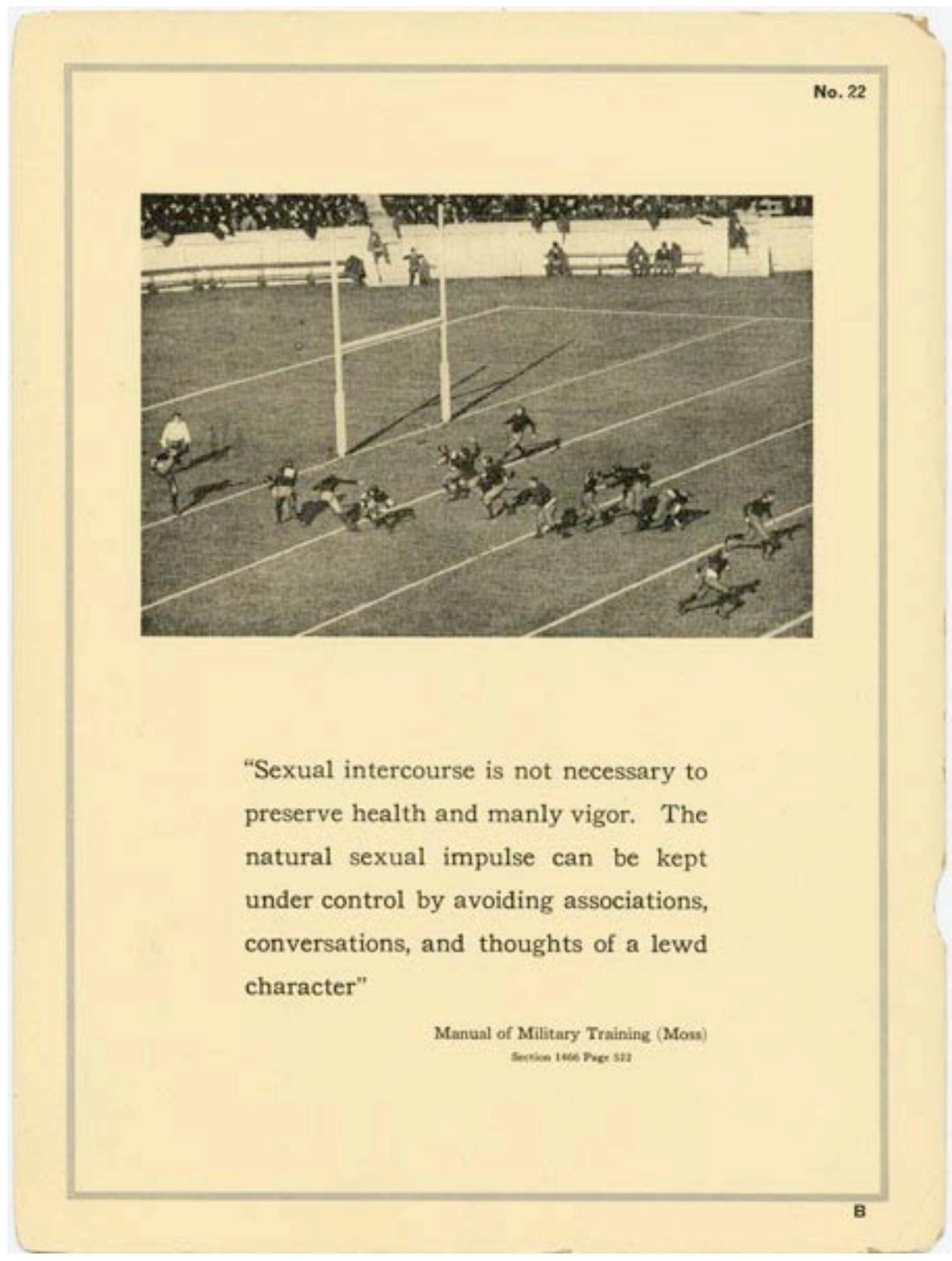

Figure 1.

Poster 22 from the Public Health Service “Keeping Fit” Campaign.

(Scanned from original posters that are a part of the American Social Health Association <http://special.lib.umn.edu/findaid/xml/sw0045.xml> records in the Social Welfare History Archives $<$ http://special.lib.umn.edu/swha/ $>$ at the University of Minnesota. Copyright to the original posters has expired, but University of Minnesota libraries <http://www.lib.umn.edu/> holds copyright to the scanned images and grants this permission for use.) 


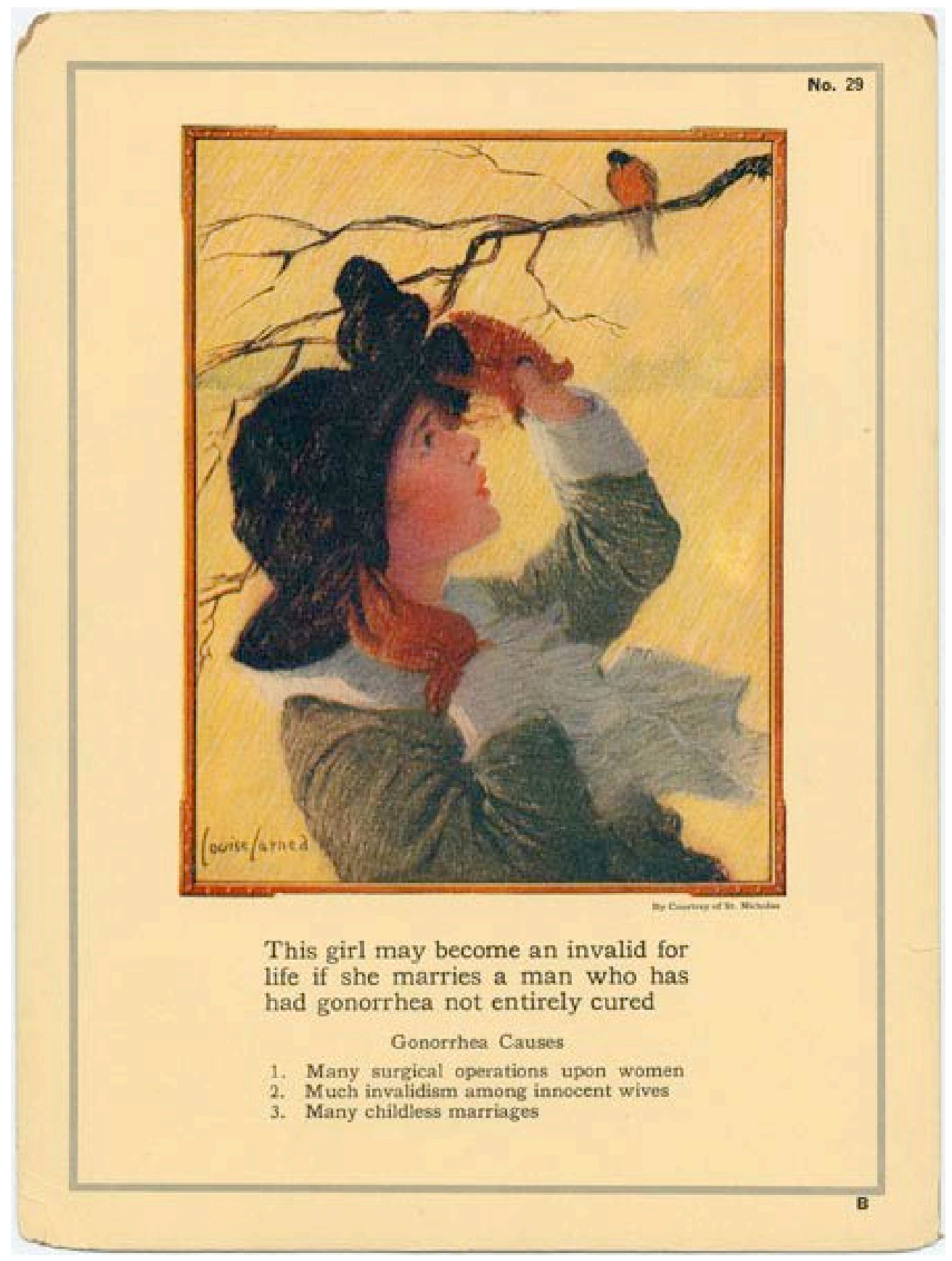

Figure 2. Poster 29 from the Public Health Service “Keeping Fit” Campaign.

(Scanned from original posters that are a part of the American Social Health Association <http://special.lib.umn.edu/findaid/xml/sw0045.xml> records in the Social Welfare History Archives $<$ http://special.lib.umn.edu/swha/> at the University of Minnesota. Copyright to the original posters has expired, but University of Minnesota libraries <http://www.lib.umn.edu/> holds copyright to the scanned images and grants this permission for use.) 
moral absolutism and moral relativism in their application of the principle (Blanshard, 1923), and the outworking of that theory predicted the nature of sex education that was recommended. The school setting became a testing ground for new theories and social experiments, much of which was led by Dewey and the Progressive Education Association. This educational reform movement sided heavily on the side of "nurture" as opposed to the heavy reliance on "nature” by eugenics. Musolf (2003) asserted that educational progressives opposed the view taken by eugenics that whole sectors of the population could not benefit from formal education. They dismissed biological determinism in favor of self-determination, believing that education was transformative. They wanted students to learn experientially (Berube, 1994). They wanted students to become responsible citizens in the future and this meant more than registering to vote; they also needed to act responsibly in their sex lives.

Educational progressives and social hygienists prepared the environment for sex education. Advocates argued that sexual problems prevailed because there was an unwillingness to address the problems openly. "Mystery and silence" were not effective in keeping young people sexually abstinent. Children needed to learn to control their sexual appetites and this was not possible without adequate information, reported Pivar (2002). Young people needed to know that sex could be healthy and wholesome, both pleasurable and reproductive in nature (Bigelow, 1916). The work of G. Stanley Hall (1905) changed the way the world looked at youth by identifying a definite period in a person’s life called “adolescence,” the time when sexual reproduction was possible. That age had special challenges and special needs that sex education could address. Hall stressed the need for sexual restraint during this critical developmental period. 
In 1912 and 1914, the National Education Association (NEA) passed resolutions calling for the adoption of sex education in the schools. Proponents acknowledged that this undertaking would fail without broad cooperation from home, church, and community organizations (Bigelow, 1916). Chicago was to be the first experiment in implementation (Moran, 1996). Webb and MacCarthy (1998) described the chief architect behind this experiment as being Ella Flagg Young. She was both the first female superintendent of a major urban school system and the first female president of the NEA. Lagemann (1996) indicated that Young was a University of Chicago colleague of John Dewey who described her as the wisest educator he had ever met. Young and Dewey had many very similar views on education. As a pragmatist, she contended that a perusal of the Chicago curricula would make one conclude, "people have no sex organs" (Moran, 1996). She agreed with social hygienists that ignorance provided the perfect breeding ground for sexual vice and she resolved to use her position to take affirmative actions to curb the problem.

Chicago was thought a natural place to begin the experiment because prostitution was rampant and the hygienist movement was strong there. Jane Addams, founder of Hull House, was an active participant and the University of Chicago provided significant leadership to the social hygiene movement (ASHA, 1916b). Many shared the view that prevention of social ill was more effective than treating those already entwined in problem behaviors. Energy, then, seemingly needed to be directed at the young, so that the health and moral framework of the city could be improved from the inside out. The Chicago Vice Commission (1911) endorsed moral and scientific sex education in the schools for children who already reached puberty. They encouraged parents to teach the 
younger children (or doctors if parents felt uncomfortable) regarding the subject. They acknowledged that school sex education was still experimental but that it offered significant promise, if trained professionals taught it. They also acknowledged that school-based sex hygiene information would have little effect without a basis on religious and moral principles. Superintendent Young had her own thoughts, however, asserting that scientific information was moral information (Jensen, 2007).

Moran (1996) noted that Young proposed a series of three lectures be delivered to the 20,000 Chicago high school students during the 1913-1914 school year. For the first time, medical experts would present sexually related information in a systematic way within the public school. Male physicians would speak to boys and female physicians would speak to girls. Superintendent Young explained that the first lecture would present physical facts; the second and third would cover venereal disease and the need for personal “continence” until marriage. Since only about $20 \%$ of all students continued high school after the primary grades, she also recommended that younger children receive a more generic talk about the need for sexual purity.

Opponents fiercely protested the program, insisting that such knowledge would awaken an unhealthy curiosity about sexual subjects, destroying their natural innocence (Jensen, 2007). The Illinois Governor, for example, insisted that many students would not come into contact with sexual immorality unless they were taught about it in school (Jensen). School sex education opponents also asserted that knowledge acquisition alone would not lead to moral or proper behavior. They were concerned that schools were usurping a role that uniquely belonged to parents. Additionally, parents were offended that hygienists questioned their ability to be sex educators to their own children. 
Religious groups, Catholics in particular, bristled that moral teaching was being separated from the supernatural source of morality (Moran, 1996). Bigelow (1916) noted that most professional educators and scientists supported sex education, but that the "uninformed masses” needed a propaganda campaign in order to convince them of the need for this new approach. Most parents did not yet support open sex education because of three reasons: (1) they believed their children would not receive inaccurate information elsewhere, so they wanted to protect them from receiving any sex information, (2) sexual experimentation was just a part of growing up, so efforts to curb such activity were useless, (3) girls should remain pure and boys should "sow their wild oats" during their youth, so the messages to both genders should not be uniform (Bigelow).

Young resigned in protest over a loss of confidence in her leadership by members of the school board. With her resignation, the "Chicago controversy" ended, lasting only one semester. Sex education supporters used the failed attempt in Chicago to fine-tune a stronger approach in other cities. They were able to learn from Chicago's mistakes and many errors were attributed to Young's harsh advocacy efforts. Other schools quietly implemented many social hygiene principles in their classrooms, but away from the public fanfare and without school board approval. The lessons were integrated into extant classes such as biology and home economics, using models suggested by social hygienists. Widespread sex education in the schools was still an idea whose time had not yet come, but the foundation was largely built during this period. In fact, by 1920, 40\% of all high schools responding to a survey said they implemented sex education in some form (Carter, 2001). 


\section{Intermediate Era}

The time period between the end of the progressive era (1920) and the beginning of the sexual revolution (1960) was the intermediate era in the development of public school sex education in America. During this period, many of the movements begun during the progressive era continued, such as eugenics, birth control and social hygiene. Several new developments presented themselves that significantly impacted the development of modern sex education. They included: (1) the new morality of the 1920s, (2) initiation of family life education, and (3) the influence of Alfred Kinsey.

Building on efforts begun in the progressive era. Engs (2005) reported that the influence of the eugenics movement reached its peak in the 1920s, but began to wane as more information from genetic science emerged in the 1930s. Americans recognized that the simple description put forth by eugenic proponents did not adequately describe the cause of physical, mental, or social problems. Further, the widespread use of the eugenics theory for the mass eradication of minority groups in Nazi Germany caused many to disassociate themselves from the movement (Engs).

Sanger and advocates within the birth control movement gained momentum as they continued to push for easy access to birth control, beginning the American Birth Control League in 1921 (which was to become Planned Parenthood in 1942). Planned Parenthood adopted its first official statement on sex education in 1946. Sanger won an important court ruling in 1936 when the court decided that birth control devices and materials could no longer be considered “obscene” (Tuhus-Dubrow, 2007). By January 1940, Henry Fairchild, president of the American Eugenics Society noted that "these two great movements, [eugenics and birth control], have now come to such a thorough 
understanding and have drawn so close together as to be almost indistinguishable” (Gordon, 2002, p. 202). This admission was telling, for as the eugenics movement was losing social acceptability, the birth control provided them a new venue for renewed, less obvious, advocacy. In 1948, Sanger helped fund Gregory Pincus, a research biologist, to develop an early birth control pill (Lawrence, 2008), which was introduced to the public in 1959 (Galvin, 1998). This paved the way for future sex education programs to include contraceptive advocacy as a priority message.

The Public Health Service continued to fund programs designed to prevent and treat STDs and targeted one part of the campaign toward teen girls and boys (Public Health Service, 1924). The economic results from the depression required the government to temporarily discontinue the program but, in 1936, the campaign was again renewed following a severe syphilis outbreak (Cutler, 1988). World War II further supported the campaign, with soldiers again heading overseas and away from the watchful eyes of family (Rotskoff, 2001). A War Department (1941) document stressed that prevention assisted in creating an "efficient military force," suggesting that messaging for WWII was similar to that of WWI - avoiding illicit sex was both a personal and patriotic effort. ASHA (1942) cooperated with the government to distribute Fit to Fight....and Fit for Life, a campaign designed to reduce sexually transmitted disease transmission. Loss of pay and possible court martial were penalties for contracting an STD. Treatment centers were also created and the discovery of penicillin, which was effective in treating the two venereal diseases of the day, aided in the cure (Cutler, 1988). 
The new morality of the 1920's. A 1922 survey regarding youth concluded that the primary concern of adults was that of decline in sexual morality (Spring, 1992). Adult concern was well founded. A vocal subculture was developing during the 1920's that promoted sex without strings, even though the dominant cultural expectation continued to be abstinence until marriage. The popularity of naturalism brought a new impressionistic freedom to a significant number of young people (Carter, 2001). Although alcohol was illegal, speakeasies made it easy and exciting to acquire. Short skirts, Jazz, the Charleston, and loose morals became an electrifying lifestyle that defined segments of the new younger generation of "flappers." For example, a popular 1929 magazine included this poem:

I want the lights that boringly shine;

I want the men - I want the wine;

I want the fun without the price;

I want to be naughty and yet be nice (Stevens, 1989, p. 28).

A college newspaper editor at the time expressed concern that flappers thought nothing of petting, smoking, or drinking (Spring, 1992). Magazines like True Story and True Romances provided sexual titillation in the 1920s, albeit usually leaving much to the imagination (Stevens, 1989). This type of media attracted a relatively wide audience with the explicit intent to set young girls' imaginations free (Bashford \& Strange, 2004).

In 1939, college educated women were surveyed whether or not they engaged in premarital sex. Of those born in 1900 or before, only 26\% said “yes", but 69\% of those born after 1913 replied “yes”. Another study showed a steady increase of women since 
1900 who were pregnant when they married. Between 1920 and 1950, the percent of women who admitted to premarital sex more than doubled (Tolson, 1999).

Films, burlesque shows, and fashion all hurtled away from modesty and toward increased sexual content. During the 1920s, some movies showed fully nude women (Spring, 1992). Catheryn Gilman took the national spotlight as she advocated for movie picture reform that produced "decent" films in the 1920s; she was largely unsuccessful. Gilman proposed replacing the explicit movies with explicit sex education so that students would learn sexual information, but within the proper context, and with healthy messages attached to it (Russett, 2006). Activists intensified their efforts to successfully push for a moral code on entertainment and finally succeeded in 1930 with the Production Code. The goal of the Code was to encourage moral conduct through the cinema, rather than the immorality that had previously characterized its fare. The Code put specific restrictions on sex, language, and crime; it required that movies depicting married couples showed them sleeping in separate beds, since the actors were only playing the part of husband and wife. Similar to sex education advocates, movie reform advocates wanted the societal expectation of abstinence until marriage and good moral conduct to be given primacy. The Code also banned "sex hygiene" movies, although many continued to be shown in towns across America (Spring, 1992). Enforcement of the Code continued until 1952, when movies were granted free speech protection and the Code was completely abandoned in 1968.

The new morality of the 1920s provided a window into the changing values among a significant number of young people. Sex and the liberal consumption of other vices were becoming increasingly commonplace. This public display of recklessness, 
together with the outrage by concerned members of the community, foreshadowed a coming battle over moral expectations that would move the debate to the schools.

Influence of Alfred Kinsey. Indiana University zoologist, Alfred Kinsey, published two books on research of sexual behavior in the late 40's and early 50s. He allegedly collected around 18,000 sexual histories, the largest collection of such data ever assembled. At the time, many communities banned the book and open discussion of sexual behavior was considered off limits. The books contained controversial information about such topics as bestiality, homosexual behavior, widespread marital infidelity, and alleged infant sexual responses (Turan, 2004).

At a time that monogamy and premarital abstinence persisted as the cultural norm, Kinsey advocated "open marriage” and filmed couples having sex as a part of his research (Turan, 2004). Kinsey (1948) was the first to hold that $10 \%$ of the male population was homosexual. To arrive at his information on normal sexual behavior, Kinsey interviewed a nonrepresentative proportion of sex offenders, participants in the homosexual bathhouse community, and at least $25 \%$ of his population was from the prison population. Some of the participants were also alleged pedophiles ("Really, Dr. Kinsey,” 1991), since Kinsey's (1948) research described the sexual manipulation of babies as young as 2 months old. For example, he described one 11-month infant, citing that he had 14 "orgasms" within 38 minutes, a shocking detail that has led to the claim in modern sex education that humans are sexual from birth.

Although Kinsey's views were countercultural during his life, they provided a foundation for modern sex education decades after his death. Abrams (1998) contended that Kinsey "established the sexual license he (personally) espoused” (p. 37). Kinsey 
(1948) created an "anything goes" mentality in regards to sexual experimentation by stating that abstinence before marriage could lead to psychological or emotional harm. His research also prepared the way for gay rights, sexual rights, and women's rights movements in the future (Turan, 2004).

A survey of young people at the end of 1920 revealed that many were engaging in sexual activity, including oral sex, but were not receiving any sex education (Wheeler, 2000), so an effort to quietly implement sex education continued during the intermediate era. From the 1920's through the 1950s, the goal of American public school sex education was to encourage premarital abstinence and faithfulness within marriage in order to better assure a satisfying and happy marriage (Carter, 2001). Sex education advocates began using a new argument for premarital abstinence: that sex in marriage would be more fulfilling if individuals remained abstinent when single. This argument signified a departure from identifying sex as merely a function of procreation, but also made certain that students knew that the pleasurable aspects of the behavior were meant for marriage (Kett, 2002).

Sex education became a formal part of the character education movement. In 1922, the Public Health Service published a manual for high schools. Continuing the view of hygienists from the previous era, the manual stated that sex education was holistic, operating as a "phase of character formation” (Gruenberg, 1922, p. 2). It warned schools that the surest way to raise opposition to the program was to call a program "sex education.” Advocates learned from the mistakes of the "Chicago Experiment.” Therefore, the manual provided practical ways to integrate sex education within academic courses such as biology, physical education, English, and the social sciences, thus 
avoiding controversy (Gruenberg). For example, the "birds and the bees” was often taught in biology class. By 1927, 45\% of schools were offering some type of sex education, though few parents were aware of the matter (Carter, 2001).

Sex education continued to adjust to the times. During World War II, the danger of venereal disease again became a priority when syphilis peaked to the highest level to date (Smallman-Raynor, \& Cliff, 2004). Campaigns connected sexual abstinence to national security and protection of the family (ASHA, 1942). Figure 3 depicts a poster created for the campaign. Athletics and other extracurricular activities were encouraged as a healthy alternative to premarital sex (Gruenberg, 1946). The priority of including STDs in sex education decreased after antibiotics were discovered to be an effective treatment of gonorrhea and syphilis in the mid-1940's (Public Health Service, 1959).

Public school sex education subsequently turned toward the sociological and psychological aspects of sex education. The term "family life education” (FLE) became an important part of school-based classes during 1940s and 1950s in which the discussion of character building, relationships, money management, marriage, and childbearing was part of home economics classes. Marriage was increasingly seen as a companionship rather than merely an institution that legitimatized procreation. Burgess and Locke (1945) noted that this transformation had been gradually taking place for several decades. The family provided a healthy and safe place for children to be born; therefore sexual restraint before marriage was deemed necessary (Kris, 1953), and FLE classes generally reflected this sentiment.

Changing the direction of sex education classes to economic and relational subjects also helped them become much more palatable to the public (Carter, 2001). 
Freeman (2008) suggested that schools taught sex education without controversy "in proportion to their discretion" (p. 45) and this new focus was one part of that discretion. Though usually not addressing an explicit discussion of sex, the classes treated family life as an "academic subject” (Rotskoff, 2001). Parents continued to be concerned that teaching about sex in public schools could lead teens to experiment sexually. Indeed, sometimes boys reportedly referred to sex education lectures as "smut talks" (Gruenberg, 1940). Opponents continued to believe that parents, not the school, should teach moral values, so most schools persisted in keeping the instruction embedded, or hidden within other academic subjects.

\section{The Sexual Revolution Era (1960s and 1970s)}

The era that began in the 1960s was iconic for strong feelings of both love and hate, often simultaneously communicated by a growing subculture of cultural dissidents who protested the Vietnam War by staging love-ins. Long hair, open-air sexual orgies, drugs, student rebellions, Vietnam, and racial tensions all marked this same time period. Increased numbers of young people emerged from the safety of their suburban homes to join a discordant assembly who demanded their rights (often without responsibility). Sexual license became a political statement of defiance against the traditional morals and social system. Within this milieu, many of the ideas and movements begun in the Progressive and Intermediate Eras grew to new dimensions. The emergence was so quick that, even during the 1960s, professionals were grappling with their ability to make full sense of it all. Feldman (1969) told fellow psychologists that the sexual revolution "may ultimately be seen as one of the most sweeping significant social developments in our history” (p. 54), not realizing at the time just how prophetic his words would become. He 
saw a move toward focusing on self rather than on others. The sexual revolution was signified by exhibitionism, immediate sexual gratification, sex without emotional connection or commitment, and a general freedom to use one's body “as he wishes, to give himself pleasure” (p. 55). Not surprisingly, the public display of sexuality impacted school sex education, further greasing the wheels on a train headed toward heated battles in the near future. The following key indicators of the sexual revolution affected the debate: (1) a growing subculture of Hippies, drugs and free love, (2) the rise of Situational Ethics, (3) the Pill \& abortion, sex education, and government funding, and (4) the birth of "pro-sex" organizations.

Growing subculture: Hippies, drugs and free love. The traditional values of sex after marriage and faithfulness within marriage continued to be held by most Americans, but sexual attitudes and behaviors were making noticeable changes and the social norms were challenged by a very diverse, often young, and vocal minority. The predilection was fed by fatalism over the Vietnam War, race riots, and anger with the “establishment” (Allyn, 2000). Kinsey’s report helped justify many in this counterculture to sexually experiment in unconventional ways. The introduction of the birth control pill (the "Pill") in the early 1960s ushered a new era of sex without pregnancy “complications.” Continuing through the 1970s “swing clubs,” open nudity, gay bathhouses, and pornographic movies also shocked some Americans, while luring others into more participatory sexual practices (Allyn, 2000). These behaviors existed prior to the advent of the sexual revolution but, for the first time, their existence was visible and more tolerated within contexts of varying "community standards." The public face of the revolution took the form of a number of different subgroups. Although they were not 
officially part of the debate over sex education, they did influence teen perception of normalcy and morally acceptable behaviors (Allyn, 2000). Their combined rise as a public subculture also became a target of some local school boards vis-à-vis behaviors they sought to curb through the adoption of sex education in their school districts.

Beatniks represented a group of writers who publicly rebelled against the "establishment," and called for sexual freedom of speech and expression. They cemented their camaraderie by casual sex of all kinds (Allyn, 2000). Hippies were known for their commitment to "free love.” They purported that sex was a natural part of life and should be enjoyed without restraint.

By the early 1960s, there were several homosexual advocacy organizations, including Mattachine and Daughters of Bilitis (Costain \& McFarland, 1998). The Stonewall riots of 1969 increased public awareness of homosexual demands when a police raid on a gay bar sparked a violent three-day riot. The riots symbolized the confrontational organizing point for gay rights activists seeking equal access to sexual freedom (Carter, 2009).

A particular businessman rose to capitalize on the new public sexual permissiveness. Although Hugh Hefner founded Playboy in 1953, it was not until 1960 that he opened his first Playboy Club. Within 3 years, he opened 6 clubs with 250,000 regular patrons, signifying a rapid growth in the mainstreaming of pornography (Allyn, 2000). The profits that amassed through this lucrative business helped give the Playboy Foundation the wherewithal to help fund the creation of the Sex Information and Education Council of the United States (SIECUS), a new organization that supported "values neutral" sex education (Reisman, 2000). 
Birth of "pro-sex" organizations. Women's liberation drew headlines with the release of Helen Gurley’s (1962) infamous Sex and the Single Girl. It described, in graphic detail, a young girl's uninhibited sexual life. Her expose was followed by Betty Friedan’s (1963) The Feminine Mystique, which officially launched the Women’s Liberation Movement (Heer, 1981). In 1966, Friedan founded the National Organization for Women (NOW). Among other agendas, it focused efforts on attacking the sexual double standard and eliminating the male domination they insisted was intrinsic within marriage. The group also claimed at least partial victory by legalization of the Pill and abortion. NOWs membership increased from 1,000 in 1967 to 40,000 by 1970 (Chappell, 2002). Women's rights activists became heavily involved in the fight for sex education in the schools.

Moran (2003) noted that SIECUS was formed in 1964 with the help of former Planned Parenthood medical director, Mary Calderone. Vespa (1980) argued that Calderone did as much for sex education as Sanger did for birth control; her work with SIECUS accounted for most of this credit. They supported values neutral “comprehensive" sex education that encouraged students to decide for themselves when to engage in sex, whether to seek an abortion, and how to obtain easy access to contraception (Kett, 2002). SIECUS (1969) maintained that the "old morality" of abstinence until marriage was widely challenged and that the "new morality" of relativism offered the most hope for modern sex education. Nonetheless, they were careful not to discount the "morality of indulgence" found among hedonists (p. 10). This philosophy of sex education may have been too radical for some because in 1969, the 
California legislature banned SIECUS materials in sex education classes in that state (Mehlman, 2007).

In 1967, SIECUS leader, Patricia Schiller, formed the American Association of Sex Educators and Counselors and Therapists (AASECT) to offer training and standards for sex education providers (Engel, 1989). By 1969, school districts were already using SIECUS consultants to assist their development of sex education classes (Moran, 2000). By 1973 over 450 people applied to AASECT for certification as professional sex educators (Engel, 1989). Another organization assisted the collection of research in support of sex education. The Alan Guttmacher Institute (AGI), a part of Planned Parenthood until 1977, was formed in 1968 to promote "reproductive health and rights" through the use of research, analysis and education (AGI, 2009).

Situational ethics. Joseph Fletcher (1966) published an influential book, Situation Ethics: The New Morality. He suggested a new philosophy, advancing the notion that all decisions were relative to their respective situations. Love was the only absolute. Within that one absolute, every other decision could be individually determined: "What is sometimes good may at other times be evil, and what is sometimes wrong may sometimes be right when it serves a good enough end - depending on the situation,” argued Fletcher (p. 123). The theory became popular with proponents of sex education. SIECUS (1969) produced a booklet on values for sex education and referred to situation ethics as "the emerging new morality" (p. 9). The argument was that students should decide the prudence of a given sexual behavior based on the particular circumstances in which they found themselves. As an example, the booklet provided an application of the principle to premarital sex: "If you feel good about it, it’s right; if you 
feel bad, it’s wrong.” (p. 22). SIECUS promoted "value free” sex education, appealing to numerous local school boards within the context of a pluralistic society.

The Pill, abortion, sex education and government funding. Margaret Sanger devoted most of her life to affording women easy access to birth control. Her dream became realized when the birth control pill was approved by the U.S. government for widespread societal use. The Pill became one of the symbols of the sexual revolution with the FDA licensing its use in 1960 (Tolson, 1999). By 1962, over 1 million women were using it (Allyn, 2000). By 1965, 1 in 4 married women under 45 years of age used the Pill (Planned Parenthood, 2009). Penicillin already removed the danger from some STDs, but the Pill uniquely removed potential pregnancy as a major reason to avoid premarital sex. Now women could have sex anywhere, anytime and with whomever they desired, without the previous fear that they might suffer pregnancy consequences. The Pill was fraught with controversy at the time of its introduction to American society. This technological advance quickly became the source of heated debates over sex education in America's public schools. Opponents warned that its usage encouraged casual sex and women's rights groups proclaimed it a step toward a single standard of sex for men and women. (It should be noted, however, that the single sex standard promoted during the sexual revolution was antithetical to that promoted during the progressive era.) The Supreme Court ruled in 1965 that contraceptive use was a constitutional right (Galvin, 1998), but many school districts were still nervous at the time to include contraceptive information in school sex education classes.

Lyndon Johnson was the first president to endorse birth control when he told the nation that family planning was one of four serious problems facing the nation (Planned 
Parenthood, 2009). His support provided an official acceptability to its use, but also opened the doors to increased access across the United States due to his Great Society agenda and its accompanying federal funding (Cohen, 1967). Funding earmarked at least $6 \%$ of all maternal and child health dollars for "family planning services” (Planned Parenthood).

President Nixon continued the emphasis on family planning by signing Title $\mathrm{X}$ into law, the first funding program devoted exclusively to family planning education and services. Scales (1981) reported that, as a result of this funding, the number of teens who received contraceptive education and services jumped 600\% between 1969 and 1976. President Carter amended Title X in 1978, specifically mandating that part of the services and education must be devoted to unmarried teens, providing the first explicit funding stream for community-based sex education designed to prevent pregnancy through risk reduction measures (HHS, 1970).

The 1973 Roe v. Wade Supreme Court decision legalized abortion and sent shockwaves through much of the nation. It provided another solution to the possible unintended consequences of sexual activity. The 1977 Supreme Court decision, Carey v. Population Services International established a new precedent ruling that minors could receive contraception without parental knowledge or consent (Finkel, 2007). Abortion and contraceptive counseling was promoted in the 1978 Adolescent Health Services and Pregnancy Prevention and Care Act, making the topics possible for sex education classes (Colker, 1992). The Hyde Amendment of 1976 prohibited the use of federal funds for abortions, the same year that the Republican Party passed an anti-abortion platform and 
the Democratic Party adopted a pro-abortion platform. These actions signified the formal entrance of partisan politics into the debate (McBride, 2007).

Altman (1982) believed that the sexual revolution marked an increasing obsession with sex. It brought an upheaval to sex education (Jimenez, 2005). It began in sex education books written for adults. Though the release of Kinsey's books a little over a decade earlier met with vicious attacks, the release of Masters and Johnson’s (1966) Human Sexual Response, met with an overwhelmingly positive press. The book made them instant household names among a significant portion of the American population (Allyn, 2000). Alex Comfort's (1972) The Joy of Sex further opened the public discussion of topics previously reserved for the married couple’s bedroom. Reading and discussing the books in public unlocked a new curiosity among youth that made its way into the halls of public schools, if not inside the classrooms (Cornog \& Perper, 1996).

The sexual revolution significantly changed public values about sex as well as sexual behavior among an increasing number of Americans, including youth. In 1965, $3 \%$ of all White births were outside of wedlock and $24 \%$ of Black births were nonmarital (Akerlof, 1996), but by 1978, the numbers jumped to 20\% for White mothers and $75 \%$ for Black mothers (Moran, 2000). Before 1970, nonmarital parenthood was stigmatized, but the sexual revolution broke down many barriers to premarital sex and young people were among the most affected by the change (Akerlof, 1996). To address this growing problem of teen pregnancy, the U.S. Office of Education in 1966 funded 645 agencies to help develop sex education programs throughout numerous American communities (HEW, 1966). The Sexuality Information and Education Council of the United States (SIECUS) was presented a grant to develop a sex education training manual for teachers 
(Larson, 2002). Among public schools, the curricular content greatly varied, but "comprehensive" sex education with an emphasis on birth control, was a hot topic (Balanko, 2002). Gallup polls in 1969 and 1971 showed a drop in support for public school sex education from $71 \%$ to $65 \%$ but most Americans still approved the effort (Scales, 1981). Nixon’s 1971 White House Conference on Youth supported a requirement that all public elementary and secondary schools implement a sex education program within academic curriculum (Engel, 1989). In the 1970s, the mission of sex education proponents changed. The goal was not as much to prevent teens from engaging in sex, but rather to prevent pregnancy as a consequence of their experimentation (Rotskoff, 2001). Balanko (2002) noted that the 1970s assisted the development of a sex education component that placed "an emphasis on pleasure and sex equity” (p. 118). Disease and morality were quickly becoming seemingly unimportant reasons to abstain from sex. The sexual revolution was invading the classroom with its me-centered emphasis and the changes in sex education goals were evidence of it.

At the same time, some groups began to organize in order to counter the effects of the sexual revolution. They specifically focused their efforts to oppose sex education in the public schools (Kline, 2005). Mahoney (1979) described a national survey conducted in 1977 showing that most Americans who favored the traditional family and abstinence until marriage disapproved of sex education in public schools. Among respondents, age, religiosity, and ideology were unrelated factors in determining support or opposition. Mahoney noted: "Sex education is not a political issue which finds itself in the moral arena, but a moral issue which finds its way into the political arena” (p. 274). Nonetheless, by the late 1970s, about 35\% of private and public schools provided sex 
education, but the content varied widely, determined in large part by local community standards (Scales, 1981).

\section{The Modern Sex Education Era (1980 to the Present)}

By the dawn of the 1980s, new counter-revolution groups fixed their sights on turning back the perceived harm of the sexual revolution. Tactics changed. Rather than advocating against sex education, groups requested that "safe sex" education be replaced with abstinence education (SIECUS, 2003). Innovative organizations emerged, working to put political leadership in charge of taking on the "culture wars" in favor of more traditional values (Irvine, 2002). For the first time, abstinence education was a designated federally-funded program (Pear, 1986). The increase of modern and persistent STDs caused health concerns to resurface as an additional reason for teaching sexual restraint to America's youth. The discovery of HIV in the early 1980s caused fear over a virus that had no cure and led to almost certain eventual death (Balanko, 2002). In 1996, the bipartisan passage of a new welfare reform bill placed the debate over sex within a seemingly unrelated debate - that of child poverty and the escalating welfare rolls (Haskins \& Bevan, 1997).

Two sides of the debate advocated two very different solutions to modern problems related to teen sex. Sex education advocates of the 1960s called for "safe sex" or so-called "comprehensive" sex education, which permitted a continuation of sexual freedom, as long as contraception was used. Abstinence proponents sought to equip teens with the skills to avoid any of the potential risks of sex, both physical and emotional (Rector \& Kim, 2007). The issue of sex education became increasing volatile during the Modern Sex Education Era as indicated by the emergence of two oppositional efforts: (1) 
the first designated funding for abstinence education, and (2) the increased strength of pro sex organizations.

First designated funding for abstinence education. In 1980, only 6 states mandated public school sex education. But by 1989, 17 states (plus the District of Columbia) had the requirement (Donovan,1989). Landry (1999) reported results of a national survey indicating most sex education courses taught about puberty, STDs, and pregnancy prevention, with at least a mention of abstinence. Birth control methods, abortion, and homosexuality were topics that were more scattered in their coverage by most public schools. The decentralized nature of curriculum decisions accounted for the wide variance.

Because of local school board control, there is no definitive source that fully explains the exact content of sex education in each district, but a contemporary study found that $68 \%$ of public schools described their sex education curriculum as "comprehensive" sex education, rather than abstinence education and almost 9 out of 10 students stated that they received sex education during their middle or high school career (Kaiser, 2002).

The creation of Title X in 1970 and its subsequent use for teen sex education motivated others to create a new funding program in order to encourage teenage sexual abstinence. President Reagan signed The Adolescent Family Life (AFL) program into law in 1981 in order "to promote self discipline and other prudent approaches to the problem of adolescent premarital sexual relations”(Pear, 1984, p. 2). The ACLU (n.d.) immediately filed a lawsuit against the program, claiming that abstinence education was inherently a religious topic and therefore violated the Establishment Clause of the 
Constitution. Eventually, the ensuing Supreme Court case determined that AFL grants had a valid nonreligious purpose, focused on eliminating or reducing the consequences of teen sex (Bowen v. Kendrick, 1987).

In 1996, President Clinton signed the Welfare Reform Act into law (Klein, 2006). A small provision was included within the massive bill that began a new state block grant for abstinence education, called the Section 510 Title V Abstinence Education Program. Funding was designated to states in proportion to their child poverty figures, since abstinence education was passed primarily in order to avert child poverty through the prevention of nonmarital sex (Haskins \& Bevan, 1997). Lawmakers reasoned that, since generational poverty was related to behavioral poverty, acquiring skills for personal responsibility would help to break the poverty cycle.

A specific definition for abstinence was included in the bill. Known as the "A-H Guidelines” because of their location within the legislation, they mandated that all programs funded under the Act teach the benefits of abstinence until marriage, reestablishing this behavior as the expected standard for school age youth. The definition also listed an assortment of possible physical, social, psychological and economic consequences that could ensue if a teen engaged in premarital sex (Social Security Administration, 2009). Support for the program was significant as the number of teachers who implemented this approach in public schools jumped from 2\% in 1988 to 23\% in 1999 (Moran, 2003). The same year Title V Abstinence Education Funding passed, Gloria Feldt, president of Planned Parenthood signified that another battle was brewing by stating: "It's an example of the kinds of things the religious political extremists would like to write into law everywhere” (Purnick, 1996, p. 1). 
George W. Bush campaigned on a promise to provide equal funding for abstinence and so-called "comprehensive” sex education. While governor, Bush visited an abstinence education teacher-training workshop in Waco, where he gained an appreciation for the approach. Bush learned that abstinence education offered a practical, comprehensive skill building approach that reportedly made sense to a father of 2 teenage daughters (L. Benn, personal communication, August 11, 2009). True to his promise, the Community Based Abstinence Education (CBAE) Program was initiated in 2002.

Popularity for the CBAE program resulted in it quickly becoming one of the most highly competitive grants offered by the federal government (U.S. OMB, 2009). Contraceptive-based sex education proponents regrouped their efforts after discerning the support for abstinence education across the country. They rebranded contraceptivecentered education as "abstinence-plus” (Landry, 1999), in part, to assuage nervous schools boards and anxious parents that students were receiving the same abstinence until marriage message that was taught before 1960, when in fact, they were not.

Despite the rise of abstinence education funding, contraceptive or so-called “comprehensive” sex education continued to be given precedence. Abstinence education only received a fraction of the funds available for so-called "comprehensive" sex education (Pardue, Rector, \& Martin, 2004). Following the panic due to the discovery of the HIV/AIDS virus in the early 1980's, by the mid 1990s, most states mandated that schools teach HIV/AIDS prevention. (Stein, 1998). This discovery created a platform for sex education advocates to press for more explicit contraceptive instruction, together with a discussion of homosexuality. The focus for HIV prevention funding and other STD or pregnancy prevention programs assumed that teens could not, or would not, abstain from 
sex; therefore, they must learn to use condoms correctly and consistently (St. Lawrence, 1998).

Advocates for "comprehensive" sex education increased their insistence for confidentiality in testing and counseling teens. The argument was that youth would not seek treatment if they knew parents would be contacted. This line of reasoning also strengthened the argument for school-based clinics (SBC), which afforded students easy access to birth control and pregnancy or STD testing, together with an array of other general health services. Although the SBC movement had its roots in the 1970's, it generally did not gain popularity until the 1980's (Card, 1999). In 1984, there were only 12 SBCs in the United States; by 1993, the number had increased to 500 ("School-based clinics,” 1993). The Clinton Administration attempted to insert funding for SBCs into a bill for healthcare overhaul, but the effort crumbled, leaving the current Obama Administration to renew the SBC effort within the 2009 health care debate (Obama for America, 2008).

The election of Barack Obama as President in 2008 significantly influenced the debate over sex education. During the campaign, he was chided by some for supporting the SIECUS-based model for K-12 sex education (Davis \& Ellerson, 2007) while a Legislator in Illinois (Illinois General Assembly, 2005). During the campaign, he reiterated his support for "comprehensive” sex education. Once installed as President, Obama submitted his 2010 budget proposal to Congress. In it, he called for the elimination of all funds previously devoted to abstinence education. In its place, he proposed a new "pregnancy prevention program” that would create a new dedicated funding stream for "comprehensive” programs supported by pro-sex organizations 
(White House, 2009). Although President Bush did not decrease funding for “comprehensive” sex education during his administration, he did work to increase the primary prevention programs of abstinence education. By contrast, President Obama recommended increasing "comprehensive” sex education programs beyond their current 4:1 funding advantage by totally eliminating abstinence education. At the present time, the $111^{\text {th }}$ Congress has yet to make a final determination, but it appears poised to follow the President's request, changing the messaging once again for youth in America.

Pro-sex organizations gain strength. During the Modern Sex Education Era, competing views of sex education intensified, in large part due to the fact that the federal government was funding both approaches (HHS, 2008d). Advocacy groups like SIECUS, Advocates for Youth, and Planned Parenthood receive significant funding from influential foundations, as well as from the federal government. This assists them in building their infrastructures to better lobby for "comprehensive” sex education (Guidestar, 2009).

SIECUS is the only national organization dedicated solely to advocating for socalled "comprehensive” sex education (Irvine, 2002). They do so on an annual budget of around \$2 million a year, much larger than any single-issue advocacy organization in support of abstinence education (Moran, 2003). They immediately entered the sex education battles shortly after their 1960s founding, but their influence strengthened in 1991, when SIECUS published the first edition of Guidelines for Comprehensive Education (Physicians Consortium, 2002). This is a curricular framework for school districts to follow when implementing so-called "comprehensive” sex education school programs, beginning in kindergarten. The lessons include general information about 
human maturation, but the guidance also recommends that instructors discuss masturbation, sexual orientation, abortion, contraception, and the role of sexual fantasies in sexual health (SIECUS, 2004). It is impossible to fully know the number of states that have implemented the Guidelines. As an example, however, Moore (2000) acknowledged that Florida implemented the Guidelines throughout the state. Beginning in 2003, Minnesota schools also implemented the Guidelines and found that they had no effect on reducing teen pregnancy rates (Hedman, 2008).

SIECUS took the lead on a No More Money Campaign, designed to discourage future funding for abstinence education during the G. W. Bush Administration. They also assembled a conglomerate group of supporting organizations, drawing mostly from abortion rights, feminist, family planning, and gay rights groups. Participants also included the ACLU, Advocates for Youth, the American Social Health Association (formerly the American Social Hygiene Association), Planned Parenthood, and the NEA (SIECUS, 2008a). With the election of Obama as President in 2008, SIECUS claimed a cautious victory for their quest to deliver so-called “comprehensive” sex education across the nation:

Make no mistake; we are witnessing a fundamental paradigm shift in Washington, D.C. and in states and communities across the country when it comes to our nation's approach to sex education. (SIECUS, 2009, p. 6)

Other organizations assisted SIECUS' mission to discredit abstinence education. Advocates for Youth (AFY, 2008b) was founded in 1980 as the Center for Population Options. From the start, they were active in the school-based clinic, the gay rights, and "comprehensive" sex education movements, as well as the campaign to eliminate 
abstinence education funding (AFY, 2008a). Fletcher’s situational ethics provided the philosophical basis for their sexual experimentation beliefs. Their 3Rs Campaign of "rights, respect, and responsibility" seeks to change social school policy in favor of “comprehensive” sex education. AFY believes American youth are better served if adults understand teen sex as "normal and natural" (AFY, 2001, p. 6). They introduce the campaign as follows:

Come along with us and begin to create a society where sexuality is treated as a normal, healthy, positive aspect of life. Envision with us a time when adults do not demonize young people's sexual development, but view it instead as a natural and valuable part of growing up (AFY, 2001, p. 3).

In 1989, Planned Parenthood and others began a concerted effort to work together on common concerns, including the content of school sex education (Planned Parenthood, 2009). They also created a political and lobby arm of their organization in order to elect leaders who agreed with their views and to rally support for their legislative initiatives. Each year, Planned Parenthood provides sex education to more than 1.2 million teens and adults. As a result of their "comprehensive” sex education public relations campaign, $82 \%$ of Americans indicated that they favored "comprehensive” sex education over abstinence education (Planned Parenthood). However, apart from the Planned Parenthood campaign, once parents were shown the differences between the two approaches, their views changed dramatically and instead supported abstinence education 2:1 over "comprehensive" sex education (Zogby, 2007). This resulted in the "war of words” during the Modern Sex Education Era, with parents sometimes uncertain of the alternatives in the sex education debate. 


\section{Summary}

An overview of the history of sex education provides an essential foundation for understanding the current state of sex education in America. Before 1900, there was virtually no school-based sex education, but the progressive era proved to be an important departure from the status quo. For the first time, government saw its role move inside America’s bedrooms. The serious outbreaks of syphilis and gonorrhea required drastic measures in order to defend the national security and protect America's families. The “social disease," venereal disease and the age-old sexual double standard became the impetus for the nation's first sex education classes. Many believed that schools held the most promise in addressing society’s ills, so they easily became the natural landing-spot for sex education. Movements begun during the progressive era proved to greatly influence the course of sex education, not only during that time, but also for the next century. Although sex education was controversial from the very start, the main message was character-based, health-based, and centered on abstinence until and faithfulness after marriage.

The Intermediate Era was a time of significant change. The blatant decadence of the 1920s prompted some to consider it the first sexual revolution. Nudity on the screen and an attitude of sexual permissiveness among many of the younger generation led to a conservative reemphasis on sexual "continence.” The era saw a change of sex education from disease prevention to "family life education," where students learned the importance of remaining abstinent in order to strengthen their future marriages. Relational understanding and marriage preparation skills were key components of this emphasis. Kinsey’s books on human sexual behavior, however, reignited the topic of sex and 
prepared America for a renewed debate on how this new information should be integrated into future sex education discussions.

The sexual revolution of the 1960s and 1970s turned America's moral sensibility on its head. A synergy of countercultural groups flaunted lawlessness, drugs and sex. Although most Americans still believed sex should be reserved for marriage, a strong undercurrent was developing that would challenge this "old morality.” Situation ethics gave Americans intellectual permission to discard moral absolutes. Sex education moved away from abstinence as a priority to preventing pregnancy. The Pill and abortion provided the opportunity to experiment with sex without the previous fear of potential consequences. All of these cultural signposts afforded a healthy environment for the emergence of pro-sex organizations and governmental funding for the first contraceptivebased "comprehensive" sex education.

The Modern Sex Education Era began with a reaction to the excess of the 1960s and 1970s. Abstinence education received federal funding for the first time, but it did not keep pace with funding available for "comprehensive" sex education. Funding disparity and a misunderstanding of the two approaches contributed to the result of most schools teaching the "comprehensive" approach. Pro-sex organizations used every opportunity to attack abstinence education. They employed public relations campaigns and political action committees to advocate for their agenda. This agenda was (and is) at least as much about destroying abstinence education as it is about supporting "comprehensive" sex education and free expression of nearly all sexual behaviors among young people. The current Obama Administration is prepared to use its fiscal scalpel to eliminate the growth of abstinence education within America's school systems. 


\section{Methodology}

Cultural observers often look at a modern problem and want to know why it exists. Social scientists desire to understand how various problems affect society and the interrelationship of its people. Policy writers often are given the challenging task of fixing the identified problem. But social participants (common individuals in society), not only would like the problem fixed, but also wish for steps to be taken in order to assure the problem does not occur again. Historical analyses can make positive contributions to that end by providing insights regarding individuals involved at each step in the above process.

Historical analysis is a research method that inspects events from the past, organizes the events around common themes, and then uses the information to gain new insights (Johnson \& Christensen, 2008). Peterson (2006) argues that the "essence” of analysis involves "interrogating the text, image, or artifact” (p. 294). Merely reading primary and secondary historical sources is insufficient. Researchers using this method seek to gather a fairly exhaustive offering of historic information surrounding the topic being studied. While this is only the beginning of the historical analysis process, researchers also must examine each source for purpose and context. For example, researchers who use historical analysis might ask: Why was this document created? Who wrote it? When was it created? Who was the target audience? Does other evidence support or dispute the source? How are all sources connected (Peterson)? 
Researchers also analyze information, looking for common themes. They seek a gestalt, of sorts, as they comb the historic record. Researchers note the recurring importance of key indicators throughout history and attempt to make sense of these themes. Investigators draw conclusions, based on the assessment of the various facts of history (Wiersma, 2009). Historical analysis is an intellectual inquiry of the past, but its purpose reaches beyond the mere creation of an historical narrative. It seeks to make sense of the past in order to inform the future (Wyche, Sengers \& Grinter, 2006). History is both predictive and explanatory; historical analysis leverages both. Patten (2007) summarized:

In historical research, information is examined in order to understand the past. Note that good historical research is not just a matter of developing a chronological list of so-called facts and dates. Rather, it is an attempt to understand the dynamics of human history. As such, it is driven by theories and hypotheses. In other words, by reviewing historical evidence, researchers are able to develop theories that may explain historical events and patterns (pp. 9-10).

\section{Rational for the Method}

Sex education in public schools is likely here to stay. Since teen sex and its consequences persist as a perennial problem, sex education in public schools will likely continue as one strategy to address it. Therefore, the present research does not seek an answer to the question: "Will sex education in the public schools continue?" Rather, this thesis seeks to answer the question: "What key events contributed most notably toward the development of present priorities in public school sex education?” Quantitative research does not provide the best paradigm for answering this question. The impact of 
culture, policy, and polemics on the implementation of sex education in the schools is difficult to assess with statistical data-collection instruments. Among the various types of educational research, the exploratory and contextual nature of the question fits better within a historical research design (Neuman, 2006). This method of scholarly inquiry permits the researcher to study both the breadth and depth of a subject. It encourages an examination of trends, related descriptors, and holistic features that are necessary to answer the question of this thesis (Leedy, 2010).

Research should bring new information or fresh perspectives to intellectual inquiry. Literature database searches located nearly 20,000 results for "sex education," indicating that the topic of inquiry is popular. Some authors studied the lives of specific individuals who significantly influenced the development of sex education. For example, Judith Reisman (2000) explored the research of Alfred Kinsey and Miriam Reed (2003) told the life story of Margaret Sanger, but the focus was narrow. Very few articles or books have specifically examined the history of sex education from the turn of the $20^{\text {th }}$ century to the present, however. Klein (2006), Moran (2000), Herzog (2008), and Irvine (2002) devoted at least a part of their research to the history of the movement, but only Moran spent considerable time exploring events prior to 1960. A closer examination of the work of Klein, Moran, Herzog, and Irvine, identifies a similar perspective regarding the sex education debate. Each author characterizes “comprehensive” sex education as the preferred option for public school children, and most are animated as they characterize abstinence-centered education with vitriol. They interpret history through a pro-sex perspective and it predictably taints their writings. 
This thesis represents a fresh approach to the study of sex education. I identified the key turning points in history that led to the current debate surrounding the issue. I scrutinized the zeitgeist present in each of the eras. I also explored the political implications that sex education decisions made in the past as a way to discern their impact on present sex education. Further, I examined the pro sex movement to identify elements that had their genesis in bygone eras. From a historical perspective, I identified not only the beginnings, but also the ways factions have influenced policy decisions and community standards. This apparently is uncharted territory.

\section{Procedure}

The present study evaluates potential historical contributions that made sex education a seemingly permanent fixture in modern school classrooms. Warren warned that the past is in the business of reprimanding the present (Warren \& Watkins, 1990), an analogy that appears fitting for the present research endeavor. In other words, the look backwards in the present thesis contributes to potential forward applications.

Conducting the present historical analysis required combing primary and secondary sources in order to find key events that contributed to the current state of sex education in public schools today. As the world's largest repository of books and other historic documents, the Library of Congress was particularly valuable. The collection of almost 142 million items, including 32 million books and documents, helps provide resources to find answers to my research question. In particular, the Library contained rare finds, including sex education books from the turn of the $20^{\text {th }}$ century and a trove that included the following: unpublished writings by Margaret Sanger, World War I reports by the War Department that detailed their fight against venereal disease among American 
soldiers, first hand accounts of individuals who fought sex education battles mid-century, and early documents by SIECUS (the advocacy group that promotes a pro-sex agenda for sex education in public schools). Additionally, an extensive online search for additional primary materials located many out of print books that were available electronically.

In addition to exploring written records, I also spoke with individuals who were a part of the countercultural response to the sexual revolution of the 1960s. This provided personal insights and additional details that sometimes are not part of formal written records. Secondary sources also supported the research process, including journal articles, newspaper clippings, and other reports that expanded my understanding of the history of sex education in America. In all, I thoroughly explored the writings of both abstinence and pro-sex groups - endeavoring to understand both sides of the contentious issue - from the groups' respective vantage point.

A comprehensive assessment of all the data showed four eras that seemingly hallmarked sex education in American public schools from 1900 to the present. They are the Progressive, Intermediate, Sexual Revolution, and Modern Eras. The divisions were not arbitrarily chosen. They were derived because of common themes that bound certain decades together in reference to the development of public school sex education. While each era played a key role in propelling sex education forward, not all events were equally important vis-à-vis their full respective impacts. Key turning points in the history of school sex education were subsequently evaluated. These turning pints were identified on the basis of how various events changed or significantly impacted the subsequent direction of sex education in the American public school. I cited scholars who recognized that the events were significant; the unique element in the present thesis is how I have 
threaded together the various events, showing their overall impact, and also the analysis I provided within each era.

An event qualified as a key turning point if it significantly influenced the culture of that particular period, as well as having the quality of exercising a continuing influence on subsequent public school education. As such, key figures, the zeitgeist, and policy implications were considered. Following the identification of key turning points, the final step of this study involved a discussion of the implications of the findings. What can be discovered from history that will assist in making wise choices regarding sex education in the future? In the past, well-intentioned individuals and groups implemented sex education programs that they believed would help teens make better sexual choices. The consequences of these changes had an effect - sometimes for the better, sometimes for the worse. This thesis separated the two and made recommendations for the future. This final step in historical analysis sought to make the study intensely practical, as the issue of sex education is more than an academic or cultural debate. 


\section{Results and Analysis}

Since 1900, six key events provided a catalyst for the growth of modern public school sex education. These same events also offered foundational underpinnings for the development of one of the two major views of sex education ("comprehensive" sex education and abstinence education). Each turning point set major changes in motion, but the respective changes often reached far beyond the sex education debate. Sometimes sex education was not even the intended target, but the impact was felt nonetheless. At times, the results were most pronounced long after the event took place.

As previously noted, an event qualified as a key turning point if it significantly influenced the culture of that period and exercised a continuing influence on modern society and subsequent public school education. Key figures, the contemporary zeitgeist, and policy implications were considered. The salient events were based on affirmative responses to these questions:

- Were important policy or social decisions made as a result of the event?

- Did the event influence the current or future zeitgeist?

- Did the event have social and political implications for the implementation of sex education?

The six resultant major turning points are as follows: (1) The work of the social hygiene and (to a lesser degree) the birth control movements during the progressive era, (2) research by Alfred Kinsey, (3) the sexual revolution, (4) creation of SIECUS, the singleissue sex education advocacy group, (5) the discovery of AIDS and, (6) the reform of the 
welfare system. This chapter explores the unique characteristics of the six historical turning point events and the role each played in shaping the development of public school sex education. Sex education likely would not have evoked the heated controversy that it has nor would it presently have its prominent place in the public school classroom had these events not transpired.

\section{Description and Analysis of the Key Turning Points}

\section{Efforts of social hygienists and the birth control movement during the}

progressive era. The first major historical event that laid the foundation for public school sex education involved the efforts of the social hygiene and the birth control movements during the progressive era. The cultural climate was ripe for reform during the early part of the $20^{\text {th }}$ century and both movements were eager to assist in the effort. A number of factors simultaneously were engaged, but epidemic rates of venereal disease and rampant prostitution hastened the public sentiment in favor of the hygienist's call for sex education (Cornog \& Perper, 1996).

The growth in governmental involvement during the early 1900s supported this attempt. The Comstock Laws virtually outlawed distribution of information and education about birth control devices to women (Jacoby, 2005). Birth control activists like Margaret Sanger wanted to overturn this law, so that sex and reproduction could be disconnected. They sought to raise the profile of the perceived injustice of the Comstock Laws by purposely disobeying them. They recognized that their arrests would hasten change in the laws. With changes in the law, increased access to birth control would be facilitated for women of all ages. Although birth control advocates did not focus on school based sex education at this time, their influence would become important to this 
effort in the future through the eventual insertion of birth control instruction within messages given to students.

Key figures. During the progressive era, two individuals were particularly important in what eventually would become public school sex education. The first was Margaret Sanger, founder of the birth control movement. She was a radical in her time, an atheist when being one was unpopular, and a socialist during a World War (Byfield, 1997). Sanger began the nation's first birth control clinic, which served mostly poor immigrant women (Tolson, 1999). The vice squad raided the clinic soon after opening. Sanger was jailed but eventually won a legal victory when the court ruled that doctors, for any health reason, not merely the prevention or treatment of STDs, could prescribe contraceptives to women (Powderly, 1995). Goldberg (2008) related that Sanger also was arrested for violating obscenity laws in 1917 by distributing condoms. Sanger (1917) distributed Family Limitation to American women as a how-to manual, detailing home remedies of contraception, with the warning that birth control was the "only cure for abortion.” Sanger predicted that her efforts would give women the ability to practice one’s sexuality free of consequence (Chesler, 2003). Her labors seemingly did not have a direct effect on school and community-based sex education for decades, but “comprehensive” sex education eventually adopted her seeming aversion to abstinence (Antonucci, 1995) vis-a-vis their own advocacy efforts. The later approach also would emphasize the use of birth control as the priority message to avoiding pregnancy.

The second person who was significantly influential during the progressive era was Prince Morrow, founder of the social hygiene movement. The high rates of STDs called for action and the social hygienists proposed a solution. They advocated an all-out 
assault on the disease, using morality to bolster their health perspective (ASHA, 1916a).

The social hygiene drive became an extraordinarily popular movement and was heavily connected with governmental efforts to curb the STD epidemic, lending the leaders' expertise, time, and organizational efforts. Hygienists believed that silence was the primary reason for the problems of vice. If men and women fully understood the possible consequences of their illicit sexual decisions, they would avoid them. Boys would learn that they could exercise self-control over their sexual impulses and that they had no "sexual necessity” during adolescence (Bigelow, 1916). Morrow lent credibility to the movement as a doctor and he enlisted his colleagues in the medical profession to join his efforts. Morrow created a sex education model (detailed later in this section), but it was Maurice Bigelow who fleshed out the model in great detail and advanced the campaign for school and community-based sex education after Morrow's death.

Zeitgeist influences. Two features of society during the progressive era were particularly notable as they relate to turning points in future American public school sex education. The first was the national effort to eliminate the sexual double standard for men vis-à-vis women (Kimmel, 1916). For decades, society tacitly acknowledged that men retained a "sexual necessity" that required experimentation virtually from the time of puberty. During the progressive era, social hygienists, women's groups, religious leaders, and social workers exhorted men to live by the same standard of morality as women. Women were encouraged to expect purity from men, thereby raising the standards in relationships and society as a whole (Moran, 2000). Men and boys did not "fall" because they set too high a standard and then failed to reach it, insisted Moore (1914). Rather, they fell because they had no standard to which they ought to aspire. The 
"single standard" provided a positive expectation of abstinence. This principle was incorporated into the sex education model of the early 1900s and it continues to be a topic in sex education classroom discussions (Marks, 2008; Measor, Miller, \& Tiffin, 2000).

A second zeitgeist influence during the progressive era was the open public discourse about sexual hygiene. Social hygienists like William Foster (1914), President of the Pacific Coast Federation for Sex Hygiene and President of Reed College, supported the advancements made in educating the public regarding the need for sexual "continence" in order to avoid STDs. However, they were also frightened by what they considered to be a potential "monster" that was unleashed as a result. Public exhibits and films depicted the horrors of venereal disease and showed how innocent girls were turned into "white slaves" (prostitutes). Lectures were conducted throughout the country on sex hygiene. Professionals and opportunists used the movement to turn profits from various enterprises they developed for the public. Suddenly, the floodgates were open and publicity about social ills was a part of the daily news. Leaders of the hygiene movement were concerned that the manner in which the message was being communicated could be harmful and not appropriate for all ages of people who were receiving it. Materials were so prevalent and explicit that some young people used the information as an excuse to discuss the subjects for pure titillation. Some books that were written in order to carefully instruct the reader on proper conduct were tossed aside in favor of erotic publications produced under the guise of hygienic education. The immorality of the age was redirected to an open discussion of the social ills that social hygienists hoped to eliminate (Foster, 1914). The concern over explicit content and the fear of moving from sex "education" to 
sex “advocacy” remains a concern in regard to sex education for many parents today (Zogby, 2007).

Salient decisions and political implications. Four critical decisions were made at the federal level during the progressive era that contributed to it being a key turning point in American public school sex education. The first was the regulation of prostitution. Though illegal, law enforcement officers often turned a blind eye to the industry. Hygienists believed that, if women knew the dangers of the profession, they would avoid it, and men would stop frequenting houses of ill repute, if they understood the ravages of venereal disease (ASHA, 1919). A concerted campaign by a wide coalition of groups began an information initiative to make the public aware of prostitution's enormous social and health problems (ASHA, 1916a). Subsequently, steps were taken to censure it. Hygienists created model legislation that defined prostitution as a sex crime and the legislation received widespread support (Pivar, 2002). By 1920, at least 32 states had enacted a portion of the model legislation, often extending punishment to other enterprises that assisted prostitution in any way, such as saloons, theaters, and taxi services (ASHA, 1921).

The second political decision made of importance to the rise of sex education was the requirement that doctors register cases of STDs. Venereal disease was a "silent disease” because men were reticent to admit their sexual behavior or the resultant contraction of an STD. Morrow observed: “ Social sentiment holds that it is a greater violation of the properties of life publicly to mention venereal disease than privately to contract it” (Schaefer, 1999, p. 21). Sanger was arrested in 1912 for distributing a pamphlet that was deemed obscene, since it included a discussion of venereal disease 
(Brandt, 1987). This attitude made it exceedingly difficult to treat the disease or to accurately count the extent of the prevalence. Physicians pleaded for an end to this secrecy, with Morrow serving as spokesperson. The efforts were successful since by 1916, 22 states required STD notification, jumping from only 3 in 1911 (Fairchild, Colgrove \& Bayer, 2003). This endeavor served as a precursor to today’s mandatory reporting of prevalent STDs in all U.S. states. The decrease in STD rates provides one measure for success in current sex education programs.

The third political decision important to the development of sex education was federal funding for STD educational, prevention, and treatment efforts. The funding of the Commission on Training Camp Activities (CTCA) during World War I began the concerted effort in the $20^{\text {th }}$ century (Moran, 2000). A small budget prevented extensive services, but STD rates plummeted in the military as a result of the campaign. The Chamberlain-Kahn Act created a more liberally funded program to fight STDs in 19181919 (Stevens, 2006). It gave monies to state health departments in order to develop prevention and treatment programs. Today, STD prevention is the most common reason that schools provide sex education because nearly all states mandate STD or HIV prevention education in their public schools (Page, 2003).

The fourth important decision concerned government involvement in social issues and in areas pertaining to human behavior. Prohibition (ASHA, 1920), the regulation of prostitution (Pivar, 2002) social (sex) hygiene education for young men and women (Brandt, 1987), and eugenic sterilizations (Knight \& Callahan, 1989) were salient examples of federal encroachment in mostly previous matters of private charity or debate. Comparatively speaking, the influence was minimal, but it signified the beginning of 
increased investment, oversight, and responsibility by the government that would never abate. Not surprisingly, the progressive movement of the $21^{\text {st }}$ century is directly related to the philosophy pertaining to the government's present role in solving social problemsteen sex being only one such issue.

\section{Impact on contemporary and future sex education policies. The} progressive era marked the beginning of school-based sex education. Efforts by the social hygiene movement and its cohorts influenced future sex education policies. The first major impact pertaining to sex education made during the progressive era was the creation of the two models for sex education. Margaret Sanger and the birth control movement lit the spark that would eventually become "comprehensive" sex education. This sex education approach focuses primarily on the same two chief concerns of Sanger and her colleagues: advocacy for contraception and delinking sexual activity from pregnancy (Degette, 2008). Although social hygienists held values very similar to that of contemporary abstinence education leaders, many of their campaign components describe elements similar to those of today's general sex education implementation model.

Chiefly physicians, leaders in the hygiene movement believed that knowledge was power and, if individuals were provided accurate and scientific information, then they would make better choices. However, in order to achieve maximum impact, the message needed to have a clear abstinence until marriage focus (Cocca, 2006). These leaders called for a community saturation model, dispersing the information. Table 1 illustrates how closely the social hygiene model mirrors many components of modern sex education programs. (A discussion of the two modern models of sex education is presented in Chapter 5). 
Cedarville University

School of Graduate Studies

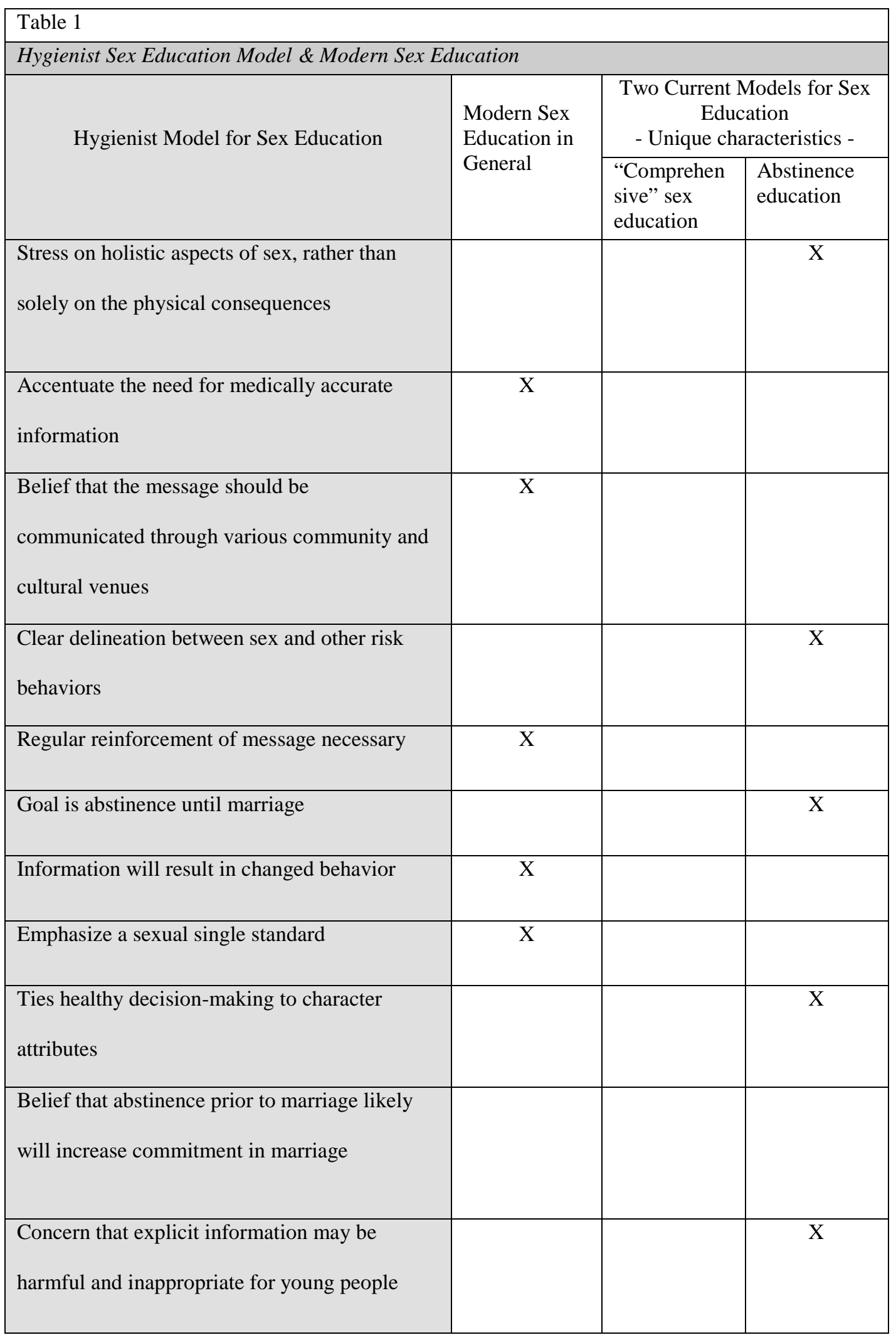


The second impact was the controversy surrounding the district-wide public school implementation of sex education, particularly during the Chicago experiment. Opponents were able to discontinue the program through highly organized efforts (Cocca, 2006). Opponents disagreed that knowledge alone was sufficient to affect behavior change. They argued that, if knowledge was sufficient, then doctors would always make good health decisions. Sadly, such was not the case. Sex education should not be valuesneutral, they added (Jensen, 2007). Opponents to sex education also argued that parents should provide sex education instruction to their children, not the school, and not the government (Jensen). Their success in halting the Chicago experiment was an early foretaste of the public outcry that would occur when schools attempted to implement sex education in local schools, against the wishes of its local citizens.

Research by Alfred Kinsey. The second major historical event that laid the foundation for public school sex education involved the efforts of Alfred Kinsey (1948, 1953) in publishing his research on the sexual behavior of men and women. His study was revolutionary in its frank discussion of what he described as typical behavior among Americans. The works were extremely controversial at the time, breaking new ground regarding the open conversation about sex. Many of his findings form the basis for sexual science research and thematic content in sex education texts.

Key figures. Two individuals associated with Kinsey's research were particularly notable. The first, of course, was Alfred Kinsey. A professor of zoology at Indiana University, Kinsey first expressed public interest in the study of sex when he taught a marriage class for engaged couples in which he discussed sex in explicit details (Jones, 1997). He is best known, however, as the individual who challenged nearly every 
previously held assumption regarding sexual behavior. He personally interviewed thousands of individuals to learn their most intimate sexual practices and even permitted his own sexual history to be recorded by a colleague. Kinsey maintained an open marriage with his wife and a bisexual relationship with Clyde Martin, one of the coauthors of the Sexual Behavior books (Jones, 1997). Kinsey was careful to avoid passing judgment on any sexual behavior, insisting that culture imposed values on sexual activities, but that none were intrinsically wrong. Kinsey's colleague, Paul Gebhard added:

He felt that neither male nor female was inherently monogamous, and he thought sex was a wonderful thing, and it was just a pity that it had to be constrained and unnecessarily restricted...It didn’t much matter what you did sexually as long as it didn’t hurt anyone else and it made you and our partner happy (Jones, 1997, p. 519-520).

He was quick to pass judgment, however, on “celibacy, delayed marriage, and asceticism,” calling them “cultural perversions” (Panzer \& Mosack, 2009, p. 49). Bullough (1998), summed Kinsey's life as follows:

He changed the nature of sexual studies, forced a reexamination of public attitudes toward sex, challenged the medical and psychiatric establishment to reassess its own views, influenced both the feminist movement and the gay and lesbian movement, and built a library and an institution devoted to sex research. His reputation continues to grow, and he has become one of the legends of the twentieth century (p. 131). 
The second individual who was important to Kinsey's research and its long-term application to society was Wardell Pomeroy. Pomeroy $(1948,1953)$ worked with Kinsey for two decades and was coauthor to both the male and female versions of Sexual Behavior. He and Kinsey conducted about $85 \%$ of all the sexual histories collected for the two books and he helped to keep the Kinsey Institute operational after Kinsey's untimely death (Pomeroy, 1982). In addition to co-authoring the books with Kinsey, Pomeroy $(1968,1991)$ also wrote two books for teens: Boys and Sex and Girls and Sex. In the latter book, he gave this non-judgmental advice to girls as young as sixth grade: "Sex play with boys (or, for that matter with girls) can be exciting, pleasurable, and even worthwhile in the sense that it will help later sexual adjustment” (Pomeroy, 1991, p. 48).

Pomeroy was instrumental in the formation and leadership of several organizations that are involved in contemporary sexology and sex education. He was director of the Institute for Advanced Study of Human Sexuality (IASHS), the only graduate school in the United States approved to train sexologists (IASHS, 2009). Pomeroy served as president of Society for the Scientific Study of Sexuality (SSSS, or "quad-S"), an organization formed to study all aspects of sex (SSSS, 2009a). The American Board of Sexology named Wardell Pomeroy as a Board Certified Diplomate in Sexology (American Board of Sexology, n.d.). He was also a founding board member and president for the sex education advocacy group, the Sex Information and Education Institute of the United States (SIECUS), now known as the Sexuality Information And Education Institute of the United States (SIECUS, 1978). The influence of these organizations to provide guidance for sex policy and sex education guidelines cannot be overstated. They continue to aggressively advocate for "comprehensive" sex education. 
Zeitgeist influences. Two features of society (due to Kinsey's research) were especially prominent as they relate to turning points in future American public school sex education. The first was an erosion of the institution of marriage. Kinsey's assertion that nearly $50 \%$ of married men and women were unfaithful shook the foundation of marital monogamous expectations (Mestel, 2004). It seemingly mattered little that Kinsey's research sample was seriously unrepresentative of the population (Gathorne-Hardy, 1998). His public pronouncement of widespread infidelity became an almost established "fact," serving to assuage the guilt of men or women who participated in marital affairs and planting the seed of possibility among those who had not. Kinsey further weakened the sense of marital bond by reporting that, in his sample, less than half of all male sexual encounters were within marriage (Kinsey, 1948). A further blow to the belief in marital monogamy was the influence of Kinsey's research on mainstreaming the pornography industry. He reported that $70 \%$ of all males engaged a prostitute at one time or another (Kinsey, 1948). This information served to permit pornographic exploration among the newly curious and sexually frustrated. Hugh Heffner considered Kinsey’s research to be the empirical validation for his lucrative business (Gathorne-Hardy). Reiss (2006) explained: “[The] philosophy favored increasing the range of sexual behavior that Americans accepted as moral” (p. 55). As a result, Hefner helped to bankroll the Kinsey Institute (Gathorne-Hardy). On at least one occasion, the Kinsey Institute organized gatherings at the Playboy Mansion in order to discuss the rise and acceptability of sexual pluralism (Reiss).

The erosion of marriage, the social tolerability of nonmarital sex, and rise in acceptability of pornography cogently affects sex education in public schools. Since the 
time of Kinsey, abundant social science research has emerged showing that children born within marriage typically have brighter social, economic, and personal outcomes (Stanton, 1997). Unfortunately, most teen births are outside of marriage (CDC, 2009a). For some students, marriage has not been a part of their familial experience for several decades, so abstinence education classes seek to rebuild an appreciation for marriage Phelps, 2006). Teen boys, in particular, often view pornography, usually on the Internet. The addictive nature of pornography is frequently a topic of discussion in abstinence education classes (For Keeps, 2007).

The second element that demonstrated Kinsey's influence on the spirit of the times was the belief that children were sexual from birth. The belief was based on Table 34 in Kinsey’s (1948, p. 180) seminal book. The table described pre-adolescent "sexual response” for children as young as 2 months (Kinsey). Kinsey appeared to tacitly affirm the possibility when he reported: "In five cases of young pre-adolescents, observations were continued over periods of months or years until the individuals were old enough to make certain that true orgasm was involved” (p. 177). John Bancroft of the Kinsey Institute later admitted that pedophilia was an involved source of the data collected on young children (Bancroft, 1998). But the assertion that children are sexual from birth remains, despite an inadequate foundation for the assertion. The relatively recent ability to view boys in vitro reinforced those who hold this view. They now contend that children are actually sexual before birth (Reinisch \& Beasley, 1991). This philosophy provides a grounded rationale for advocating that sex education begin as early as kindergarten (Haffner, 2008). 


\section{Salient decisions and political implications. Kinsey's research made}

two important contributions of academic and political implications. The first contribution was the founding and continuation of what was to be known as the Kinsey Institute located on the Indiana University campus. The Institute houses the largest assembly of sexually explicit material in the world (Gathorne-Hardy, 2000). It also tenders collections on pro-sex organizations such as the Sexual Freedom League and the Society for the Scientific Study of Sexuality (Kinsey Institute, 2009). The Institute continues to contribute to Kinsey's original research by sponsoring current research in sexual decision-making, sexual arousal, and condom use (Kinsey Institute). This research serves to inform the field of sexology as well as school-based sex education.

The second major implication of Kinsey’s research was its vast influence on a gradual change to American penal codes. Kinsey, himself, provided expert testimony before committees in 21 state legislatures that were considering revision of their sex offender laws (Jones, 1997). However, his research was most helpful to the creation of the American Law Institute’s 1955 Model Penal Code, which was a project that began in 1953, but finally took shape, partly due to funding by the Rockefeller Foundation (Wechsler, 1952). In the Code, $33 \%$ of all social science citations and $100 \%$ of all scientific citations in regard to sexual behavior were from Kinsey’s research (Panzer \& Mosack, 2009). His research also was eventually instructive to landmark court cases, such as the Lawrence v. Texas (2003), a Supreme Court case that invalidated states' sodomy laws in support of homosexual rights to privacy (Chauncey, 2004). For example, the majority opinion referred to the Model Penal Code (MPC) to support its view; the only scientific research cited in the MPC for sodomy is from Kinsey, further illustrating 
the continuing influence of the famed research (Reisman, 2003). Some states, such as Ohio, require that students learn the legal consequences of certain sexual activities as a part of their school-based sex education (ODH, 2007). Consequently, changes in the penal code not only influenced the content of school lessons, but also impact the activities in which teens could legally engage.

\section{Impact on contemporary and future sex education policies. The}

research by Kinsey made an enormous contribution to what is now known as sex education. Two specific contributions added intellectual gravitas to values that have now been incorporated into sex education in the public schools. The first was the creation of "sexology," a scientific, academic field that focuses on the study of sexual behavior and related themes (Irvine, 2005). Kinsey wanted sex to be studied in the same methodical and scientific manner in which animal reproduction was studied (Bullough, 1998). His formation of the Kinsey Institute was a beginning to that pursuit. Other organizations followed. The SSSS was formed in 1957 by psychologist Albert Ellis in order to study sexuality, but its founding was intricately related with Kinsey and his team of researchers. The organization annually presents an Alfred Kinsey award to an honored sexologist (SSSS, 2009b). The American Association of Sexuality Educators, Counselors and Therapists (AASECT) was founded in 1967 by Albert Ellis and Patricia Schiller as a professional organization for sex educators, sex therapists, and others interested in sexuality (AASECT, 2004). They believe "all peoples whatever their age, family structure, backgrounds, beliefs and circumstances [are entitled to] freedom of their sexual thoughts, feelings and fantasies; freedom to engage in healthy modes of sexual activity” (AASECT, n.p.). The Institute for the Advanced Study of Human Sexuality (IASHS) 
began in 1968 to provide training and degrees in sexology (IASHS, 2009). Since the field of sexology studies the mechanics of sex, as well as sexual development and sexual relationships, it naturally informed the field of sex education. A second profound influence of Kinsey on the field of sex education was the effect his findings had on how a significant portion of society came to view sex. Kinsey was obviously interested in sex education as evidenced by the fact that his last lecture before he died was to biology teachers on how to teach sex education in high school (Gathorne-Hardy, 1998). Eventually, Kinsey and colleagues revolutionized the assumptions that many Americans held about various sexual behaviors. He argued that any sexual experience could be healthy, regardless of one's age and that abstinence until marriage was not only unrealistic, but also harmful to healthy sexual development (Kinsey, 1948, 1953). Table 2 summarizes the major contributions Kinsey made to the public understanding of sex and the values inherent within "comprehensive" sex education.

The Sexual Revolution. The sexual revolution of the 1960s and 1970s was a period in which powerful countercultural forces succeeded in making dramatic changes to the way Americans viewed sex and sex education. The public display of sexual behavior was sometimes an expression of irreverence to the status quo. Sex was increasingly disconnected from commitment and "self" became key to behavioral decisions. "If it feels good, do it" became a moral edict for many in the younger generation although the content of public school sex education widely varied, depending on the school district (D’Emilio \& Freedman, 1998). 
Cedarville University

School of Graduate Studies

\begin{tabular}{|c|c|c|c|}
\hline \multirow{2}{*}{\multicolumn{4}{|c|}{\begin{tabular}{|l|} 
Table 2 \\
Common Components: Kinsey’s Assertions \& Modern Sex Education
\end{tabular}}} \\
\hline & & & \\
\hline \multirow{2}{*}{$\begin{array}{l}\text { Kinsey's Assertions }(1948,1953) \text { in His Research } \\
\text { of Sexual Behavior on the Human Male and } \\
\text { Female }\end{array}$} & \multirow{2}{*}{$\begin{array}{l}\text { Statements } \\
\text { Accepted By } \\
\text { the General } \\
\text { Culture }\end{array}$} & \multicolumn{2}{|c|}{$\begin{array}{l}\text { Two Current Models for Sex } \\
\text { Education } \\
\text { - Unique characteristics - }\end{array}$} \\
\hline & & $\begin{array}{l}\text { "Comprehensive" } \\
\text { sex education }\end{array}$ & $\begin{array}{c}\text { Abstinence } \\
\text { education }\end{array}$ \\
\hline Humans are sexual from birth & $\mathrm{X}$ & $\mathrm{X}$ & \\
\hline $10 \%$ of males identify themselves as homosexual & $\mathrm{X}$ & $\mathrm{X}$ & \\
\hline $\begin{array}{l}\text { Values-neutral view of sex: All sexual activity is } \\
\text { "normal” (He included bestiality, though not widely } \\
\text { accepted by values-neutral proponents) }\end{array}$ & & $\mathrm{X}$ & \\
\hline $\begin{array}{l}\text { A large portion of married individuals are } \\
\text { unfaithful to their spouses }\end{array}$ & & & \\
\hline Abstinence is an aberration, or at best, unrealistic & & $\mathrm{X}$ & \\
\hline $\begin{array}{l}\text { Sexual experimentation can be healthy behavior } \\
\text { for teens }\end{array}$ & & $\mathrm{X}$ & \\
\hline $\begin{array}{l}\text { Minimize risks associated with multiple sexual } \\
\text { partners }\end{array}$ & $\mathrm{X}$ & $\mathrm{X}$ & \\
\hline
\end{tabular}


Key figures. During the sexual revolution, two individuals were especially important for the development of "comprehensive" sex education. Bill Masters and Virginia Johnson (1966) wrote the first mainstream, academic book sharing the intimate details of sex. The work was based on more than 10,000 observed sexual acts and gave confidence to the launch of a wider assortment of sex research (Reiss, 2006). Masters understood that Kinsey set the precedent for sexual research, and theirs was the next natural step. While Kinsey took the sexual histories of individuals via interview, Masters and Johnson directly observed the physiological changes that occurred during sex. They believed this provided a much more definitive understanding of sexual behavior than did often inaccurate self-reporting (Maier, 2009). Like Kinsey, they wanted the study to be scientific with documented evidence of each assertion. The findings also added more detail to Kinsey's original assertion that children were sexual from birth, by citing evidence of sexual responses in infants (Masters \& Johnson, 1966). Goldstein (2009) argued that the Masters and Johnson research made the study of sex legitimate. Reiss (2006) added that the study also revolutionized sex education in America. Masters and Johnson espoused that society harmfully hindered natural sexual expression. They also believed that sex deserved equal enjoyment by both men and women, thereby creating an environment where sexual pleasure became seen as a right.

Zeitgeist influences. A single feature of society during the sexual revolution was particularly notable as it related to being considered a turning point in future American public school sex education. This attribute was the rise in a "new morality” that advocated a non-judgmental response to any behavior. Alternatively advanced by a variety of theologians, philosophers, and social scientists, this value was 
directed to every segment of the population. Herbert Marcuse’s (1955) Eros and Civilization impact came to be more fully appreciated during the sexual revolution era. Marcusean theory could be summed this way: "Repression of sexual urges was a major cause of human misery" (Spann, 2003, p. 39). This idea was part of the "new” morality that questioned submission to traditional moral regulations. Spann continued: "Students took it as an obligation as well as a right to challenge conventional moral thinking” (p. 40). Fletcher's (1967) Situation Ethics further provided a guidebook for the Christian "new morality," the last bastion in the "outmoded" belief in absolutes. He explained that the "rightness" or "wrongness" of an action depended on the person and the situation. Regarding questions relating to the "rightness" of premarital sex and adultery, his response was “I don’t know. Maybe. Give me a case. Describe a real situation” (p. 142). No action was fundamentally wrong or fundamentally right and he even cited Scripture at times in order to drive home this new definition of decency. The nonreligious also adopted moral individualism by summing up the principle: any action is acceptable so long as it doesn't harm others (Spann, 2003).

"Make love, not war" had a peripheral connection to the "new morality" principle that stressed love as the only law. Many young people were disillusioned by the Vietnam War and believed a cathartic response to social violence was uninhibited sex (Allyn, 2000). Usually linked to student anti-war activism, John Lennon and Yoko Ono, for example, moved the concept to the public consciousness when they held a public "lovein” (in opposition to the war). Larry Bercovitz, a shock actor who was arrested for public lewdness during the presentation of Che, summed up the rationale for public nudity and 
sexual acts: "Frustration and repression leads to violence. Lack of love, mental and physical, leads to violence, then to war.... MAKE LOVE NOT WAR!!!” (Allyn, p. 127)

The new morality impacted national birth statistics, resulting in the marked increase of nonmarital births, beginning during the sexual revolution and continuing to this day. Although single parenthood was still stigmatized, the new moralists argued that such should not be the case. The "new" morality made it ethically incorrect to question the actions of others. The previous multiple barriers to premarital sex were evaporating (Akerlof, 1996). A national poll illustrated that acceptability of premarital sex dramatically increased during the sexual revolution. Percentages rose from $20 \%$ acceptance in 1963, to 28\% in 1965, and 52\% in 1970 (Reiss, 2006). During this same time, the Census Bureau noted a steady increase in premarital births (Bachu, 1999), which was closely associated with a cultural acceptance of single parenting (Booth \& Crouter, 2005). More premarital sex resulted in more nonmarital births, despite increased access to contraception and abortion. This escalation in births to single women precipitated the growth in "comprehensive" sex education, but most notably in the rise of abstinence education.

Salient decisions and political implications. Three important political or social changes were made at the federal level that proved to be a key turning point in American public school sex education during this era. The first two were the legalization and widespread distribution of the birth control pill (the Pill) and the 1973 Supreme Court decision legalizing abortion. These two decisions were inextricably linked in regard to their impact on the development of sex education. Both offered potential solutions to the possible unintended consequences of sexual activity. For those who previously abstained 
from sex merely in order to avoid a pregnancy, the Pill and abortion provided what seemed to be a newfound freedom. The impact was felt within sex education classes as well. The emphasis moved from preventing a behavior to treating a symptom of a behavior; what one did not accomplish, the other could. Sex education classes subsequently did not seemingly need to emphasize abstinence until marriage. Robert Kirstner was involved in the early development of the birth control pill, but acknowledged: "For years I thought the pill would not lead to promiscuity, but I've changed my mind. I think it probably has” (Payne, 2001, p. 100). Keeping with the spirit of the sexual revolution, classes could now recommend that students "play responsibly" as long as they used contraception (Hecht, \& Eddington, 2003).

The third important verdict with far-reaching implications for the rise of sex education was a federal statute that permitted minors to receive contraception without parental consent or knowledge. The passage of the Title $\mathrm{X}$ family-planning initiative in 1970 required equal access to contraception by minors (Jones, 2006). It was implemented with the belief that teens would not seek services or treatment if parental consent were required (Finkel, 2007). Regardless of the efficacy of this argument, the very practical reality was that students could now receive contraceptive instruction in their sex education classes and confidentially could obtain contraceptive services within their school-based health clinics.

\section{Impact on contemporary and future sex education policies. Two} decisions significantly influenced sex education during the 1960s and 1970s, creating repercussions on current sex education programs. The first decision was the launch of government-funded community-based sex education. President Lyndon Johnson supplied 
federal money to over 600 groups for the purpose of developing sex education programs across the nation (HEW, 1966). The growing teen pregnancy problem required a solution and sex education served as one potential means of curbing the crisis. Johnson's move to fund sex education with federal dollars was significant for these reasons:

- Grassroots organizations were perceived in many communities as “experts" since the government was funding their efforts.

- Government funding provided “outside” money in order to address a local problem, making it easier for schools to agree to the services.

- Organizations were able to significantly increase the numbers of students they served with the infusion of additional funding to their local efforts.

- Government funding supplied a means to develop an intensive and concentrated body of curricula specifically devoted to sexual activity issues, apart from the more generic general health curricula.

- Since the government deemed the problem serious enough to allocate taxpayer dollars to the prevention effort, then the public's general perception was that the problem must be real and the proposed solution (sex education) must be implemented.

Although Johnson was the first president to federally fund sex education, he was not the last to do so. Particularly, each subsequent President contributed monies to the implementation of sex education. It was not until the election of President Reagan, however, that a modern, federal funding emphasis was placed on avoiding sexual activity (White, 1991). Until that time, a “comprehensive” sex education model was recognized as the only way reasonably to respond to the teen pregnancy problem. Reagan did not 
defund "comprehensive” sex education; rather he merely initiated a new primary prevention strategy.

Each President after Reagan (until the current Obama Administration) continued this approach of funding both "comprehensive” sex education and abstinence education. Two new abstinence funding initiatives began in the interim - one by Bill Clinton and one by George W. Bush (NAEA, 2008). Despite the rise in abstinence education funding, however, equity between the two approaches was never reached, with "comprehensive" sex education able to access around four times as much money as abstinence education (HHS, 2008d). For 2010, Obama proposed a return to the 1960s approach of sex education, again stressing pregnancy prevention as the primary goal of the program (Melby, 2009).

The sexual revolution significantly impacted the growth of "comprehensive” sex education by changing the focus from preventing teen sex to reducing the risk of sex. The soil for more extensive sex education in schools was prepared by the rise in "progressive" educational approaches, which stressed a "child centered" approach which met the individual needs of every student. Preparing children to successfully navigate their futures was the most important role of education, progressives reasoned (Spann, 2003). Sex education was a significant component in the overarching grand scheme of life, so this subject conceivably trumped other academic subjects that seemingly only presented stodgy facts from the past (Spann). TIME magazine named all young people 25 and under as their annual "Man of the Year" in 1967, pointing to the influence of what they referred to as the Now Generation. They were "pleasure seeking, [but] they supposedly practiced an honest hedonism without adult hypocrisy, one especially notable for its absence of 
sexual inhibitions” (Spann, p. 101). The reasoning followed that, since young people lacked sexual reticence, sex education needed to help them avoid pregnancy. Additionally, the theories surrounding the "new morality" prompted support for discarding the previous morality-based sex education in favor of what was purported to be a more "scientific" approach. SIECUS and AASECT were founded in order to take up the mantle of advocating for and preparing professionals to provide "science-based" sex education (Fahlbusch, Bromiley, \& Barrett, 2008). The seeds for growth in "comprehensive" sex education were planted during the sexual revolution. A federal grant to SIECUS, tasking them to write a national training manual for sex education teachers, served to fertilize and reproduce the concept in schools across America (Marshall \& Donovan, 1991). Table 3 describes the major influences of the sexual revolution, together with their impact on the development of modern sex education. Compared with Table 1, that demonstrated the social hygiene movement was most closely related to many components of abstinence education, this table illustrates the influence of the sexual revolution on "comprehensive" sex education.

Creation of SIECUS. The Sexuality Information and Education Council of the United States (SIECUS) was formed in 1964. Created during the sexual revolution, the group in many ways reflected the ideals of the era. SEICUS sought to change the sexual culture by promoting a "value free" sex education to students in schools across America (SIECUS, 1969). The organization's ideals signified a sharp departure from that of the social hygiene program by refusing to inflict "shame" or "morality" on youth for their sexual behaviors (Levine, 2002). Although other organizations advocated for "comprehensive" sex education, SIECUS was (and is) the only single-issue 
Cedarville University

School of Graduate Studies

\begin{tabular}{|c|c|c|c|}
\hline \multicolumn{4}{|l|}{ Table 3} \\
\hline \multicolumn{4}{|c|}{ Cultural \& Countercultural Influences of the Sexual Revolution on Modern Sex Education } \\
\hline \multirow[t]{2}{*}{$\begin{array}{l}\text { Contributions of Thought \& Policy from the Sexual } \\
\text { Revolution }\end{array}$} & \multirow{2}{*}{$\begin{array}{l}\text { Modern Sex } \\
\text { Education in } \\
\text { General }\end{array}$} & \multicolumn{2}{|c|}{$\begin{array}{l}\text { Two Current Models for Sex } \\
\text { Education } \\
\text { - Unique characteristics - }\end{array}$} \\
\hline & & $\begin{array}{l}\text { "Comprehensive" } \\
\text { sex education }\end{array}$ & $\begin{array}{l}\text { Abstinence } \\
\text { education }\end{array}$ \\
\hline Student-centered education & $\mathrm{X}$ & & \\
\hline $\begin{array}{l}\text { Pregnancy prevention is a primary goal of sex } \\
\text { education }\end{array}$ & $\mathrm{X}$ & & \\
\hline Sex education should be "science-based" & $\mathrm{X}$ & & \\
\hline $\begin{array}{l}\text { No sexual action is "wrong" unless it harms another } \\
\text { person }\end{array}$ & & $\mathrm{X}$ & \\
\hline Sexual pleasure is a "right" & & $\mathrm{X}$ (among some) & \\
\hline $\begin{array}{l}\text { Risk reduction of sexual activity is given priority } \\
\text { over avoiding sex }\end{array}$ & & $\mathrm{X}$ & \\
\hline $\begin{array}{l}\text { Parental notification of their child's sexual behavior } \\
\text { should be restricted }\end{array}$ & & $\mathrm{X}$ & \\
\hline
\end{tabular}


organization dedicated explicitly to this purpose (Levine). The single focus provides its leaders the ability to keep this issue at the forefront of America's consciousness.

Consequently, implementing open morality has become an important turning point in the debate over sex education.

Key figures. During the progressive era, two individuals were particularly important in the development of public school sex education. The first individual was Mary Calderone, former medical director for Planned Parenthood and then founder of SIECUS. Of her role as executive director and founder, she said, "The point is, not that I am so important, but that I am the focal point in an organization that has become focal in a nationwide and worldwide movement” (Mary Steichen Calderone papers, 1973, p. 2). She sought to move sex education away from discouraging premarital sex and away from inducing potential guilt for sexual expression (Kett, 2002). Calderone said, "We cannot talk about human sexuality without talking about values, but they're not the 'no' values; they're the 'yes' values” (Levine, 2002, p. 27).

Debra Haffner was the second person of prominence to SIECUS' impact on public school sex education. She was a former president of SIECUS, and currently serves as director of the Religious Institute on Sexual Morality, Justice, and Healing. Haffner (2005) describes herself as a Unitarian Universalist evangelical minister who believes that many in the religious community want to deny humans of their "sexual rights." An empowering message to teens should say "it is not a wedding band that makes sex moral...but whether that relationship is consensual, non-exploitive, honest, mutually pleasurable, and protected" (p. 37). As president of SIECUS, she recommended oral sex 
as a pregnancy prevention alternative to intercourse (Haffner, 1988), although such actions have the potential of contributing to the spread of STDs (CDC, 2008, 2009b).

Zeitgeist influences. SIECUS leaders helped to shape the culture of sex education in two ways. The first was their role as spokes-organization for “comprehensive” sex education almost since the organization's founding. The first edition (1991) of Guidelines for Comprehensive Education became a framework for schools to implement into their sex education classes (SIECUS, 2004). The lessons currently include information about many controversial topics, including masturbation, sexual orientation, sexual fantasies, contraception, and abortion (Irvine, 2002). SIECUS leaders believe that all persons have the right to "sexual expression" and that sexual rights are human rights (SIECUS, n.d. [b]). They believe that there is a need to educate teens on the relationship between sexual pleasure and sexual health (Fay, 2002). Therefore, they recommend students visit websites that normalize every kind of sexual activity and encourage risky sexual experimentation (Grossman, 2009). The organization also opposes perspectives that they believe might stifle "sexual openness” (Levine, 2002).

SIECUS leadership has furthered the expansion of “comprehensive” sex education through their calculated use of the English language. SIECUS understands that the group who can best articulate its position often wins the "war of words." An important part of this strategy involves framing the debate in a way that does not make an agenda appear extreme. For example, they discerned that parents were uncomfortable with "sex" education, but were more comfortable with "sexuality” education. Formerly known as the Sex Information and Education Council of the United States, SIECUS 
changed their name to Sexuality Information and Education Council of the United States. Presently, the organization advocates for "comprehensive sexuality education” which they believe is more than genital sex, but includes a lifelong pursuit to understand one's total personal and unique "self” (SIECUS, n.d. [b]).

When parents favor abstinence education in a particular community, SIECUS refers to this support as "restrictive" or "censorship" in order to better frame the issue to their favor. Similarly, when a community denies explicit texts in their schools, they are derided for banning books and censorship. For example, a school board voted to restrict It's Perfectly Normal in elementary school libraries after a parent complained: "We do not believe a book with pictures of people having sex, naked bodies, people masturbating, people putting on condoms, a student having an erection in front of a school class, or gay people hugging is necessary at the (elementary) school level” (SIECUS, 2003, p. 5). In sum, SIECUS leaders have mastered the skill for framing their position as reasonable.

Salient decisions and political implications. SIECUS made two specific policy decisions that helped the organization become a major influence in the growth of “comprehensive” sex education. The first was their targeted quest for federal funding. This effort helped them gain a national policy voice, and also provided funding to build the organization's influence and infrastructure. Early in the organization's existence, SIECUS received a federal grant to establish Parent Learning Centers, reportedly in order to help children develop healthier views of their sexuality. Calderone contended that parents needed to change their outlook: "Parents reflect our sexophobic society," she said in an interview (Vespa, 1980, n.p.). In 1970, SIECUS received a grant to train sex educators (Marshall \& Donovan, 1991). In the late 1990s, they received a CDC contract 
to evaluate and provide input to the HIV/AIDS and sex education programs being implemented in states (Panzer \& Mosack, 2009). This type of federal funding for specific projects related to sex education continues to this day.

The second decision made by SIECUS was to intentionally work with other organizations for a common purpose. SIECUS supports “comprehensive” sex education as a part of every grade in school, beginning in kindergarten and continuing through high school (Rodriguez, 2000). They learned that in order to gain success in the implementation of their goal, however, the movement needed extensive support. In 1970, conversations took place between Planned Parenthood and SEICUS regarding the need to work together for a broad service model for youth. Planned Parenthood would advocate for clinical services and SIECUS would advocate for sex education programs for youth. They worked to convince both the legislative and executive branches of their agenda (Marshall \& Donovan, 1991). In 1980, Calderone explained the relationship between the Kinsey Institute and SIECUS as an intentional division of labor. She noted that the Institute "was formed very specifically with one major field omitted - sex education. This was because it seemed appropriate, not only to the Institute but to its major funding source, the National Institute of Mental Health, to leave this area for SIECUS to fill” (Reisman, 2000, p. 179). In 1999, SIECUS and Advocates for Youth cooperated on a poll designed to denigrate abstinence education (Rodriguez, 2000). In 2002, SIECUS partnered with almost 150 other organizations to oppose abstinence education and press for an expansion of “comprehensive” sex education (Panzer \& Mosack, 2009). 


\section{Impact on contemporary and future sex education policies. SIECUS}

leaders made a strategic move that increased their impact on sex education. In the 1990s, they opened a Washington, D.C. office for public policy so they could play a crucial role in federal policy-making (Richard, 2003). In 1992, the Community Advocacy Project began to track debates over sex education in communities and to assist them in weathering attacks against "comprehensive” sex education. They described “controversies” as any attempts to implement abstinence education in classrooms (SIECUS, 2003).

The D.C. office for advocacy efforts gave SIECUS more direct access to the policy centers of American politics. Each year, they provide congressional briefings and offer input to congressional offices on policy recommendations, suggesting legislative language and identifying Members of Congress who agree to introduce "comprehensive” sex education legislation. Their self-described mission for 2009 was to cut all funding for abstinence education and increase funding for "comprehensive” sex education. They concluded their 2008 Annual Report this way: "If the Obama administration is serious about science and evidence, not ideology, setting the standard for policy, then abstinenceonly-until marriage is out and a more comprehensive approach to sex education is in” (SIECUS, 2008b, p. 6).

Discovery of AIDS. The discovery of HIV in the early 1980s added a new dimension to sex education. The worry of an unplanned pregnancy now was secondary to life preservation. A new deadly disease emerged to the top of public concern and preventing its spread became top priority. Sex education morphed into AIDS prevention 
education in many communities. An ensuing clash of beliefs over the "best" way to prevent AIDS in sex education classes intensified.

Key figure. A single individual was key to the impact that AIDS played on the evolution of sex education in public schools. C. Everett Koop was U.S. Surgeon General when AIDS was first discovered. He remembers: "If ever there was a disease made for a Surgeon General, it was AIDS” (National Library of Medicine, n.d.). Though AIDS was identified during his first term with the Reagan Administration, it was not until his second term that he was given the leadership role in addressing the disease. Being a conservative physician, he supported abstinence until marriage, but wanted sex education to be implemented as young as possible (Carlson, 1989). Fearing that AIDS may become a modern American epidemic, Koop believed that radical measures needed to be undertaken if the disease was to be contained. In many speeches, he stressed the need for abstinence and monogamy, but he admitted that some individuals nonetheless would engage in extramarital and homosexual sex. As Surgeon General, he insisted that America must do what it reasonably could in order to prolong the lives of all citizens, including those who engaged in behaviors that were in conflict to his own personal values (NLM, n.d.). His speeches and public appearances elevated the discussion of sexual behavior and AIDS. He surprised many Americans when he called for a condom-centered style of sex education, if individuals chose not to remain in a monogamous relationship. His quest to address the AIDS crisis led him to admonish television producers to encourage condom use in their scripts. His visibility on the issue made him one of the most recognizable figures in Washington D.C. (Carlson). 
After consulting with a wide breadth of individuals and organizations, Koop set about drafting his recommendations for the war on AIDS. On October 22, 1986, Koop released the Surgeon General's report on AIDS. Soon, 16 million copies of his report were in print (Carlson, 1989). In 1988, as a result of Congressional mandate, he sent an 8page booklet on AIDS to every household in the country, making it the largest mailing in American history and the first time the federal government sent sexually explicit material to citizens enmasse (Koop, 2007).

Koop devoted most of his second term as Surgeon General to the AIDS epidemic; he stated that addressing AIDS consumed his life during that time. The National Institutes of Health relate:

Through his report and his many speeches and interviews on AIDS, Koop did more than any other public official to shift the terms of the public debate over AIDS from the moral politics of homosexuality, sexual promiscuity, and intravenous drug use, practices through which AIDS was spread, to concern with the medical care, economic position, and civil rights of AIDS sufferers (NLM, n.d.).

He supported abstinence but he also encouraged the use of condoms. It was the condom message that took flight. As a result of Koop’s recommendation, Congress allocated \$176 million for targeted education to high-risk populations. Teens were included in that group and "comprehensive” sex education was the recommended strategy (Smith, 1987).

Zeitgeist influences. The fearful spirit of the times upon the discovery of AIDS in the 1980s was particularly notable as a turning point in American public school sex education. AIDS was first reported in the United States in June 1981. It potentially 
impacted every American. Initially, very little was known about the disease, but misinformation fueled panic. Altman (2001) recalled part of the reason for the fear: "Because health officials and journalists used the phrase 'bodily fluids' instead of specifying semen, blood and vaginal secretions, many people feared that they could contract AIDS from toilet seats or drinking fountains, or by eating at restaurants or going to school” (p. 2). The disease affected mostly homosexual men (CDC, 2001), but Americans were learning other details about the disease at almost the same time as medical community. The leading risk factor for contracting AIDS in the U.S. was through men having sex with men (msm), but another transmission point was through infected blood. In 1993, 1098 individuals contracted the disease before blood was screened for HIV (CDC, 2001). Heterosexual transmission was possible and IV drug use added to the risk. AIDS was a serious disease - deadly serious. It claimed the lives of 66,0000 during the 1980s with 1.5 million having been HIV infected (Stein, 1989). In that sense, it was the disease of the 1980s. A fear of sex's potential consequences reappeared. The former "miracle drug” of the birth control pill offered no protection against the transmission of AIDS. Westheimer (2007) warned of the risks of sex that began in this era: "In case you haven't heard already, the sexual revolution of the previous decades, in which people suddenly felt free to have sex with a number of partners, is over” (p. 259). Sex educators needed to rethink their approach in a way that would address the new problem without adding to the fear (Halstead \& Reiss, 2003).

Salient decisions and political implications. Two critical decisions were made at the federal level that contributed to AIDS being a key turning point in American public school sex education. The first was the initiation of specific HIV/AIDS education. 
By 2009, 36 states, plus the District of Columbia mandated HIV/AIDS education for schools. The rest of the states addressed AIDS prevention in various ways within legislative language (Guttmacher, 2009).

Beginning in 1987, HIV education grants were awarded to school-based programs through the CDC (2001). The grants totaled $\$ 82$ million (Moran, 2000). The programs were to be "comprehensive" in their approach (CDC). Many of the popular AIDS prevention programs for youth as young as 10 years old were highly explicit and taught how to correctly use a condom as well as where to obtain one. The focus was not on avoiding sex, but on taking intentional steps to reduce the risk of acquiring AIDS (Tremblay \& Ling, 2005), so sexual activity was condoned as long as "precautions" were taken. Other funding for sex education often included AIDS education within the curricula, even though the primary purpose was pregnancy prevention (HHS, 2008d). Inschool, HIV prevention funding for 2000 was approximately $\$ 47$ million. The program was implemented in coordinated school health programs, serving students in 48 states. Additionally, over 150,000 students were trained on condom-based HIV/STD prevention. The continued present-day investment indicates that HIV/STD prevention is still a priority (Kaiser, 2002)

The second federal decision that had significant impact on the growth of sex education was the initiation of specific funding for risk avoidance. Beginning in 1983, Congress passed funding for the Title XX, Adolescent Family Life Program. It was designed to prevent teen pregnancy by encouraging sexual abstinence (Schwarz, 2007). However, since the program began shortly after AIDS was discovered, the abstinence message was also vital to AIDS prevention. The strategy was especially important for 
fighting the spread of a disease that could only be sexually restrained through abstinence. The funding was small, but the significance was cogent because it was the first federal money directed at primary risk prevention in the area of adolescent sexual decisionmaking (NAEA, 2008). In 1996 and again in 2000, additional funding streams were begun for the risk elimination message of abstinence, but the approach was still a minor part of the total financial support available for pregnancy prevention and STD/HIV prevention for youth (HHS, 2008d).

\section{Impact on contemporary and future sex education policies. Two} significant phenomena heavily influenced sex education following the discovery of AIDS. The first was that gay advocacy groups made the defeat of abstinence education a major priority in their agendas. Altman (2001), a New York Times reporter on the frontlines during the initial AIDS research noted that, when he first covered the illness, gay activists ridiculed the report: "Gay pride had come into its own after long legal and social struggles. An ill-defined health threat, possibly linked to behavior, was not gay advocates' top concern in 1981” (p. 1). Activists were skittish about how AIDS would be characterized and how they would be characterized. The Village Voice complained that Altman's coverage of AIDS would “wreck the July 4 holiday break for every homosexual in the Northeast” (p. 1). The only prevention for AIDS was sexual abstinence, but gay activists were uncomfortable advocating that their constituents discontinue an activity that largely defined their sexual identity. Though abstinence education in the schools was aimed at teens, gay activists took offense and accused abstinence advocates of "homophobia." For example, the Gay and Lesbian Activists Alliance of Washington, D.C. (Rosendale, 2003) presented this pointed testimony to a Congressional Committee: 
As equal citizens of this country, we will not accept being told by our government using our tax dollars that the only acceptable sexuality is none at all. It has been a decade since we successfully rid the District of its own damnable law that rendered us felons for consensual, private, adult sex, and we are not about to have the same stigma brought in through a back door (np.online).

Since the discovery of AIDS in the early 1980s, gay activists have mounted vitriolic attacks against abstinence education, often in tandem with "comprehensive” sex education groups. They have not abated with time.

The second element of particular importance to the future of sex education was the intense clash between proponents of the two approaches for sex education (i.e. abstinence and "comprehensive" sex education). As former SIECUS president Debra Haffner noted: "The landscape changed dramatically with the advent of AIDS” (Donovan, 1998, p. 189). Pro-sex education advocates used the discovery to insist that teens receive condoms, condom instruction, and "fun" activities to encourage their practice of safe sex. They demanded an inclusion of a frank discussion of homosexuality in a way that removed any preference of one orientation over another (Halstead \& Reiss, 2003). Patricia Ware (1997) from Americans for a Sound AIDS Policy asked participants at the Welfare Reform Academy conference for prudence in the debate: "This (abstinence education) is but one source of money from which to apply. It is the only one that clearly allows us to do what I believe is essential in ending many of the societal problems facing our nation today” (Ware, n.p. online). In other words, she argued that the two sex education approaches could coexist. They served different purposes. There were two dissimilar ways to address the AIDS prevention effort, but only a finite number of 
schools and a finite sum of money to devote to the effort. Not everyone agreed with Ware, so the debate only intensified in the years following the discovery of AIDS.

The Reform of the Welfare System. The Personal Responsibility and Work Opportunity Reconciliation Act of 1996 (PRWORA) signified a dramatic overhaul of the welfare system in the United States (Coleman, \& Rebach, 2001), but it also heavily impacted the rise of abstinence education. In order to curb the spiraling welfare rolls, this new program put limits on the amount of time an individual could access welfare benefits. The new legislation created the Temporary Assistance to Needy Families (TANF) block grant, giving states the freedom to develop and implement a program to provide benefits to needy families while also encouraging them to become self sufficient (HHS,2008a). TANF focused on these priorities:

- assisting needy families so that children can be cared for in their own homes

- reducing the dependency of needy parents by promoting job preparation, work and marriage

- preventing out-of-wedlock pregnancies

- encouraging the formation and maintenance of two-parent families (HHS). Congress passed Title V (Section 510) abstinence education block grants as part of the welfare reform package in order to give states funds to address the third TANF priority. Congress stated in the legislation: "In light of this demonstration of the crisis in our nation, it is the sense of the Congress that prevention of out-of-wedlock pregnancy and reduction in out-of-wedlock birth are very important Government interests and the policy contained in part A of Title IV of the Social Security Act... is intended to address the crisis” (PRWORA,1995, p. 8). Section 905 increased the accountability of the program 
by stating that the Secretary of HHS must assure at least $25 \%$ of states implement a program to prevent nonmarital teenage pregnancies, so the legislation gave an enormous boost to school based sex education (PRWORA).

Key figure. One individual was critically important to the inclusion of abstinence education as a strategy for welfare reform. Representing a group of pro-family organizations, Robert Rector of the Heritage Foundation took a lead role in making abstinence education a part of the welfare reform overhaul (Haskins \& Bevan, 1997). Rector was (and is) a senior research fellow for domestic policy at the Washington, D.C. think tank. He published his first paper on the need for reform in 1995, calling for a complete change in the manner in which the federal government addressed the issue (Rector, 1995). Specifically, he advocated an emphasis on decreasing nonmarital births, citing a poll, showing that $75 \%$ of Americans believed the current system encouraged out-of-wedlock births. Rector worked closely with Senator Lauch Faircloth’s (R-NC) staff to draft legislative language that would promote abstinence education within the bill. This language became known as the "A-H Guidelines" for abstinence education that, for the first time, defined what an authentic abstinence program could teach:

(A) has as its exclusive purpose teaching the social, psychological and health gains to be realized by abstaining from sexual activity, (B) teaches abstinence from sexual activity outside marriage as the expected standard for all school-age children, (C) teaches that abstinence from sexual activity is the only certain way to avoid out-of-wedlock pregnancy, sexually transmitted diseases and other associated health problems, (D) teaches that a mutually-faithful monogamous relationship in the context of marriage is the expected standard of human sexual 
activity, (E) teaches that sexual activity outside of the context of marriage is likely to have harmful psychological and physical effects, (F) teaches that bearing children out-of-wedlock is likely to have harmful consequences for the child, the child's parents and society, $(\mathrm{G})$ teaches young people how to reject sexual advances and how alcohol and drug use increases vulnerability to sexual advances, and $(\mathrm{H})$ teaches the importance of attaining self-sufficiency before engaging in sexual activity (HHS, 2008b, 2008c).

Due to the efforts of Rector working closely with family organizations and supportive Senators Santorum and Faircloth, "abstinence” became codified (Haskins \& Bevan, 1997), and abstinence education became a new treatment for helping to address economic problems.

Zeitgeist influences. Two cultural factors influenced the development of abstinence education within the welfare reform effort of the late 1990s. The first was the federal welfare caseload that expanded out of control. From 1965 to 1994 welfare rolls grew each year, with states recognizing the crisis when the total number of people enrolled reached 14 million (Mead, 2004). The costs to taxpayers were increasing so quickly that Congress was unsure how to accurately estimate the cost for the coming year. Rector and Bradley (2009) noted that before 1996, the average welfare recipient spent 13 years on government assistance. Additionally 1 in 7 children was enrolled. A full $81 \%$ of women who had a nonmarital birth before age 20 , were registered in the welfare program by the time they were 30 (Kaestner, Korenman, \& O’Neill, 2003). The culture of government subsistence living was growing, but skills necessary for selfsufficiency were dwindling. Since the bulk of welfare recipients were single parents, 
Congress recognized that they could either address the core problem (nonmarital sex) or continue to treat the symptoms. When asked, Americans were more than twice as concerned, however, with the increase in nonmarital births than they were about the lack of self-sufficiency (Rector, 1995). Americans wanted a solution to the problem and many reported believing that abstinence education would provide at least part of the resolution.

The second cultural factor that influenced the development of abstinence education within the welfare reform effort was the accumulation of social science research in favor of delaying sexual activity and childbearing until marriage (PRWORA, 1995). Waite and Gallagher (2000) released their findings after the passage of the Welfare Reform Act, but much of the research was accumulating long before that time. Although opponents insisted that "abstinence until marriage” was a moral or religious agenda being thrust upon the American taxpayers, advocates disputed their claim. Studies revealed the emotional, physical, academic, and social benefits of delaying sex until a monogamous marriage. When a couple delayed sexual contact until marriage, there was no worry of an unplanned pregnancy or transmission of an STD. But the advantages went beyond this obvious result. Stepp (2007) found that students who engaged in sexual relationships were likely to suffer emotional consequences, even if they personally initiated the sexual activity. Rector, Johnson and Noyes (2003) reported that sexually experienced teen girls were 3 times more likely and sexually active boys were 7 times more likely to commit suicide than their abstinent peers. McIIlhaney and Bush (2008) revealed the medical reasons that casual sex could become addictive and impede the development of long-term committed relationships. Researchers also found 
that sexual relations within a cohabiting, but nonmarital arrangement were risky. For example, couples who lived together before marriage were more likely to divorce (Rhoades, Stanley \& Markman, 2006), and to be victims of domestic violence (Kenney \& McLanahan, 2006). Another study reported that abstinent teens were significantly more likely to complete high school and graduate from college (Rector \& Johnson, 2005).

Researchers also pointed to the advantage that children had when born within a committed marriage. The benefits were far reaching. Marriage directly influenced wealth (Young, 2007), and children born to single parents were much more likely to spend their formative years in poverty (Kim \& Rector, 2006; McLanahan \& Sanndefur, 1994). Children who lived in a stable marriage also performed better in school, presumably because they had a mother and father to help them with homework and keep them accountable regarding school activities (Waite \& Gallagher, 2000). Children born within marriage were less likely to suffer physical abuse and less likely to become involved with the criminal justice system than their peers who were born to single parents (Fagan, Patterson, \& Rector, 2002). The research was compelling and focused on "best outcomes" for the teen couple, as well as for the child potentially born of a sexual union. The overall societal consequences caused policymakers to realize the importance of primary prevention. Abstinence education again was an appropriate response.

Salient decisions and political implications. The most obvious decision of import with the passage of welfare reform was the insertion of the Title V (Section 510) abstinence education block grant to states. The funds, carefully tied to the "A-H Guidelines,” were reserved for programs that encouraged students to avoid all risk related to sexual behavior. The block grant provided $\$ 50$ million per year to teach abstinence 
education with the requirement that states must contribute a match of $\$ 3$ for every $\$ 4$ in federal funds received. States would be allocated funds based on the child poverty rate within their states, since the funding was tied to decreasing poverty-related reliance on government assistance (Haskins \& Bevan, 1997). The special significance in this funding stream was twofold. First, this represented the first widespread implementation of abstinence education across the nation. Although Title XX provided for small demonstration grants, Title V (Section 510) distributed monies to each state in order to “take aggressive action to create abstinence education programs” (Haskins \& Bevan, p. 473). According to the Haskins and Bevan (1997) White Paper chronicling the development of the program, those states that received smaller allocations would presumably use it for more modest activities, while those states whose allocations were larger, would implement expansive community-based programs, many of which were within the public school setting.

A second decision of political implication proved to be important in the development of sex education in the schools. Government health policy tended to stress a public health model of primary prevention (Haskins \& Bevan, 1997) in all areas, except teen sexual activity. Secondary or even tertiary prevention was the dominant focus of "comprehensive" sex education, encouraging a reduction of risk, rather than the prevention of risk. The new funding moved the focus of sex education to align itself with other prevention programs. For example, anti-drug or anti-drinking programs always stressed that students make decisions that would result in the healthiest outcomes. Now, sex education would do the same, through the abstinence approach. The successful antismoking campaign became an important model for abstinence educators. Only a 
generation ago, smoking was deemed "glamorous” and almost “expected,” but a concerted effort to change the cultural mores regarding the behavior was effective (Jenkins, 2008). Focusing on a primary prevention message that encouraged Americans not to smoke, or to quit if they presently smoked, slowly made an impact. Behavior and the public consciousness about smoking changed within a short time. The message was primary prevention. Advocates argued that abstinence education could do the same.

Impact on contemporary and future sex education policies. The Welfare Reform Act of 1996 created two important benchmarks for the furtherance of sex education in American communities. First, it set in motion the bipartisan support for abstinence education as a preventive measure against nonmarital pregnancy and birth. A Republican Congress and a Democratic President agreed to begin the largest single funding stream for abstinence education up to that time. In fact, President Clinton’s signing of Welfare Reform Act into law signified the largest increase in abstinence education funding for a single year. Haskins \& Bevans (1997) related that Democratic conferees made no attempt to change the language of the abstinence education provision. Throughout the entire House-Senate conference, the language remained essentially intact, with conferees noting that federal funding was already available for "comprehensive” sex education through a number of other funding streams - and at a much greater level. Haskins and Bevins explained: "Congressional intent in funding this new program was not to disrupt any ongoing programs, including those that feature birth control instruction or distribution. Rather, Congress wanted to ensure that some federal dollars were used exclusively to support true abstinence education programs” (p. 477). 
President George W. Bush continued the two-track funding of abstinence education, but sought to achieve parity between the two approaches. In 2002, a new program for abstinence education was begun to narrow the gap in funding, but “comprehensive” sex education continued to receive more federal dollars, nonetheless. Under a Democratic Congress and the Republican Bush presidency, the bipartisan continuation of abstinence education persisted (Congressional Research Service [CRS], 2009). Table 4 provides a visual depiction of the bipartisan funding for abstinence education and Title X funding (which includes education, but also women's reproductive services). The Obama administration's call for the elimination of abstinence education, however, is a striking departure from the bipartisan nature of federal funding, which began during the welfare reform overhaul (Meckler, 2009).

The second important benchmark in the evolution of sex education during the period of welfare reform related to an intentional shift in emphasis for the program. The progressive era stressed abstinence until marriage but, from a moral and health perspective. It was a strategy that continued for decades. Sex education during and following the sexual revolution stressed risk reduction by encouraging teens to use contraception when they had sex. The advent of AIDS turned the attention back to the health-related hazards of sex.

The Title V (Section 510) abstinence funding, however, relied on social science research to create a school-based program for youth. Based on that research, abstinence education treated sexual activity as one part of interconnected decisions. Healthy decisions tended to beget other healthy decisions. Poor decisions beget other unhealthy decisions. Drug use, violence, depression, underage drinking, and sex, all 
Cedarville University

School of Graduate Studies

Table 4 (CRS, 2009).

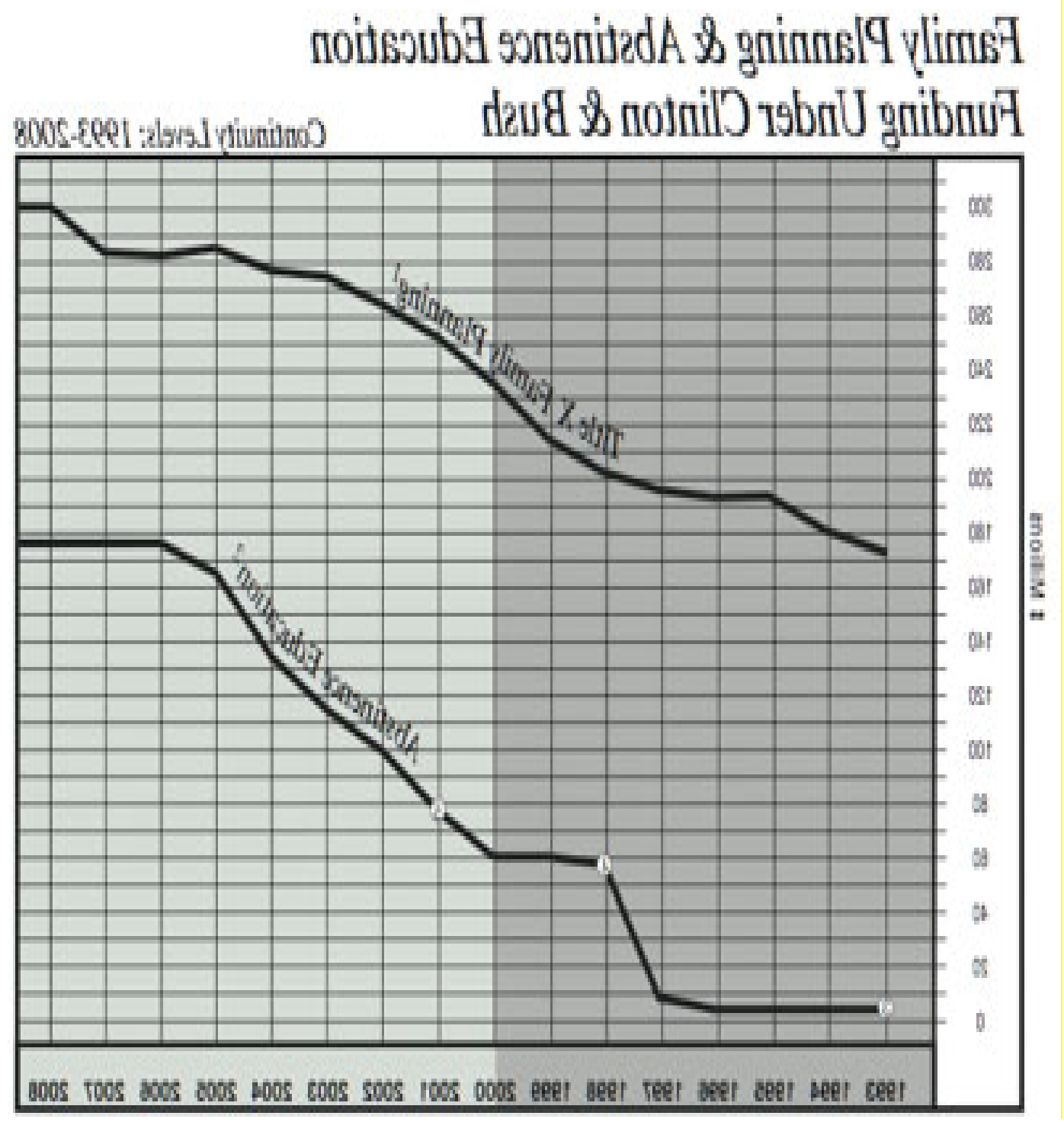


potentially overlapped as risk behaviors among students (Resnick, 1997) An additional research finding related to the social, physical, and economic benefits of "abstinence until marriage, " moved the expectation for sexual restraint away from a moral viewpoint. Rather, economic and social science studies advocated for the behavior, totally apart from a moral rationale (PRWORA, 1995). Since research made the clear connection between single parenthood and poverty, abstinence was now deemed a potential poverty prevention tool. Further, this new paradigm recognized that the decision whether or not to have sex had a greater impact on the student than merely a concern about pregnancy or an STD. The research provided students with the skills to avoid sex for reasons that impacted their lives holistically. It encouraged them to think beyond the Saturday date, to the next year, to college and beyond. Students were empowered to grow confident in comparing one decision to its impact on other areas of their lives. Students who previously had segmented their sexual lives from all other areas of their lives were confronted with a new way of thinking (NAEA, 2009a).

This paradigm shift, however, only related to abstinence education programs. The “A-H Guidelines” were retroactively applied to the Title XX Adolescent Family Life Program and also would be applied to the Community Based Abstinence Program, yet to be initiated under President Bush (HHS, 2008b). The holistic treatment of sexual activity was made a part of all three abstinence programs, while "comprehensive" sex education continued to narrowly define their messages around reducing risk to the physical consequences of sex (NAEA, 2007). 


\section{Conclusions}

The six turning points in the historical development of present-day public school sex education continue to influence the sex education debate. The progressive era was arguably the most important historical event studied because a synergy of unlikely coalitions created what became a nascent model for sex education. Additionally, the seeds of both models of sex education were planted during this era. Although sex education in the schools was not firmly established by the end of the era, the policies and the personalities of that time continued for many years to come.

The publication of Kinsey’s books on human sexual behavior was a key event in the development of sex education because the findings would become foundational to modern intellectual thought on sexuality. While not scientifically reliable, the analysis shook traditional marriage and morals, giving Americans the opportunity to question the definition of normalcy. Kinsey’s research also would become very important as a scientific basis for many tenets of modern “comprehensive” sex education. The "new morality” of the sexual revolution provided a philosophical basis for a sex education message permitting consensual sex, with the legalization of abortion and contraception, as a way to minimize the effects of sexual experimentation. Teens were protected from parental oversight when the federal government precluded parental notification for their access to contraception, further assisting in the development of a new "comprehensive" paradigm for sex education.

The launch of SIECUS, the first single-issue “comprehensive” sex education organization was the fourth key factor in the historical development of sex education in public schools. The institution's intentional organizational model helped them effectively 
advocate for "comprehensive” sex education. While some organizations have fiercely competitive relationships with like-minded groups, SIECUS capitalized on each group's strengths in order to amass a powerful advocacy force for sex education.

The discovery of AIDS was the fifth turning point contributing to the development of modern sex education. Taking even the medical profession by surprise, a virus related to sexual activity was once again wreaking havoc on a significant number of Americans. Sex education immediately added a component regarding AIDS prevention, with a heavy emphasis on condom negotiation skills. Abstinence education received its first dedicated funding stream in order to provide a strong risk avoidance skill-based message to teens and assertively taught that avoiding sex was the only way to prevent the sexually transmitted spread of AIDS. Gay rights activists inserted themselves into the debate, feeling that their identity was being attacked by abstinence education message.

Finally, the reform of the welfare system in 1996 moved sex education into the arena of counteracting the possible negative consequences of nonmarital childbearing. Social science research found that the economic, physical, academic, and overall well being of the child was potentially compromised when born without the benefit of a mother and father committed to one another (and to the child) within a healthy marriage. Congress took the first step to treat holistically the possible consequences of teen pregnancy in a way that advocated for the best health outcome for the child born from a sexual union, as well as the successful future for the couple. Each of the six turning points added an essential quality to this development of sex education. The American public school sex education model was now created, complete with its two differing strategies for implementation and a guaranteed battle for dominance. 


\section{Discussion and Implications}

The present study was conducted in order to analyze the major turning points in American history after 1900 that affected the development of modern sex education in the public school. Care was taken to identify the extent to which specific events prompted revisions or additions to a given sex education approach. Impact on contemporary and future sex education policies, zeitgeist influences, important decisions and political implications, and their impact on contemporary sex education were explored.

Sex education began with the federal investment of taxpayer dollars to combat venereal disease in the early 1900s, making the progressive era pivotal. Health and morality were two unlikely, but comfortable, partners in early sex education, but the publication of Kinsey's research on human sexual behavior sparked a different approach from that of early sex education. Teen sexual experimentation was described as healthy, but it was not until the sexual revolution of the 1960s that sex education departed from an expectation of abstinence for youth to one that condoned sexual experimentation, so long as the teen behaved "responsibly." During the same time, SIECUS was formed, creating the first single-issue advocacy organization for "comprehensive" sex education. The dedicated efforts and partnerships with other pro-sex groups strengthened the influence and voice of the message, preparing the soil for a new battle over sex education that began with the discovery of AIDS, making a profound impact on American culture. It also launched a sex education pluralism within the school settings, with opposing camps arguing that their respective approach was superior. Gay activists involved themselves in 
the battle more dramatically. Abstinence education received its first funding during this time, but to a lesser degree than "comprehensive” sex education. Finally, welfare reform of the 1990s introduced a paradigm for abstinence education that was holistic and sought to teach teens needed skills to successfully navigate the many difficult decisions of adolescence. It was tied to economics, health, social interactions and other social science indicators. "Comprehensive” sex education continued, achieving increasing investment, but abstinence education began its ascent during the Bush Administration in the new millennium. The recent election of President Obama may mark a new era for sex education, but indicators are still too preliminary to assess if such is the case. Early signs predict that a different emphasis may soon emerge in sex education across the nation.

\section{Ways Relevant Paradigms Affect the Study}

Two paradigms exist in modern school or community-based sex education for youth. The two approaches are commonly known as abstinence-centered education (often called abstinence education) and contraceptive-centered education (often called “comprehensive” sex education). The goals, methods, and philosophy behind the two approaches are vastly different. The historical underpinnings of the two approaches also are vastly different. A better grasp of sex education is achieved when each paradigm is understood.

Abstinence-centered education (ACE) begins with the view that teens do not need to have sex. It believes that if young people are given the information, skills and guidance to avoid sexual activity, they can, and many indeed will, delay sexual onset, preferably until marriage. ACE addresses sexual activity as a decision that potentially affects each area of teens' lives. Drawing from abundant social science research, ACE believes that 
even if teens do not contract STDs or become pregnant, there are other emotional consequences that can be detrimental. Therefore, the discussion is holistic. Topics that are a part of an ACE program include: (1) identifying healthy relationships and avoiding unhealthy ones, (2) understanding the symptoms of STDs and how to avoid them, (3) informing students that, while contraception can reduce some physical risks associated with sexual activity, only abstinence can eliminate all risks, (4) providing students with a model for good decision-making, (5) encouraging students to identify future goals and put steps in place to reach them, and 6) giving students the ability to successfully use refusal skills to avoid risks in dating. An ACE class often makes the connection between self-restraint and good character. All discussions are within the context of why abstinence is the healthiest choice and "health" is defined as more than the absence of disease. Delayed sexual onset is the measure for success.

"Comprehensive” sex education (CSE) begins with the premise that most students will be sexually active. Therefore, reducing the risk of sexual activity is the desired goal. The focus is almost entirely on addressing possible physical consequences of pregnancy and STDs and the prominent skill taught is condom negotiation. While all varieties of contraception are advocated, the condom is the device of choice. Many programs demonstrate condom use in class and encourage students to "practice" with partners on anatomical models. While the approach often mentions "abstinence" as the only way to prevent physical consequences, since advocates do not believe the approach is realistic, little time is typically spent on the discussion. When it is discussed in detail, abstinence is usually individually defined by the student with possible "abstinent" activities provided that include "showering together," "watching pornography movies," "cuddling naked,” or 
other sexual gateway activities (NAEA, 2007). Authentic "no risk” abstinence skill building is not typically part of CSE. The goal is reducing the risk of pregnancy or STDs, but usually not on reducing sexual initiation.

Since the two approaches are almost antithetical in terms of measures for success, it is easy to see why the battle lines are drawn so distinctly. The sex education debate is more than a question of preference. The two approaches are grounded in differing definitions of "health" for teens and very different ways to achieve the goal.

\section{Interpretations of the Results}

History is a good teacher if those who study it are engaged learners. Concerned parents and policy makers would be well advised to consider the implications of history when judging the content of contemporary sex education classes. There are four specific historical summarizations that paint an extremely troubling picture related to the current state of sex education in America. They are the following: (1) countercultural voices of previous eras have become the current dominant voice in sex education, (2) the philosophical development of "comprehensive” sex education is linked to a personal justification of unconventional sexual behaviors, (3) the insertion of "science" within the sex education debate usually means "change" of the status quo, (4) the progressive era of the early 1900s may be reinventing itself in a present day.

\section{Countercultural voices of previous eras have become the current dominant}

voice in sex education. A review of history since 1900 illustrates that the dominant cultural message has strongly emphasized premarital abstinence in America (Booth \& Crouter, 2005). During that same time, however, countercultural groups, individuals and philosophies have promoted sexual license, asserting that such behavior was necessary 
for healthy human development. They stressed that sexual freedom was a basic human right. Throughout most of the $20^{\text {th }}$ century, however, this view was held by a small subsection of the population. The influence of this view varied from decade to decade, but most Americans rejected the idea of sexual freedom as an appropriate expression of behavior. When the sexual license philosophy would gain ground in policymaking, such as during the 1960s and 1970s, grassroots organizations emerged to expose the agenda and usually succeed in moderating the countercultural effect. After claiming victory, however, the grassroots groups typically weakened, disbanded, or operated as ad hoc committees reacting to the next crisis, but taking few proactive measures to assure that the cultural norm (abstinence until marriage) remained strong.

Countercultural forces, however, used a different tact. They fully understood that theirs was a minority opinion; that their belief in sexual freedom was not consistent with the general values of the time. Therefore, they took strategic measures to normalize their philosophies. They often used tangential issues in order to give credence to the underlying philosophy. Today, the reasoning that "teens are going to do it (sex) anyway," has become the pragmatic face to the philosophy of hedonism. But a careful look at the websites of organizations, which are at the forefront of the sex education debate, reveals that little has changed in the philosophy since the early 1900s.

The difference, of course, is the fact that contemporary organizations promoting the philosophy of sexual license are considered mainstream and are providing recommendations on sex education to policymakers. Groups like SSSS, for example, have members scattered in respected universities across the country, publishing their views under the umbrella of highly regarded academic research. At organizational 
conferences, however, where the media is often banned from admission, a different story sometimes emerges. For example, the book by Hani Miletski (2002), Understanding Bestiality \& Zoophilia (which requested that those with this sexual orientation be permitted to continue their behavior in peace) was a recommended book by the SSSS leadership for attendees at the 2002 annual conference. The same forum hosted an evening film festival for attendees which included movies such as When two won't do, which was a "convincing, heartfelt documentary about the urge to go beyond the limitations of monogamy," For the fun of it, which was a video of a pornstar's live performance, and another described as “a funny, poignant, refreshingly honest documentary based on interviews with men about their members” (SSSS, 2002, n.p.). Others, like Advocates for Youth, publicly support sexual delay among teens, but a careful look at their website is more revealing of their belief that sexual restraint actually hampers normal human development (AFY, 2008a). Leaders from organizations like SIECUS insist that they support abstinence, but are concerned that students receive "all the information" they need in order to make healthy choices at "age appropriate” levels. Most Americans likely do not read the SIECUS Guidelines, however, to evaluate what SIECUS considers "healthy" choices or "age appropriate" information for children beginning in kindergarten.

These groups sponsor congressional briefings on sex education, submit articles to journals attacking abstinence education, speak authoritatively to the press, and meet with the White House to advocate their position. They soften language to increase popular palpability permitting them to claim a legitimate seat at the policymaking table and to influentially contribute to the debate over sex education, all the while promoting the 
extreme views of a hedonistic counterculture. Most American parents want their children to abstain from sex until marriage (Zogby, 2007). Most teens want a strong abstinence message from their parents (Albert, 2007). These groups, among the strongest proponents for "comprehensive" sex education (and strongest opponents of abstinence education) are now attempting the restructuring of sex education in American public schools. Their entrée to major media and policy has enabled them to craft "reasonable" messages that, if they were carefully unpacked, would be seen to run counter to the sensibilities of most Americans.

\section{The philosophical development of "comprehensive" sex education is linked to} a personal justification of unconventional sexual behaviors. Key individuals in the development of "comprehensive” sex education appeared to use their platform as a way of validating their own alternative sexual practices. Margaret Sanger, arguably the first individual in the $20^{\text {th }}$ century to promote the ideals that would become "comprehensive" sex education, spoke negatively of the restraints of abstinence before marriage and faithfulness within marriage (Antonucci, 1995). She was involved in numerous affairs while married and many more liaisons when unmarried (Chesler, 2003). This intimate detail of her personal life gives special meaning to Sanger’s (1920) desire for women to create their own "new morality" which was designed apart from the "bonds of submission and unwanted progeny" (p. 182), and on whose foundation would "tend to make fruitful the impulse which is the source, the soul and the crowning glory of our sexual natures” (p. 185). In other words, in Sanger's particular case - the theorist was the theory. Birth control assisted in breaking the bonds that were "negative, inhibitory, and repressive” (p. 179). 
Alfred Kinsey studied the sex lives of thousands of individuals, but his interest was deeper than scientific research. Jones (1997) related that Kinsey had a personal obsession with sex, of both homosexual, heterosexual, and masochistic varieties. He had voyeuristic tendencies and enjoyed watching others have sex. He organized and participated in orgies with staff members and their wives in which the evening was spent swapping partners, much of it captured on film. Kinsey engaged in extensive masochistic self-mutilation of his genitalia (Gathorne-Hardy, 1998). On scientific field trips, several students recorded details of the trips in letters and diaries in which they described how Kinsey incessantly talked about sex and had sexual "sessions” with several students. Jones related that Kinsey's behavior with his students "showed the risks a sex-obsessed man would take in exchange for a modicum of erotic satisfaction” (p. 285). Similar to Sanger, studying Kinsey's theory of sex education is difficult to do with intellectual honesty - apart from connecting it to himself as a theorist and the personal behaviors that led to his sexual ideation.

Masters and Johnson wrote about sexual response, based on scientific observation, but their personal lives mimicked their professional work. Masters hired Johnson with the understanding that part of her job description would be to have sex with him. Their relationship eventually led Masters to divorce his wife and marry Johnson (Maier, 2009) The examples of Sanger, Kinsey, Masters, and Johnson do not present an exhaustive list, but illustrate that an emphasis on sexual freedom defined their personal lives as well as their public advocacy. Their respective contribution to the formation of 
essential tenets of "comprehensive" sex education suggests that their advocacy had as much to do with validating their own behaviors as changing the sexual mores of the culture.

\section{The insertion of "science" within the sex education debate usually means} "change" of the status quo. Science was first linked to sex education during the progressive era. Medical experts shared information about STDs and the need for sexual “continence" (King, 1918). The injection of "science" into the rationale for sex education made it more palatable to resistant groups. Kinsey's research was the first prominent induction of "science" into human sexual behavior study. Masters and Johnson later studied sexual responses from a scientific standpoint, further influencing the tenor of future sex education classes. Today, “comprehensive” sex education advocates call for “science-based” strategies. In each case, "science” has been used to justify a desired result for change in the status quo. The progressive era elicited a change toward public discussion of private sexual issues by encouraging a return to sexual restraint. Each subsequent insertion of "science" in the debate over appropriate sexual behavior or appropriate sex education resulted in a loosening of sexual restraint.

Currently, science is used as a seeming public relations tool intended to swing public opinion in favor of "comprehensive" sex education (Vu, 2007). However, this use of "science" is often characterized by the selective use of scientific information, cherrypicking research and details that bolster the desired position (NAEA, 2009b). Few policy makers seemingly give careful examination to the "scientific" information given them. Since they are not scientists, they often tend to rely on the "experts" who, in this case, are often motivated to spin available information to their biased viewpoint. For example, 
recent debates on sex education have focused on evidences of "effectiveness" for the respective approaches. A Congressional hearing on the effectiveness of abstinence education provides an apt case in point. When a Member of Congress asked "comprehensive" sex education "experts" if they would support continued funding for abstinence education if research demonstrated its effectiveness, 5 of the 6 majority witnesses said they would not support abstinence education, regardless of the research (“Assessing the Evidence,” 2008).

During his recent budget proposal to Congress, President Obama called for abstinence education to be eliminated in favor of "science based" effective models of sex education. A careful and objective analysis of the foundational research used for this recommended policy change, however, reveals little evidence of efficacy for most “comprehensive” sex education programs deemed "effective” (Weed, 2009). The weaknesses in research for "comprehensive” sex education are many and varied: (1) failed attempts at replication, (2) assertions of reducing teen pregnancy rates when the research did not measure such statistics, (3) broad generalizations of success for clinic setting programs to the school setting; and (4) attempts to generalize success for narrow populations to the larger, representative student population (Weed, 2009). When science is manipulated for political or ideological ends, the results threaten the integrity of objective scientific undertaking (Mooney, 2005). While scientific inquiry provides a worthy endeavor for legitimate investigation, the use of "science" by pro-sex advocates merely spreads misinformation in order to advance a progressive, ideological agenda.

The progressive era of the early 1900s may be reinventing itself in a present

day. A study of sex education's history suggests that the face of sex education is 
significantly predicated on cultural events, values of the citizenry, and the priorities of policy makers in power at the time. For example, the public sexual license in the 1920s was repeated with increased gusto in the 1960s, but intervening decades recoiled and moved toward a more conservative approach. The current political climate hearkens back to many aspects of the progressive era during the early years of the $20^{\text {th }}$ century. President Obama describes himself as a progressive (Schultz, 2009), and fondly associates himself with the tenets of governmental expansion to cure the ills of society. Halpin (2009) of the progressive think tank, Center for America Progress, predicts that Obama will expand the role of government on issues of health care, energy, and education. He hints that, if the current administration delivers on their ambitious goals, it “could lead to a real and durable political realignment”(p. 28). In terms of sex education, however, the differences between the progressive era of the early 1900s and today are in stark contrast. While the hygienists of the first progressive era focused on sexual restraint and prioritized sexual abstinence until marriage, the present progressive climate promises to uproot this best health message in favor of a message that only concentrates on minimizing the risk of unhealthy sexual behaviors.

\section{Potential Applications of the Findings}

The present study provides potentially significant, relevant application for parents, educators and policymakers. Federal and state legislatures can benefit from this assessment as they decide on the allocation of funds for sex education. School boards seeking to implement school curricula can make more informed decisions by gaining a clearer understanding of the strategies for sex education and parents can use this study to 
help them become more proactive in the sex education of their children. In doing so, each of these stakeholder groups can make specific use of the analysis in this study.

The first application explores one reason that understanding historical events of sex education in America is important. The past is the root of the present and a potential prediction for the future. An analysis of history in the implementation of sex education over the years assists the understanding of recurring problems in an effort to correct them. For example, it is important that communities seeking to implement sex education in the local school district understand why parents have been opposed to its implementation in the past. It prompts curriculum developers to discover what aspects of a sex education curriculum have been the most controversial, and why.

Second, the study of the history of sex education facilitates present day educators in the identification of themes that have remained the same, that are constant regardless of apparent cultural change. Fundamentally, this analysis of history provides a laboratory of sorts. Educators can better comprehend why sex education has been important in American public school education and what precipitated enduring principles and topics within the model. For example, to varying degrees, the prevention and understanding of STDs has been a key feature of sex education discussions. Grasping the history of the educational endeavor gives clues as to why it remains an important current theme.

Third, this study encourages a closer look at "comprehensive” sex education. It illuminates the countercultural aspects of this approach. While being billed as a moderate and commonsensical approach, the origins, present players, and agenda are far outside the mainstream of American values (Grossman, 2009). “Comprehensive” sex education advocates espouse all types of youthful sexual activity as a natural and healthy part of 
adolescence, but most Americans do not approve of this normalization of adolescent experimentation (Zogby, 2007). Since the "comprehensive” approach is gaining ground in present policy decisions, the information shared in this present study can serve as a springboard for further inquiry.

Fourth, this research reveals an important advantage of abstinence education as a potential antipoverty initiative. A cycle of premarital sex and teen births serves to trap many women into a life of poverty. Their children similarly tend to spend their formative years poverty-stricken (PRWORA, 1995). Delaying sexual onset until after marriage greatly improves the life prospects for both teen and child. Revisiting welfare reform and the congressional intent to change the culture regarding abstinence until marriage, Haskins and Bevan (1997) stated: “That both the practices and standards in many communities across the country clash with the standard required by the law is precisely the point. As in the case of civil rights and smoking, the explicit goal of the abstinence education programs is to change both behavior and community stands for the good of the country” (p. 475).

Finally, this study reminds policy makers and parents that sex education should be more than a discussion of preventing pregnancy. The holistic nature of the conversation translates into the transfer of vital skills that assist the student in not only avoiding risks associated with sexual activity, but with other important life skills, such as character development, decision-making skills, goal setting, and healthy relationship-building. When parents and policy-makers gain a broader understanding of how sex education was implemented in U.S. educational systems, they can better grasp the aspects that offer the most promise for students. The timing of this study parallels the need. The current 
administration is poised to change sex education in dramatic ways, so it is vital that they use the lessons from history to address the issue. As stakeholders gain a better grasp of the important turning points in the development of sex education, as well as the implications of those turning points, they can more intelligently make decisions that will affect sex education classes of the future.

\section{Biblical Integrative Component \& Implications}

Banerjee (2008) recently reported the sentiments of Jim Beckemeier, a Christian in St. Louis: "What the church has done wrong is that it has created these 'holy huddles' of Christian magazines, music and schools that have set them apart from the world because the world is bad. Instead of doing what Christ did, and bring light to the world, they retreat from it” (p. 20). Christians should engage the culture. God's command to subdue it is written in Genesis 1:28. The directive extends beyond merely exercising authority over the created plants and animals, however. Christians must be good stewards of all that God has given and His truth should be brought to bear on every area of culture, including that culture created by man. As God takes dominion over the Christian's heart and mind, the natural outworking of that transformation should be seen in the daily practice of the individual. The Christian should promote Biblical standards in society and oppose aspects that are unbiblical; all the while understanding that lasting change only occurs within the heart of an individual and not through passage of a law or election of a presidential candidate.

Sex education is one area that the Christian should consider public engagement. Scripture is replete with examples where sexual immorality derailed a promising life. Sexual sins were common in Scripture and are common today. The Bible is very clear 
about God's standards for sex. In both the Old and New Testaments, God relates the beauty of sex within marriage and the destructive nature of sexual behavior outside of marriage (I Corinthians 7:2, Hebrews 13:4, Proverbs 6:29, Song of Solomon). Selfcontrol and sexual regulations are often used synonymously in Scripture (Ephesians 5:31, I Thessalonians 4:3-5, Matthew 5:28). Therefore, guidance on the appropriate sex education message is extremely straightforward (Ephesians 5:3, Galatians 5:19, ). Some Christians may argue that public schools are not the proper venue for a discussion of sexual practices and that Christians should be the primary educators of their children, in this and all other areas of moral content. In principle, I agree. However, the unfortunate truth is that many parents do not share their values on sex with their children. Efforts should be made to equip and encourage parents to do so.

The debate is no longer if sex education will be taught in public schools, however. The advent of AIDS moved the debate to what kind of sex education would be taught in school and this should be the entry point for Christian activism. Believers should exercise their responsibility to be "salt and light" by bringing God's perspective to the issue in a manner that is understandable by the general culture. Matthew 5:16 concludes by stating: "Let your light so shine before men, that they may see your good works and glorify your Father in heaven.” This verse reinforces the mandate in Colossians 3:23 that admonishes Christians to glorify God in everything. However, Matthew notes that one way for Christians to glorify God is by participating in "good works." Therefore, the Christian must be firm and committed to Biblical principles, but able and willing to communicate Truth in a measured, clear, yet uncompromising manner. 
Christians must understand that taking a stand for Biblical principles in sex education may elicit strong responses from opponents. They may minimize the health benefits of abstaining from premarital sex or argue that giving priority to abstinence in a sex education class is merely a thinly veiled attempt to religiously "push" an agenda. Christians know, however, that God gives every biblical principle and command for human good, often for very practical reasons. For example, God's regulation for behavior among lepers (Numbers 5: 1-4) was designed, at least in part, to segregate those who contracted the illness from infecting those not yet exposed to the disease. In the area of sex education, God's standards offer very practical advantages for obeying them. Social science research reinforces the value of God's standard for premarital abstinence. The Christian should seek to obey Him on moral grounds, alone. The non-Christian, however, might apply God's sexual guidelines to life for other more pragmatic reasons. The principle also has public health applications. Discerning Christians can promote the behaviors on any of the many levels that "make sense" to nonbelievers, all the while keeping Christian constructs at the core of their own beliefs and behavior.

Christians must understand, as they engage the culture in the area of sex education, that the battle is primarily a spiritual one. The Apostle Paul said, "For though we walk in the flesh, we do not war according to the flesh. For the weapons of our warfare are not carnal but mighty in God for pulling down strongholds, casting down arguments and every high thing that exalts itself against the knowledge of God, bringing every thought into captivity to the obedience of Christ (2 Corinthians 10:3-5).” Whether at the local school district level, the state legislative level, or at the federal level, Christians have opportunities and responsibilities for engagement. It could translate into 
vigilance of the nature of sex education in a son's or daughter's health class in school. It might mean testifying before the state legislature in support or opposition to a bill that mandates a certain sex education policy statewide. Cultural engagement might necessitate a call or visit to a local Member of Congress regarding the sex education policies at the national level. The venue for involvement could be diverse, but the requirement for Christians to apply Biblical principles to the culture in which they live is not up for debate. "You are the salt of the earth; but if the salt loses its flavor, how shall it be seasoned? It is then good for nothing but to be thrown out and trampled underfoot by men” (Matthew 5:13). Christians must provide flavor and preservation qualities to the culture in a manner that points the unbelieving world to Christ.

\section{Strengths of the Study}

This study is the first formal and intentional documenting of the historical key events that assisted the development of two separate strategies of sex education for the public school setting since 1900. Previous sex education studies were typically based on very limited historical research, usually focusing on recent events beginning with the 1960s or 1980s. The very few studies that explored sex education history prior to the modern era did so with limited analysis. They did not explore and investigate the rise of the two sex education approaches, nor did they draw comparisons to historical events with present day features of sex education.

A second strength of this thesis is the balance it provides to an academic analysis of sex education. Other research on the subject invariably offered an "anti-abstinence" bias. Herzog (2008) bitterly describes the abstinence approach this way: "I was shaken in ways I could not shrug off. The rhetoric was graphically explicit and mean and 
manipulative at once. It was intrusive and insidious. And it got under my skin” (p. ix). Irvine (2002) erroneously characterized abstinence providers as "right wing” purveyors of “distortions” and "sexual stigmatization” (pp. 120, 124). Page (2006) scathingly called abstinence programs "the worst of both worlds" (p. 67), adding that providers "may justify the lies if they effectively discourage teens from having sex. Call it collateral damage for a good cause” (p. 65). She ended her tirade by inaccurately framing the abstinence message this way: "Once the virgin lapses, once the abstainer indulges, he or she might as well hurry off to the lake of fire” (p. 82). Mooney (2005) summarized his disgust with abstinence education this way: "And it is not just that these abstinence programs do not work. They seriously and inexcusably misinform students about sex, perpetuating dangerous myths and stereotypes” (p. 213). These authors typified most who wrote on the topic of sex education. Their "comprehensive" sex education perspective unnecessarily tainted the treatment of the risk elimination aspect of sex education. The previous studies minimized the value of "abstinence until marriage" and almost always cast it as inextricably connected to the religious right. This present study, by contrast, offers a fuller historical description of "abstinence until marriage" as an important societal standard, apart from the moral or religious aspects of the concept. Economic, sociological, and academic benefits are positively associated with premarital abstinence in abundant social science literature (Waite \& Gallagher, 2000).

A third strength of this study is its comprehensive nature. The documents accessed from the Library of Congress and insights gained from living individuals offer a unique treatment of the subject. The Library of Congress contains many out of print publications from the social hygiene movement to the present, giving access to 
contemporary documents of each era. Conversations with individuals who were involved in sex education policy, legislation, legal battles, or service provision, added detail and richness to the historical record. The recent addition of numerous Google Scholar out-ofprint books to online retrieval also strengthened the study. I was able to access numerous primary sources that previously were only available in archives.

Finally, this study demonstrates potency by encouraging the cultural engagement of American citizens. This analysis of the history of public school sex education (together with its implications) provides the record of parents, activists, policy makers, and educators who became active in the sex education debate because they believed it was an important pursuit. The reasons for their involvement differed, but they were involved nonetheless. Hopefully, the response of those who read this study will contemplate their intellectual commitment to the sex education issue or a similarly important issue of public discourse. The results of the study also are useful for future historians who will more fully explore sex education's history and its impact on American society. The present study provides an apt foundation on which historiography can be built and provides a frame through which the events can best be understood or interpreted.

\section{Limitations of the Study}

One limitation of the present study is that it provides only a brief summary of cultural mores and sex education practices before the turn of the $20^{\text {th }}$ century. A broader analysis would offer a more complete picture of the development of sex education in America. Although sex education in the American public school systems did not formally develop until after 1900, a study of the foundational cultural climate and attitudes about sexual behavior would have offered a more complete perspective to the picture. 
Second, reasonable page constraints limited the extent of the analysis for this study. The purpose of this thesis was to identify the prominent key historical events that were instrumental to the development of sex education since 1900. Each of the key turning points could be developed into an individual thesis for further exploration, which would permit more detail to be given, had the purpose of this thesis been more narrow. The present format, therefore, only permitted a broad overview and beginning exploration of each key point.

A third limitation to this study was that no attention was given to sex education outside of broad community-based approaches and public schools application. This constraint potentially affected the external validity of the findings. Without probing into sex education strategies in the home, parochial, and private school venues, it is difficult to assure that the conclusions of this study would hold across educational milieu.

A fourth limitation was the relatively limited access to original archives of data. Although the materials at the Library of Congress were invaluable, I was not able to examine any original documents at the Kinsey Institute to expand my grasp for the work of Alfred Kinsey and other sexologists. Similarly, study at the National Archives would have permitted access to a greater number of government documents throughout the developmental eras of sex education in America. Other libraries contain the unpublished letters and works of key individuals instrumental in the development of sex education, but time and travel constraints did not permit such a breadth of exploration.

This study only examined the development of sex education from a broad, national perspective. It did not compare the differences in public school sex education among various regions of country. Further, it did not explore differences and similarities 
of sex education application in urban, rural, and suburban settings. Therefore, it remains unknown if sex education developed at the same pace and with the same priorities in each respective venue.

A final potential limitation of this study was the author's bias and presuppositions at the outset of this research. My personal knowledge of the issue and involvement in the sex education field could have precipitated a selective view of historical data, despite my good faith commitment to an unbiased research project. Nonetheless, my thesis advisor was extremely helpful in providing objective input throughout the entire process. His rigorous commitment to presenting a reasonably objective analysis of historical data helped to provide an apt check on my own presuppositions and pathos for communicating the historical analysis.

\section{Suggestions for Future Research}

This study provided an important beginning to the understanding of key influences in the development of sex education in America, but further study would add depth and richness to an understanding of this topic. For example, the long-term effect on student behavior of persistent contraceptive advocacy within many "comprehensive" sex education programs remains unknown. One study by Arcidiacono, Khwaja, and Ouyang (2007) for example, reported: "Programs that increase access to contraception are found to decrease teen pregnancies in the short run but increase teen pregnancies in the long run. Thus we find that even well intended contraceptive policies can be selfdefeating” (p. 1). Further study to determine if this phenomenon is a widespread result of contraceptive-based programs would be helpful to sex education revision. 
Another suggestion for future research would be to examine each era in greater detail. This might necessitate that an entire thesis would focus solely on each respective era reported in this present study vis-à-vis its contribution to the development of sex education. A detailed analysis of each era would flesh out details that were not possible in the current century-long investigation. Alternatively, this thesis could provide the basis for more extensive study within a dissertation or book format.

The present study also provides the basis for further study in the following areas: (1) explore the American historical development of the "abstinence until marriage" standard, (2) compare sexual standards of the first settlers to America with those of native American views, (3) discover early American standards and expectations for sexual conduct given to young people, (4) focus on the historical changes in views of sex for specific American ethnic groups, (5) direct a study specifically on modern sex education since the discovery of AIDS, interviewing key leaders for their perspectives on the unfolding events that resulted in the two sex education approaches, (6) compare the history of sex education in different regions of the country and in rural, suburban and urban areas. The possibilities for further research in sex education are nearly endless. Each new study would add to the richness in understanding the school implementation of American public school sex education. Each additional research project also potentially would provide policy makers, citizens, parents, and teachers with key information that could help them wisely amend current sex education programs. 


\section{References}

AASECT. (2004). American Association of Sexuality Educators, Counselors, and Therapists home page. Retrieved August 25, 2009, from http://www.aasect.org/

Abrams, K. E. (1998, June 29). Kinsey, Rockefeller and the Nazi doctors. Alberta Report Newsmagazine, 25(28), 37-38.

ACLU, (n.d.). Timeline of Important Reproductive Freedom Cases Decided by the Supreme Court. Retrieved September 4, 2009, from http://www.aclu.org/ reproductiverights/gen/16463res20031201.html

Addams, J. (1912). A new conscience and an ancient evil. New York: Macmillan. Advocates for Youth. (2001). Rights. Respect. Responsibility. The campaign. Transitions, 4, 1-19.

Advocates for Youth. (2008a). Abstinence-only-until marriage programs. Retrieved August 25, 2009, from http://www.advocatesforyouth.org/index.php?Option $=$ com_content\&task=view\&id=29\&Itemid $=58$

Advocates for Youth. (2008b). Advocates For Youth: Historical overview. Retrieved August 24, 2009, from http://www.advocatesforyouth.org/index.php?option= com_content\&task=view\&id=15\&Itemid=44

Akerlof, G. A. (1996). An analysis of out of wedlock births in the United States. (Brookings policy brief series, No. 5l). Washington, D.C.: Brookings. Alan Guttmacher Institute. (2009). The history of the Guttmacher Institute. Retrieved August 25, 2009, from http://www.guttmacher.org/about/history.html 
Albert, B. (2007). With one voice 2007: America's adults and teens sound off about teen pregnancy. Washington, D.C.: The National Campaign to Prevent Teen Pregnancy. Allyn, D. (2000). Make love, not war. New York: Little, Brown \& Company.

Altman, D. (1982). The homosexualization of America. New York: St. Martin’s Press. Altman, L. K. (2001, July 3). Recollections on the age of AIDS. New York Times. Retrieved August 25, 2009, from http://www.nytimes.com/2001/07/03/health/ 03DOCS.html? pagewanted $=2$

American Board of Sexology. (n.d.). Big oaks from little acorns...and STILLS growing. Retrieved August 25, 2009, from http://americanboardofsexology.com/whatis.htm Antonucci, M. (1995). 'The Margaret Sanger story': What TV left out. Human Events, $51,16$.

Arcidiacono, P., Khwaja, A., \& Ouyang, L. (2007). Habit persistence and teen sex: Could increased access to contraception have unintended consequences for teen pregnancies? (Working paper). Durham: Duke University Department of Economics.

Armour, S., \& Haynie, D. L. (2007). Adolescent sexual debut and later delinquency. Journal of Youth and Adolescence, 36, 141-152.

ASHA. (1916a). Social Hygiene (Vol.1, 1914-1915). New York: ASHA.

ASHA . (1916b). Social hygiene (Vol. 2, 1915-1916). New York: ASHA.

ASHA. (1919). Social hygiene (Vol. 5, 1919). New York: ASHA.

ASHA. (1920). Social hygiene (Vol. 6, 1920). New York: ASHA.

ASHA. (1921). Social hygiene legislation manual (Publication No. 812). New York: ASHA. 
ASHA. (1942). Fit to fight...and fit for life. New York: ASHA.

Assessing the evidence: Preliminary hearing transcript. (2008). Hearing on domestic abstinence-only programs before the House Committee on Oversight and Government Reform, $110^{\text {th }}$ Congress, 2nd Session.

Bachu, A. (1999). Trends in premarital childbearing, 1930-1994 (Current Population Reports P23-197). Washington, D.C.: U.S. Department of Commerce.

Baer, J. A. (2002). Historical and multicultural encyclopedia of women's reproductive rights in the United States. Westport, CT: Greenwood Press.

Balanko, S. L. (2002). Good sex? A critical review of school sex education. Guidance and Counseling, 17, 117-123.

Bancroft, J. (1998). Kinsey and children. Retrieved August 24, 2009, from http://www. kinseyinstitute.org/about/cont-akchild.html

Banerjee, N. (2008, June 1). Taking their faith, but not their politics, to the people. New York Times. Retrieved August 25, 2009, from http://www.nytimes.com/ 2008/06/01/us/01evangelical.html.

Bashford, A., \& Strange, C. (2004). Public pedagogy: Sex education and mass communication in the mid-twentieth century. Journal of the History of Sexuality, 13, 71-99.

Berube, M. R. (1994). American school reform: Progressive, equity and excellence Movements: 1883-1993. Westport, CT: Praeger Publishers. 
Bigelow, M. A., Balliet, T. M., \& Morrow, P. A. (1913). The matter and methods of sex. New York: American Federation for Sex Hygiene.

Bigelow, M. A. (1916). Sex education. New York: Macmillan.

Blaine, E. (1778, January 6). Letter in the Journal of the Continental Congress. Retrieved August 25, 2009, from http://www.archive.org/stream/journalsofcontin 11unit/journalsofcontin11unit_djvu.txt

Blair, K. J. (1980). Clubwoman as feminist: True womanhood redefined: 1868-1914. New York: Holmes and Meier.

Blanshard, B. (1923). The nature of thought. New York: Macmillan Books.

Booth, A. \& Crouter, A. C. (Eds.). (2005). The new population problem. Mahwah, NJ: Lawrence Erlbaum Associates Publishers.

Bowen v. Kendrick, 483 U.S. 1304 (1987). Retrieved August 25, 2009, from http:// supreme.justia.com/us/483/1304/case.html

Brandt, A. M. (1987). No magic bullet. New York: Oxford University Press.

Brown, R. (2002). Book Review: Transitions in American education: A social history of teaching. Journal of Interdisciplinary History, 33, 494-496.

Bullough, V. L. (1998). Alfred Kinsey and the Kinsey Report: Historical overview and lasting contributions. Journal of Sex Research, 35, 127-131.

Burgess. E. W., \& Locke, H. J. (1945). The family: From institution to companionship. New York: American Book.

Byfield, L. (1997, September 29). Funny how people with seemingly hopeless causes succeed if they just keep at it. Alberta Report Newsmagazine, 24(42), 2.

Caither, M. (2008). Homeschool: An American History. New York: Palgrave Macmillan. 
Card, J. J. (1999). Teen pregnancy prevention: Do any programs work? Annual Review of Public Health, 20, 257-285.

Carlson, M. (1989, April 24). A doctor prescribes hard truth. Time Magazine. Retrieved August 25, 2009, from http://www.time.com/time/magazine/article /0,9171,957490,00.html

Carter, D. (2009). What made Stonewall different? Gay \& Lesbian Review Worldwide, $16,11-13$.

Carter, J. (2001). Birds, bees, and venereal disease: Toward an intellectual history of sex education. Journal of the History of Sexuality, 10, 213-249.

Centers for Disease Control. (2001). HIV and AIDS - United States, 1981-2000, Atlanta: Author.

Centers for Disease Control. (2008). Nationally representative CDC study finds 1 in 4 teenage girls has a sexually transmitted disease. Atlanta: Author.

Centers for Disease Control. (2009a). Births: Final data for 2006. Atlanta: Author. Centers for Disease Control. (2009b). Most viewed disease topics. Atlanta: Author. Retrieved August 25, 2009, from http://www.cdc.gov/nchhstp/

Centers for Disease Control. (2009c). Trends in reportable sexually transmitted diseases in the United States, 2007. Atlanta: Author.

Centers for Disease Control. (2009d). Trends in the prevalence of sexual behaviors: National YRBS 1991-2007 Atlanta: Author.

Chang, M. (1985). Public schools, private schools, and the common school ideal. The Urban Review, 17, 75-97. 
Chappell, M. (2002). Rethinking women's politics in the 1970s: The League of Women Voters and the National Organization for Women confront poverty. Journal of Women's History, 13, 155-179.

Chauncey, G. (2004). "What Gay studies taught the court": The historians' Amicus brief in Lawrence v. Texas. GLQ: A Journal of Lesbian and Gay Studies, 10, 509-538.

Chesler, E. (2003, July 21). Margaret Sanger. Nation, 277(3), 24-26.

Chicago Vice Commission. (1911). The social evil in Chicago. Chicago: Vice Commission of Chicago, Inc.

Cocca, C. (2006). Adolescent sexuality: A historical handbook and guide. Santa Barbara, CA: Greenwood Publishing Group.

Cohen, W. J. (1967). Freedom of choice. Studies in Family Planning, 1, $2-5$.

Coleman, A., \& Rebach, H. (2001). Welfare Reform. Sociological Practice, 3, 279-296.

Colker, R. (1992). Abortion and dialogue: Pro-choice, pro-life, and American law. Bloomington: Indiana University Press.

Comfort, A. (1972). The Joy of Sex. New York: Crown.

Committee on Public Education. (2001). Sexuality, contraception, and the media. Pediatrics, 107, 191-194.

Congressional Research Service (CRS). (2009). Abstinence education funding, FY 19982009. Washington, D.C.: Government Printing Office.

Cornog, M., \& Perper, T. (1996). For sex education, see librarian: A guide to issues and Resources. Santa Barbara, CA: Greenwood Publishing Group. 
Costain, A. N., \& McFarland, A. S. (1998). Social movements and American political institutions. Lanham, MD: Rowman \& Littlefield Publishing.

Cremin, L. A. (1980). American education: The national experience: 1783-1876. New York: Harper and Row.

Cutler, J. C. (1988). Venereal disease control by health departments in the past: Lessons for the present. American Journal of Public Health, 78, 372-376.

Davis, T., \& Ellerson, L. (2007, July 20). Sex ed for kindergartners? ABC News. Retrieved September 4, 2009, from http://abcnews.go.com/Politics /Story?id=3395856\&page=1

Degette, D. (2008). Sex, science, and stem cells. Guiliford, CT: The Lyons Press.

Delano, J. S. (1976). When father was at Bunker Hill and mother was sewing flags, what were the children doing? Educational Leadership, 33, 261-265.

D’Emilio, J., \& Freedman, E. B. (1998). Intimate matters: A history of sexuality in America. Chicago: University of Chicago Press.

Dewey, J. (1916). Democracy and education: An introduction to the philosophy of education. New York: The Macmillan Company.

Donovan, P. A. (1989). Risk and responsibility. New York: Alan Guttmacher Institute.

Donovan P. A. (1998). School-based sexuality education: The issues and challenges. Family Planning Perspectives, 30, 188-193.

Edwards, E. (1909). For boys. New York: R. F. Fenno \& Company.

Ellenwood, S. (2006). Revisiting character education: From McGuffey to narratives. Journal of Education, 187, 21-43. 
Engel, R. (1989). Sex education - The final plague. Gaithersburg, MD: Human Life International.

Engs, R. C. (2003). The progressive era's health reform movement. New York: Praeger.

Engs, R. C. (2005). The eugenics movement. Westport, CT: Greenwood Press.

Fagan, P. F., Patterson, R. W., \& Rector, R. E. (2002). Marriage and welfare reform: The overwhelming evidence that marriage education works. Washington, D.C.: Heritage Foundation.

Fahlbusch, E., Bromiley, G. W., \& Barrett, D. B. (2008). The encyclopedia of Christianity (Vol. 4). Grand Rapids, MI: William B. Eerdmans Publishing.

Fairchild, A. L., Colgrove, J., \& Bayer, R. (2003). The myth of exceptionalism: The history of venereal disease reporting in the twentieth century. Journal of Law, Medicine \& Ethics, 31, 624-637.

Fay, J. (2002). Teaching teens about sexual pleasure. SIECUS Report, 30, 12-17.

Feldman, E. (1969). The sexual revolution. Journal of Contemporary Psychotherapy, 2, 54-56.

Finkel, M. L. (2007). Truth, lies, and public health. Santa Barbara, CA: Praeger Publishers.

Fletcher, J. (1966). Situation ethics :The new morality. Philadelphia: Westminster Press. For keeps. (2007). Twinsburg, OH: Operation Keepsake.

Foster, W. T. (1914). The social emergency. Cambridge, MA: The Riverside Press. Freeman, S. K. (2008). Sex goes to school. Urbana, IL: University of Illinois Press. Friedan, B. (1963). The feminine mystique. New York: Norton.

Galvin, R. (1998). Margaret Sanger's `deeds of terrible virtue'. Humanities, 19, 8-13. 
Gardiner, A. B. (2006). The unfit to be tied. Touchstone: A Journal of Mere Christianity, 19, 47-49.

Gathorne-Hardy, J. (1998). Sex the measure of all things. Bloomington, IN: Indiana University Press.

Gerrard, T. (1914). The Church and eugenics. New York: The Encyclopedia Press. Retrieved August 4, 2009, from http://www.newadvent.org/cathen/16038b.htm Goldberg, J. (2008, June 24). A dark past. National Review Online. Retrieved August 25, 2009, from http://article.nationalreview.com/?q= ODUxZmVmZDM0ODY 0MTFhOWJhOGIwOTYwYjRmMDQ2ODk=

Goldstein, D. (2009, May 14). Sex work. American Prospect. Retrieved August 25, 2009, from http://www.thomasmaierbooks.com/2009/05/american-prospect-masters-ofsex-is.html

Gordon, L. (2002). The moral property of women: A history of birth control politics in America. Chicago: University of Illinois Press.

Grossman, M. (2009). You're teaching my child, what? Washington, D.C.: Regnery Publishing

Gruenberg, B. C. (1922). High schools and sex education. Washington, D.C.: Government Printing Office.

Gruenberg, B. C. (1940). Schools and sex education. New York: Child Study Association of America.

Gruenberg, B. C. (1946). How can we teach about sex? New York: Public Affairs Committee. 
Guidestar. (2009). Search guidestar. Retrieved August 24, 2009, from http://www2 guidestar.org/ReportNonProfit.aspx?ein=13-2508249\&Mode= GxLite\&lid $=221152 \& \mathrm{dl}=$ True

Gurley, H. (1962) Sex and the Single Girl. New York: B. Geis Associates.

Guttmacher Institute. (2009). State policies in brief: Sex and STI/HIV education. New York: Guttmacher.

Haffner, D. W. (1988). Safe sex and teens. New York: SIECUS.

Haffner, D. W. (2005). Debra W. Haffner. Tikkun, 20, 36-37.

Haffner, D. W. (2008, September 17). Yes, sex education in kindergarten. Retrieved on August 25, 2009, from http://www.huffingtonpost.com/rev-debra-haffner/yessex-education-in-kind_b_126899.html

Hall, G. S. (1905). Adolescence. New York: D. Appleton \& Company.

Hall, G. S. (1920). Youth. New York: D. Appleton \& Company.

Hallfors, D. D. (2004). Adolescent depression and suicide risk: Association with sex and drug behavior. American Journal of Preventive Medicine, 27, 224-231.

Halpin, J. (2009, May). Progressivism goes mainstream. American Prospect, 20(4), 26-28.

Halstead, M. \& Reiss, M. (2003). Values in sex education. New York: Routledge. Haskins, R., \& Bevan, S. (1997). Abstinence education under Welfare Reform. Children and Youth Services Review, 19, 465-484.

Hecht, M., \& Eddington, E. N. (2003). The place and nature of sexuality education in society In J. R. Levesque (Ed.). Sexuality education: What adolescents' rights require. (pps. 25-47). Hauppauge, NY: Nova Science Publishers. 
Hedman, A. S. (2008). Relationship between comprehensive sex education and teen pregnancy in Minnesota. American Journal of Health Studies, 23, 185-194.

Heer, D. M. (1981). The impact of the female marriage squeeze and the contraceptive revolution on sex roles and the Women's Liberation Movement in the United States 1960 to 1975. Journal of Marriage \& Family, 43, 49-65.

Herzog, D. (2008). Sex in crisis: The new sexual revolution and the future of American politics. New York: Basic Books.

HEW. (1966). Report on family planning: Activities of the U.S. Department of Health, Education and Welfare. Washington D.C.: Government Printing Office.

HHS. (1970). Public law 91-572. Retrieved August 25, 2009, from http://www.hhs. gov/opa/about/legislation/pl91-572.html

HHS. (2007). Review of comprehensive sex education curricula. Washington D.C.: HHS.

HHS. (2008a) About TANF. Retrieved August 25, 2009, from http://www.acf.hhs. gov/programs/ofa/tanf/about.html

HHS. (2008b). Fact Sheet: Community-Based Abstinence Education Program. Retrieved August 25, 2009, fromhttp://www.acf.hhs.gov/programs/fysb/content/abstinence/ community.htm

HHS. (2008c). Fact sheet: Section 510 state abstinence education program. Retrieved August 25, 2009, from http://www.acf.hhs.gov/programs/fysb/content/ abstinence/factsheet.htm

HHS. (2008d). Health and Human Services funding for abstinence education, education for teen pregnancy, and HIV/STD prevention, and other programs that address adolescent sexual activity. Washington D.C.: HHS. 
Hogben, M., \& Byrne, D. (1998). Using social learning theory to explain individual differences in human sexuality. Journal of Sex Research, 35, 58-71.

IASHS. (2009). IASHS: An overview. Retrieved August 25, 2009, from http://www. iashs.edu/over.html

Illinois General Assembly, (2005). Full text of SB0099. Retrieved August 24, 2009, from http://www.ilga.gov/legislation/fulltext.asp?DocName=\&SessionId=3\&GA=93\& DocTypeId=SB\&DocNum=0099\&GAID=3\&LegID=73\&SpecSess=\&Session= Irvine, J. M. (2002). Talk about sex: The battles over sex education in the United States. Berkeley, CA: University of California Press.

Irvine, J. M. (2005). Disorders of desire. Philadelphia: Temple University Press. Jacoby, S. (2005). Freethinkers: A history of American secularism. New York: Henry Holt \& Company.

Jenkins, R. (2008, May 24). No social mercy for smokers. Daily News Central Health News. Retrieved August 25, 2009, from http://health.dailynewscentral. com/content/view/0002627/42/

Jensen, R. E. (2007). Using science to argue for sexual education in U.S. public schools: Dr. Ella Flagg Young and the 1913 'Chicago Experiment’. Science Communication, 29, 217-241.

Jimenez, J. (2005, June 9). Planned Parenthood's war against choice. Agape Press. Retrieved August 25, 2009 from Http://headlines.agapepress.org/archive/ 6/92005jj.asp

Johnson, B., \& Christensen, L. (2008). Educational research: Quantitative, qualitative and mixed approaches. Thousand Oaks, CA: Sage. 
Johnson, O. (1883, June). Morality in the public schools. The Atlantic Monthly. 51, 748-758.

Jones, J. (1997). Alfred C. Kinsey: A life. New York: Norton.

Jones, R. K. (2006). Do U.S. family planning clinics encourage parent-child communication? Findings from an exploratory survey. Perspectives on Sexual \& Reproductive Health, 38, 155-161.

Kaestner, R., Korenman, S., O’Neill, J. (2003). Has welfare reform changed teenage behaviors? Journal of Policy Analysis and Management, 22, 225-248.

Kaiser Family Foundation. (2002). Sex education in the US: Policy and politics. Washington, D.C.: Kaiser.

Kammen, C. (2009). The McGuffey Readers. Children's Literature, 5, 58-63.

Kaslow, F. W. (2006). The role of the family in sex education: How sex therapists, sexuality counselors and educators can assist them. Contemporary Sexuality, 40, 15-18.

Kenney, C. T., \& McLanahan, S. S. (2006). Why are cohabiting relationships more violent than marriages? Demography, 43, 127-40.

Kett, J. F. (2002). Book Review: Teaching sex. The shaping of adolescence in the $20^{\text {th }}$ century. Journal of Social History. 35, 708-710.

Kim, C., \& Rector, R. (2006). Welfare reform turns ten: Evidence shows reduced dependence, poverty. Retrieved August 25, 2009 from http://www.heritage. org/Research/Welfare/wm1183.cfm

Kimmel, V. M. (1916). The double standard of conduct for men and women today: Its origin and results. New York: author. 
King, C. (1918). War relief work. Philadephia: American Academy of Political and Social Science.

King, M. M. (1870). Social evils: Their causes and cure. Boston: W. White \& Company.

Kinsey, A. C., Pomeroy, W. B., \& Martin, C. E. (1948). Sexual behavior in the human male. Philadelphia: W. B. Suanders Company.

Kinsey, A. C., Pomeroy, W. B., \& Martin, C. E. (1953). Sexual behavior in the human female. Philadelphia: W. B. Suanders Company.

Kinsey Institute. (2009). Archival collections. Retrieved August 25, 2009 from http://www.kinseyinstitute.org/library/archives.html

Klein, M. (2006). America's war on sex. Westport, CT: Praeger Publishers.

Kline, W. (2005). Overexposed? Sex and the female body in American history. Journal of Women's History, 17, 161-168.

Knight, J. W., \& Callahan, J. C. (1989). Preventing birth: Contemporary methods and related moral controversies. Salt Lake City: University of Utah Press.

Koop, C. E. (2007). Testimony before the House Committee on Oversight and Government Reform, 110th Congress, 1st Session. Retrieved August 25, 2009, from http://www.speaker.gov/blog/?p=581

Kris, M. (1953). When children ask about sex. New York: The Child Study Association of America.

Lagemann, E. C. (1996). Experimenting with education: John Dewey and Ella Flagg Young at the University of Chicago. American Journal of Education, 104, 171-85. 
Landry, D. J. (1999). Abstinence promotion and the provision of information about contraception in public school district sexuality education policies. Family Planning Perspectives, 31, 280-286.

Larson, C. (2002, September). Pork for prudes. Washington Monthly, 3(9), 30-38.

Laughlin, H. H. (1920). Biological Aspects of Immigration by United States:

Report to House Committee on Immigration and Naturalization, $66^{\text {th }}$ Congress, $2^{\text {nd }}$ Session.

Lawrence, L. (2008, July 10). Reproductive liberty and social reform in the shape of a pill. Hem/Onc Today, 9(12), 31.

Lawrence v. Texas, 539 U.S. 558 (2003). Opinion by Justice Kennedy. Retrieved August 25, 2009, from http://caselaw.lp.findlaw.com/scripts/getcase.pl?court=US\&vol= 000\&invol=02-102\#opinion1

Leedy, P. D., \& Ormrod, J. E. (2010). Practical research (9 ${ }^{\text {th }}$ ed). Boston: Pearson.

Levine, J. (2002). Harmful to minors: The perils of protecting children from sex. Minneapolis: University of Minnesota Press.

Lowry, E. B., \& Lambert, R. J. (1912). Himself. Chicago: Forbes \& Company. Luker, K. (1998). Sex, social hygiene and the state: The double-edged sword of social reform. Theory and Society, 27, 601-634.

Mahoney, E. R. (1979). Sex education in the public schools: A discriminate analysis of characteristics of pro and anti individuals. Journal of Sex Research, 15, 264-275.

Maier, T. (2009). Masters of sex: The life and times of William Masters and Virginia Johnson. New York: Basic Books. 
Marcuse, H. (1955). Eros and civilization. New York: Vantage Books.

Marks. M. J. (2008). Evaluations of sexually active men and women under divided attention: A social cognitive approach to the sexual double standard. Basic and Applied Social Psychology, 30, 84-91.

Marshall, R. G., \& Donovan, C. A. (1991). Blessed are the barren. San Francisco: Ignatius Press.

Mary Steichen Calderone Papers. (1973). Schlesinger Library on the History of Women in America. Cambridge: Harvard University. Retrieved August 24, 2009, from oasis.lib.harvard.edu/oasis/deliver/

Masland, M. (2009). Carnal knowledge: The sex ed debate (online article). Retrieved August 25, 2009 from http://www.msnbc.msn.com/id/3071001

Masters, W. H., \& Johnson, V. E. (1966). Human sexual response. Boston: Little, Brown and Company.

Maxwell, R. C. (1919). New Jersey State Department of Health billboard. Retrieved August 25, 2009 from http://hdl.loc.gov/loc.award/ncdeaa.M0064

Mayhew, R. (1850). Popular education. New York: Harper and Brothers.

McBride, D. E. (2007). Abortion in the United States: A reference handbook. Santa Barbara, CA: ABC-CLIO.

McIlhaney, J. S., \& Bush, F. M. (2008). Hooked: New science on how casual sex is affecting of our children. Chicago: Northfield Publishing.

McLanahan, S., \& Sandefur. G. D. (1994). Growing up with a single parent: What hurts. What helps. Cambridge, MA: Harvard University Press. 
Mead, L. M. (2004). State political culture and welfare reform. The Policy Studies Journal, 32, 271-296.

Measor, L., Miller, K., \& Tiffin, C. (2000). Young people's views on sex education. Florence, KY: Routledge.

Meckler, L. (2009, May 7). Budget widens teen pregnancy prevention efforts. Wall Street Journal. Retrieved August 25, 2009 from athttp://online.wsj.com/article /SB124171750523696797.html

Mehlman, N. (2007). Sex Ed... and the Reds? Reconsidering the Anaheim battle over sex education, 1962-1969. History of Education Quarterly, 47, 203-232.

Meier, A. M. (2007). Adolescent first sex and subsequent mental health. American Journal of Sociology, 112, 1811-1847.

Melby, T. (2009). The end of abstinence-only? Contemporary Sexuality, 43, 1-4.

Mestel, R. (2004, November 15). The Kinsey effect. LA Times. Retrieved August 25, 2009, from http://articles.latimes.com/2004/nov/15/health/he-kinsey15

Miletski, H. (2002). Understanding bestiality and zoophilia. Bethesda, MD: Author. Mook, B. (2007, January 24). A short history of the 'Wobblies,' Daily Record. Retrieved August 25, 2009, from http://findarticles.com/p/articles/mi_qn 4183/is_20070124/ai_n17150978/

Mooney, C. (2005). The Republican war on science. New York: Basic Books.

Moore, H. H. (1914). Teaching phases: For boys. The social emergency studies in sex hygiene and morals. Cambridge, MA: The Riverside Press.

Moore, M. J. (2000). Utilizing the SIECUS Guidelines to assess sexuality education in one state: Content, scope and importance. Journal of School Health, 70, 56-60. 
Moran, J. P. (1996). `Modernism gone mad': Sex education comes to Chicago, 1913. Journal of American History, 83, 481-513.

Moran, J. P. (2000). Teaching sex: The shaping of adolescence in the $20^{\text {th }}$ century. Cambridge, MA: Harvard University Press.

Moran, J. P. (2003). Sex education and the rise of the New Right. Reviews in American History, 31, 283-289.

Morrow, P.A. (1904). Social diseases and marriage: Social prophylaxis. New York: Lea Brothers \& Co.

Muncy, R. (1991). Creating a female dominion in American reform, 1890-1935. New York: Oxford University Press.

Musolf, G. R. (2003). John Dewey's social psychology and neopragmatism: theoretical foundations of human agency and social reconstruction. Social Science Journal, 38, 277-295.

NAEA. (2007). Straight from the source. Washington, D.C.: NAEA.

NAEA. (2008). Voice your choice: Advocacy guide for abstinence education. Washington, D.C.: NAEA.

NAEA. (2009a). Correcting misinformation in the sex ed debate. Washington, D.C.: NAEA.

NAEA. (2009b). Abstinence works. Washington, D.C.: NAEA.

National Center for Health Statistics. (2009). Births: Preliminary data for 2007. Retrieved August 25, 2009, from http://www.cdc.gov/nchs/data/nvsr/ nvsr57/nvsr57_12.pdf. 
National Library of Medicine. (n.d.). The C. Everett Koop papers : AIDS, the Surgeon General, and the politics of public health. Retrieved August 25, 2009 from http://profiles.nlm.nih.gov/QQ/Views/Exhibit/narrative/aids.html

Neuman, W. L. (2006). Social research methods (6 $6^{\text {th }}$ ed). Boston: Allyn \& Bacon. New standard of morals for new generation.(1908, October17). Unnamed newspaper article from Miller NAWSA suffrage scrapbooks, 1897-1911, 11-12. Retrieved August 25, 2009, from http://memory.loc.gov/cgi-bin/ampage?collId= rbcmil\& fileName=scrp5003002/rbcmilscrp5003002.db\&recNum=0\&itemLink=D?rbcmill erbib:1:./temp/ ammem_hLgZ::

Nicoletti, A. (2005). The definition of abstinence. Journal of Pediatric and Adolescent Gynecology, 18, 57-58.

Obama for America. (2008). Barack Obama and Joe Biden's plan to lower health care costs and ensure affordable, accessible health coverage for all (Obama campaign document). Retrieved August 24, 2009, from www.barackobama. com/pdf/issues/HealthCareFullPlan.pdf

Ohio Department of Health (2007). Abstinence education. Retrieved August 24, 2009 from http://www.odh.ohio.gov/odhPrograms/do/aeduc/aed1.aspx

Only 33 venereal cases in week - whole A. E. F. rate down. (1919, January 17). Stars and Stripes, p. 1.

Page, C. (2006). How the pro-choice movement saved America. New York: Basic Books. Page, T. S. (2003). Fostering emotional well-being in the classroom ( $3^{\text {rd }}$ ed). Sudbury, MA: Jones \& Bartlett Publishers. 
Panzer, R. A., \& Mosack, M. A. (2009). The war on intimacy. Westwood, NJ: Center for Relationship Intelligence.

Pardue, M., Rector, R. E., \& Martin, S. (2004). Government spends \$12 on safe sex and contraceptives for every \$1 spent on abstinence. Washington, D.C.: Heritage Foundation.

Parkerson, D. H. \& Parkerson, J. A. (2001). Transitions in American education: A social history of teaching. New York: Routledge.

Parmelee, M. (1920). Poverty and social progress. New York: The Macmillan Company.

Patten, M. L. (2007). Understanding research methods (6 $6^{\text {th }}$ ed.). Glendale, CA: Pyrczak Publishing.

Payne, K. E. (2001). Different but equal. Westport, CT: Praeger Publishers.

Pear, R. S. (1984, June 3). Treating the nation’s epidemic of teen-age pregnancy. New York Times. Retrieved August 14, 2009, from http://www.nytimes.com/ 1984/06/03/weekinreview/treating-the-nation-s-epidemic-of-teen-agepregnancy.html?\&pagewanted=1

Pear, R. S. (1986, October 8). Despite U.S. objections, more schools offer family planning. New York Times (supplement), 4.

Pearsall, S. M. (2001). The state of the union: Sexuality in American history. Gender \& History, 13, 374-379.

Personal Responsibility and Work Opportunity Reconciliation Act (PRWORA) of 1996, H.R. 3734, $104^{\text {th }}$ Congress. (1995). Retrieved August 25, 2009, from http://thomas. loc.gov/cgi-bin/query/F?c104:1:./temp/ c104en0uaZ:e0: 
Pestritto, R. J., \& Atto, W. J. (2008). American progressivism. Lanham, MD:

Lexington Books.

Peterson, R. A. (1983). Education in Colonial America. The Freeman, 33, n.p. Retrieved August 14, 2009 from http://www.thefreemanonline.org/columns/educationin-colonial-america/

Peterson, S. J. (2006). Priming the historian in all planners. Journal of Planning History, 5, 289-300.

Phelps, S. (2006). Aspire: Live your life. Be free. Arlington Heights, IL: A\&M Partnership.

Physicians Consortium. (2002). Sexual messages in government-promoted programs and today's youth culture. Harrisburg, PA: Physicians Consortium.

Pivar, D. J. (2002). Purity and hygiene: Women, prostitution, and the American plan. Westport, CT: Greenwood Press.

Planned Parenthood. (2009). History \& successes. Retrieved August 14, 2009, from www.plannedparenthood.org/about-us/who-we-are/history-and successes. htm\#early

Pomeroy, W. B. (1982). Dr. Kinsey and the Institute for Sex Research. New Haven, CT: Yale University Press.

Pomeroy, W. B. (1968). Boys and sex. New York: Laurel-Leaf Books.

Pomeroy, W. B. (1991). Girls and sex. New York: Delacorte.

Powderly, K. E. (1995, January/February). Contraceptive policy and ethics. Hastings Center Report, 25(1), S9. 
Public Health Service. (1918). Regulations governing allotment of funds for venereal disease prevention work. Washington, D.C.: Government Printing Office.

Public Health Service. (1924). The venereal disease handbook for community leaders. Washington, D.C.: Government Printing Office.

Public Health Service. (1959). Milestones in venereal disease control. Washington, D.C.: Government Printing Office.

Purnick, J. (1996, August 19) Welfare Bill: Legislating Morality? New York Times, p. $1-1$.

Really, Dr. Kinsey? (1991). [Review of the book Kinsey, sex and fraud]. Lancet, 337, 547.

Rector, R. (1995). Why Congress must reform welfare. Washington, D.C.: The Heritage Foundation.

Rector, R., \& Bradley, K. (2009, June 19) Stimulus bill abolishes welfare reform and adds new welfare spending. WebMemo, No. 2496. Retrieved August 25, 2009 from http://www.heritage.org/Research/Welfare/wm2496.cfm

Rector, R., Johnson, K. A., \& Noyes, L. (2003). Sexually active teenagers are more likely to be depressed and to attempt suicide. Washington, D.C.: The Heritage Center.

Rector, R., \& Johnson, K. A., (2005, October). Teenage sexual abstinence and Academic achievement. Paper presented at the $9^{\text {th }}$ annual Abstinence Clearinghouse Conference, Las Vegas, NV.

Rector, R., \& Kim, C. (2007). Abstinence education works: A review of 15 evaluations on the effectiveness of abstinence programs. Washington, D.C.: The Heritage Foundation. 
Reed, M. (2003). Margaret Sanger: Her life in her words. Fort Lee, NJ: Barricade.

Reinisch, J. M., \& Beasley, R. (1991). The Kinsey Institute new report on sex. New York: St. Martin’s Griffin.

Reisman, J. A. (2000). Kinsey: Crimes \& consequences ( $2^{\text {nd }}$ ed). Crestwood, KY: Institute for Media Education.

Reisman, J. A. (2003, August 18). Sodomy decision based on fraudulent 'science'. Human Events, 59(28), 20-21.

Reiss, I. L. (2006). An insider's view of sexual science since Kinsey. Lanham, MD: Rowman \& Littlefield.

Resnick, M. D. (1997). Protecting adolescents from harm. JAMA, 278, 823-832.

Rhoades, G. K., Stanley, S. M., \& Markman, H. J. (2006). Pre-engagement cohabitation and gender asymmetry in marital commitment. Journal of Family Psychology, 20, 553-560.

Richard, D. (2003). 108th: SOS. Contemporary Sexuality, 37, 1-5.

Rodriguez, M. (2000). Working together for a sexually healthy America. Educational Leadership, 58, 66-69.

Rosendale, R. (2003, February 17). GLAA opposes abstinence-only education grant. Retrieved August 14, 2009, from http://www.glaa.org/archive/2003/glaaon abstinence0217.shtml

Rotskoff, L. E. (2001). Sex in the schools: Adolescence, sex education, and social reform. Reviews in American History, 29, 310-318. 
Russett, C. (2006, December). Contending with indecency in the early twentieth century. H-Net Reviews. Retrieved August 14, 2009 from www.h-net.org/reviews /showre/php?id=12675.

St. Lawrence, J. S. (1998). Becoming a responsible teen. Santa Cruz, CA: ETR Associates.

Sanger, M. H. (1917). Family limitation. New York: author.

Sanger, M. H. (1920). Woman and the new race. New York: Brentano’s.

Sanger, M. H. (1922). The pivot of civilization. New York: Belvedere.

Scales, P. (1981). Sex Education in the '70s and '80s: Accomplishments, obstacles and emerging issues. Family Relations, 30, 557-566.

Schaefer, E. (1999). Bold! Daring! Shocking! True! A history of exploitation films, 1919-1959. Durham: Duke University Press.

School-based clinics gaining greater acceptance across the U.S. (1993). Nation's Health, 23(10), 7.

Schultz, B. (2009). Obama's political philosophy: Pragmatism, politics, and the University of Chicago. Philosophy of the Social Sciences, 39, 127-173.

Schwarz, A. (2007). Comprehensive sex education: Why America's youth deserve the truth about sex. Hamline Journal of Public Law \& Policy, 29, 115-160.

Searcy, J. T. (1914). The increase of insanity. In E. F. Robbins (Ed.), Proceedings of the first National Conference on Race Betterment (pp. 167-170). Battle Creek, MI: Race Betterment Foundation.

Setran, D. P. (2003). "From morality to character": Conservative progressivism and the search for civic virtue, 1910-1930. Paedagogica Historica, 39, 435-436. 
SIECUS. (n. d. [a]). History. Retrieved August 15, 2009, from http://www.siecus.org /index.cfm?fuseaction=Page.viewPage \&pageId=493\&parentID=472

SIECUS. (n. d. [b]). Position statements. Retrieved August 15, 2009, from http://www. siecus.org/index.cfm?fuseaction=Page.viewPage\&pageId=494\&parentID=472

SIECUS (1969). Sex, science, and values. Northfield, IL: SIECUS.

SIECUS. (1978). SIECUS report. New York: SIECUS.

SIECUS. (2003). A controversial decade. Washington, D.C.: SIECUS.

SIECUS. (2004). Guidelines for comprehensive education ( $3^{\text {rd }}$ ed). Lititz, PA: Fulton Press.

SIECUS. (2008a). No more money. Retrieved August 15, 2009, from http://www. nomoremoney.org/

SIECUS. (2008b). Sexuality education and abstinence only until marriage programs in the states: Fiscal year 2008 edition. Washington, D.C.: SIECUS.

SIECUS. (2009). Sexuality education and abstinence-only-until-marriage programs in the States: An overview fiscal year 2008 edition. Retrieved August 15, 2009, from http://www.siecus.org/index.cfm?fuseaction=Page.viewPage\&pageId=487\& parentID $=478$

Smallman-Raynor, M. \& Cliff, A. D. (2004). War epidemics: An historical geography of infectious diseases in military. New York: Oxford University Press. 
Smith, L. (1987, August 31). Throwing money at AIDS: Funds for AIDS education and testing should be directed at high risk groups, not spread around. For most Americans the risk is slight - fear has already outrun danger. Fortune. Retrieved August 20, 2009 from http://money.cnn.com/magazines/fortune/fortune_archive /1987/08/31/69481/index.htm

Social hygiene posters. (2004). Original posters part of the ASHA records in the social welfare history archives at the University of Minnesota. Retrieved September 4, 2009, from http://special.lib.umn.edu/swha/exhibits/hygiene/index.htm (Reprinted with permission.)

Social Security Administration. (2009). Separate program for abstinence education. Retrieved August 24, 2009 from http://www.ssa.gov/OP_Home/ssact/title05 /0510.htm

Spann, E. K. (2003). Democracy's children: The young rebels of the 1960s and the power of ideals. Lanham, MD: Rowman \& Littlefield Publishing Group. Spring, J H. (1992). Images of American life. Albany, NY: State University of New York Press.

SSSS. (2002, November). Unresolved controversies: Sex questions in search of resolution. Conference booklet for the 2002 annual meeting of SSSS, Montreal, Canada.

SSSS. (2009a). About SSSS. Retrieved August 15, 2009, from http://www.sexscience.org/

SSSS. (2009b). Awards \& grants. Retrieved August 24, 2009, from http://www. sexscience.org/awards/index.php?category_id=426

Stanton, G. T. (1997). Why marriage matters. Colorado Springs: Pinon Press. 
Staton, M. (199). Gender differences in substance use and initiation of sexual activity. Population Research and Policy Review 18, 89-100.

Stein, G. J. (1998). AIDS update. Upper Saddle River, NJ: Prentice Hall.

Stein, R. (1989, December 11). AIDS dominates the 1980s. UPI/Boston. Retrieved August 15, 2009, from http://www.aegis.com/news/ads/1989/AD892635.html

Stepp, L. S. (2007). Unhooked: How young women pursue sex, delay love and lose at both. New York: Penguin.

Stevens, J. D. (1989, November). Media and morality in the twenties. History Today, 39(11), 25-29.

Stevens, R. A. (2006). History and health policy in the United States. Piscataway, NJ: Rutgers University Press.

Tiles, J. E. (1999). John Dewey: Political theory and social practice. London: Routledge.

Tolson, J. (1999, December 27). Sex, pills, and women's lib. U.S. News \& World Report, 127(25), 52-53.

Tremblay, C. H., \& Ling, D. (2005). AIDS education, condom demand, and the sexual activity of American youth. Health Economics, 14, 851-867.

Tuhus-Dubrow, R. (2007, July 30). Sanger vs. Sanger. Nation 285(4), 38-42.

Turan, K. (2004, November 12). There's sex on his mind. LA Times, A02. Retrieved August 15, 2009, from http://articles.latimes.com/2004/nov/12/entertainment 
U.S. Office of Management and Budget. (2009). Detailed Information on the Abstinence Education Assessment. Retrieved August 24, 2009, from http://www.whitehouse. gov/omb/expectmore/detail/10003546.2006.html

Ventura, S. J. (2009). Changing patterns of nonmarital childbearing in the United States. Hyattsville, MD: National Center for Health Statistics.

Vespa, M. (1980). America’s biggest problem? Fearless Dr. Mary Calderone says it’s “fear of sex.” People, 13, n.p. Retrieved August 25, 2009 from http://www. people.com/people/archive/article/0,20075651,00.html

Vu, P. (2007, June 4). Sex ed landscape shifting in states. Retrieved August 25, 2009, from http://www.stateline.org/live/details/story?contentId=213148

Waite, L. J., \& Gallagher, M. (2000). The case for marriage. New York: Broadway.

Wardell, D. (1980). Margaret Sanger: Birth control's successful revolutionary. American Journal of Public Health, 70, 736-742.

War Department. (1918). When you go home, take this book with you. Washington, D.C.: Public Health Service

War Department. (1941). Circular 249 - Venereal Disease. Washington, D.C.: Public Health Service.

Ware, P. (1997). Presentation at University of Maryland Welfare Reform Academy Conference. Retrieved August 25, 2009, from http://www.welfareacademy.org/ conf/past/ware.shtml

Warren, R. P., \& Watkins, R. C. (1990). Talking with Robert Penn Warren. Athens, GA: University of Georgia Press. 
Webb, L. D., \& McCarthy, M. (1998). Ella Flagg Young: Pioneer of democratic school administration. Educational Administration Quarterly, 34, 223-242.

Wechsler, H. (1952). The challenge of a model penal code. Harvard Law Review, 65, 1097-1133.

Weed, S. (2009). A closer look at the evidence: Different roles for abstinence and comprehensive sex education? Salt Lake City: Institute for Research \& Evaluation.

Weinstock, H., Berman, S., \& Cates, W. (2000). Sexually transmitted diseases among American youth: Incidence and prevalence estimates. Perspectives on Sexual \& Reproductive Health, 36, 6-10.

West, J. G. (2005, March). The American eugenics movement and the tyranny of scientific expertise. Paper presented at the Southwestern Political Science Association annual meeting, New Orleans.

Westheimer, R. K. (2007). Sex for dummies. Hoboken, NJ: Wiley.

Wheeler, L. A. (2000). Rescuing sex from prudery and prurience: American women's use of sex education as an antidote to obscenity, 1925-1932. Journal of Women's History, 12, 173-195.

Whewell, W. (1856). The elements of morality, including polity. New York: Harper \& Brothers.

White, C. P. (1991). The Adolescent Family Life Act: content, findings, and policy recommendations for pregnancy prevention programs. Journal of Clinical Child Psychology, 20, 58-70. 
White House. (2009). The President's Budget. Retrieved August 24, 2009, from http://www.whitehouse.gov/omb/budget/appendix/

Wiersma, N., \& Jurs, S. (2009). Research methods in education ( $8^{\text {th }}$ ed). Boston: Allyn \& Bacon.

Wisconsin State Board of Health. (1919). The moral and healthy community. Madison: Wisconsin State Board of Health.

Woodall, E. E. (2002). The American nudist movement: From cooperative to capital, the song remains the same. Journal of Popular Culture, 36, 264-284.

Wyche, S., Sengers, P., \& Grinter, R. E. (2006, May 9). Historical analysis: Using the past to design the future. Retrieved August 25, 2009, from http://www.cc. gatech.edu/ beki/c29.pdf.

Young, S. (2007, June). Black men benefit more from marriage. Black Enterprise, 37, 40. Zogby Internatonal. (2007, April). Survey of parents of 10-16 year old children. Utica, NY: Author. 
Cedarville University

School of Graduate Studies

INSERT BLANK PAGE HERE 